\title{
RADGEN: A Radiation Exchange Factor Generator for Rod Bundles
}

October 1987

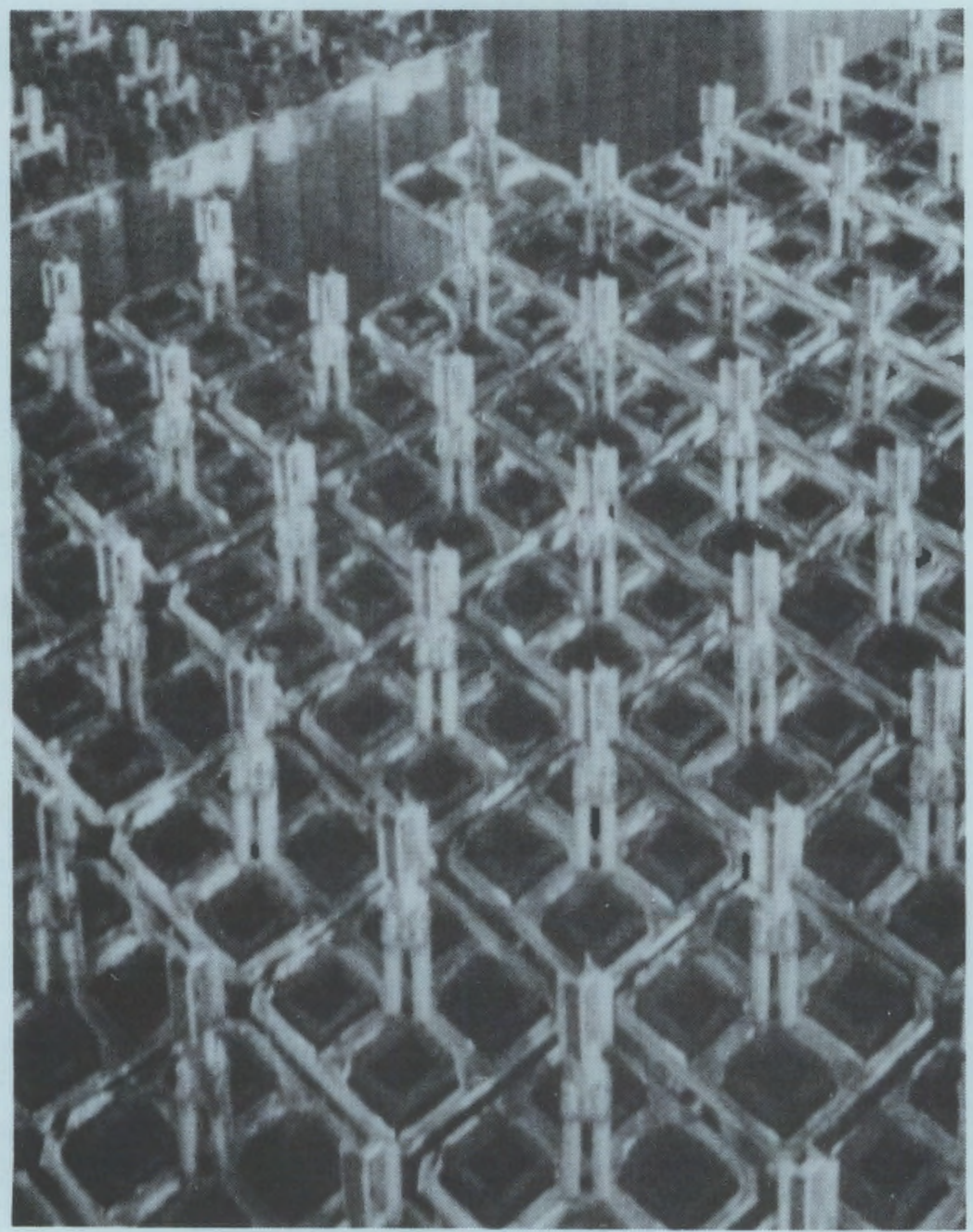

Prepared for the U.S. Department of Energy under Contract DE-AC06-76RLO 1830

Pacific Northwest Laboratory Operated for the U.S. Department of Energy by Battelle Memorial Institute 


\title{
DISCLAIMER
}

This report was prepared as an account of work sponsored by an agency of the United States Government. Neither the United States Government nor any agency thereof, nor Battelle Memorial Institute, nor any of their employees, makes any warranty, expressed or implied, or assumes any legal liability or responsibility for the accuracy, completeness, or usefulness of any information, apparatus, product, or process disclosed, or represents that its use would not infringe privately owned rights. Reference herein to any specific commercial product, process, or service by trade name, trademark, manufacturer, or otherwise, does not necessarily constitute or imply its endorsement, recommendation, or favoring by the United States Government of any agency thereof, or Battelle Memorial Institute. The views and opinions of authors expressed herein do not necessarly state or reflect those of the United States Government or any agency thereof, or Battelle Memorial Institute.

\author{
PACIFIC NORTHWEST LABORATORY \\ operated by \\ BATTELLE MEMORIAL INSTITUTE \\ for the \\ UNITED STATES DEPARTMENT OF ENERGY \\ under Contract DE-AC06-76RLO 1830
}

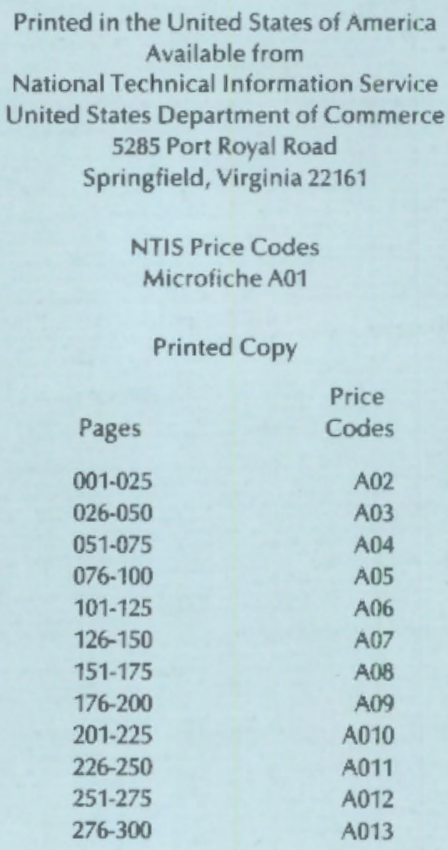


RADGEN: A RADIATION EXCHANGE FACTOR GENERATOR FOR ROD BUNDLES

D. R. Rector

October 1987

Prepared for the U.S. Department of Energy under Contract DE-AC06-76RLO 1830

Pacific Northwest Laboratory

Richland, Washington 99352 


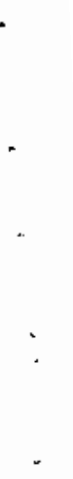




\section{ABSTRACT}

The RADGEN computer program has been developed at Pacific Northwest Laboratory (PNL) to generate input required for the thermal radiation models used in the COBRA-SFS (Spent Fue1 Storage) computer program. The COBRA-SFS program uses radiation exchange factors to describe the net amount of energy transferred from each surface to every other surface in an enclosure. The RADGEN program generates radiation exchange factors for arrays of rods on a square or triangular pitch as well as open channel geometries. This report describes the input requirements for the RADGEN code, which may be executed in a batch or interactive mode, and outlines the solution procedure used to obtain the exchange factors. 


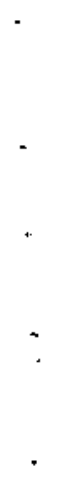

,

, 


\section{ACKNOWLEDGMENTS}

The author would like to thank the U.S. Department of Energy for sponsoring this work. Thanks are also extended to G. H. Beeman and J. M. Creer of Pacific Northwest Laboratory's Commercial Spent Fuel Management Program Office (CSFM-PO). Appreciation is extended to N. J. Lombardo for his contribution towards the development of a radiation exchange factor generator program. Finally, thanks to N. C. Waugh, word processor, and G. P. O'Connor, editor, for their assistance in preparing this document. 


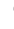




\section{NOMENCLATURE}

Symbols and Notations

$\delta$ - Kronecker delta

$\epsilon$ - surface emissivity

$\sigma$ - Stephan-Boltzmann constant (Btu/h-ft2 - $\left.\mathrm{R}^{4}\right)$

$A$ - area $\left(\mathrm{ft}^{2}\right)$

$D, d$ - fuel rod diameter ( $f t$ )

$F$ - blackbody viewfactor

$F$ - radiation exchange factor

$n$ - number of surfaces

PDR - pitch-to-diameter ratio

$Q$ - total heat transfer rate

$T$ - temperature ( $R$ )

$X$ - rod-to-wall distance (ft)

Subscripts

$i, j, k$ - surface indices

$\mathrm{n}, \mathrm{m}$ - partial-rod-indices 



\section{CONTENTS}

ABSTRACT ..............................

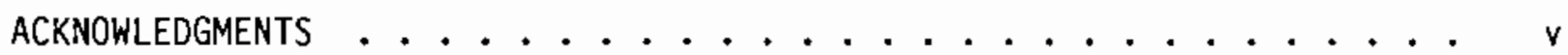

NOMENCLATURE .................................... vii

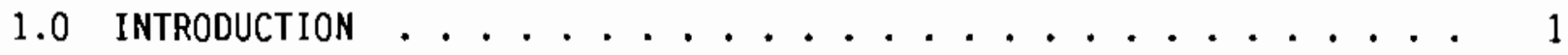

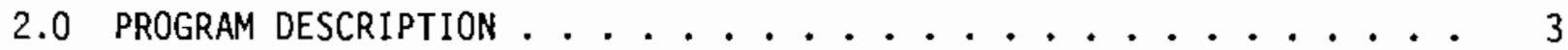

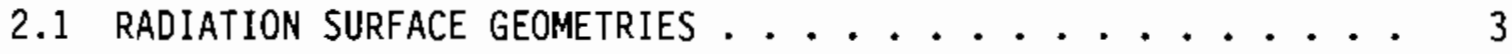

2.2 RADIATION EXCHANGE FACTORS .................... 18

2.3 COMBining EXCHANGe Factors . . . . . . . . . . 22

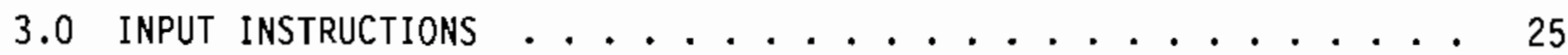

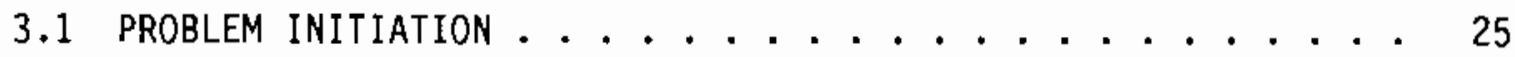

3.2 ROD BUNDLE GEOMETRY . . . . . . . . . . . . . 28

3.2.1 Rod Bundle Parameters . . . . . . . . . . . . 28

3.2 .2 Rod Location Information .......... 32

3.2.3 Canister Geometry Input . . . . . . . . . . 33

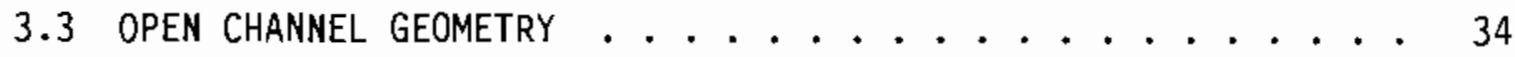

3.4 SURFACE EMISSIVITY . . . . . . . . . . . 36

3.5 EXCHANGE FACTOR LUMPING OPTIONS ............. 38

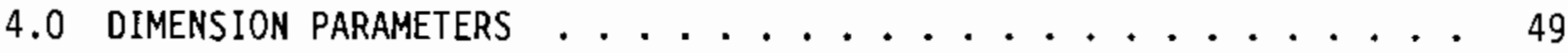

5.0 CODE Verification . . . . . . . . . . . . . 51

5.1 RODS ON A SQUARE PITCH .................. 51

5.2 RODS ON A TRIANGULAR PITCH ................... 55

5.3 OPEN ChANNEL GeOMETRIES .................. 58

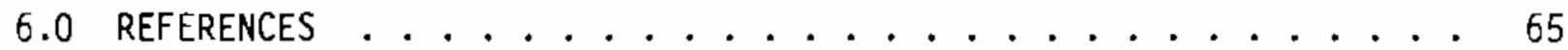


APPENDIX A - DERIVATION OF VIEWFACTOR EXPRESSIONS.$\cdots \cdots$. . . . . . A

APPENDIX B - VIEW CODE LISTING . . . . . . . . . . . . . . B.1 


\section{FIGURES}

2.1 Radiation Surface Models for a Typical Spent Fuel Rod . . . . . 4

2.2 Radiation Surface Model for a Typical $7 \times 7$ Rod Bundle . . . . . 5

2.3 Blackbody Viewfactor Distribution for Each Quarter Rod ..... 5

2.4 Viewfactor Distribution from Quarter Rods to Wall Surface . . . 9

2.5 Radiation Surface Model for a Typical Consolidated Rod

Canister................... 15

2.6 Blackbody Viewfactor Distribution for Each One-Sixth Rod

Surface ..................... 15

2.7 Blackbody Viewfactor Distribution from One-Sixth Rods to Wall

Surface ..................... 18

3.1 Typical Standard Geometry for Rods on a Square Pitch . . . . . . 29

3.2 Typical Standard Geometry for Rods on a Triangular Pitch . . . . 29

3.3 User-Specified Geometry for Rods on a Square Pitch . . . . . . 30

3.4 User-Specified Geometry for Rods on a Triangular Pitch ..... 30

3.5 Typical Open Channel Geometry ............. 35

3.6 Radiation Surface Locations for a Fu11 $8 \times 8$ Rod Bundle . . . . 39

3.7 Radiation Surface Locations for a Half $8 \times 8$ Rod Bundle with Symmetry along the Diagonal ............. 40

3.8 Radiation Surface Locations for a $15 \times 15$ Rod Bundle with OneEighth Symmetry ............... 41

3.9 Radiation Surface Locations for a Hexagonal Rod Bundle . . . . . 42

3.10 Radiation Surface Locations for a Hexagonal Bundle with One-Sixth Symmetry...................... 42

3.11 Lumped Model Representing a Typical $7 \times 7$ Rod Bundle . . . . . 43

5.1 Whole-Rod Locations for Rods on a Square Pitch . . . . . . . . 52

5.2 Viewfactor Geometry Corresponding to $\mathrm{F}_{\mathrm{cor}} \ldots \ldots . . . . . .54$ 
5.3 Whole-Rod Locations for Rods on a Triangular Pitch . . . . . . 56

5.4 Radiation Surface Model for a 2:1 Rectangle . . . . . . . . . . 61

5.5 Radiation Surface Model for a 30-60-90 Triangle . . . . . . 61

A.1 Cross-String Method .................... A.2

A.2 Geometry for Derivation of F12............... A.3 


\section{$\underline{\text { TABLES }}$}

2.1 Quarter Rod Blackbody Viewfactor Expressions . . . . . . . . 6

2.2 Rod-to-Wall Viewfactor Expressions for Rods in Square Arrays . . . 10

2.3 One-Sixth Rod Blackbody Viewfactor Expressions . . . . . . . . . 16

2.4 Rod-to-Wall Viewfactor Expressions for Rods in Triangular Arrays ...................... . . 19

5.1 Blackbody Viewfactor Expressions for Whole Rods on a Square

Pitch ...................... . . 53

5.2 Whole-Rod Viewfactor Comparison for Rods on a Square Pitch . . . . 54

5.3 Comparison of One-Quarter Rod Viewfactors to Program VIEW Results . . . . . . . . . . . . . . . . . 56

5.4 Blackbody Viewfactor Expressions for whole Rods on a Triangular

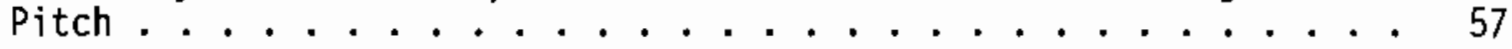

5.5 Whole-Rod Viewfactor Comparison for Rods on a Triangular Pitch . . 60

5.6 Comparison of One-Sixth Rod Viewfactors to Program VIEW Results . . 60

5.7 Blackbody Viewfactor Expressions . . . . . . . . . . . . 62

5.8 Comparison of Blackbody Viewfactors for a 2:1 Rectangle . . . . . . 63

5.9 Comparison of Blackbody Viewfactors for a 30-60-90 Triangle . . . 63 


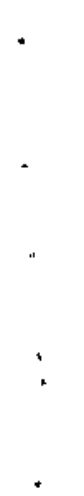

. 


\subsection{INTRODUCTION}

The COBRA-SFS (Spent Fuel Storage) computer program (Rector, wheeler and Lombardo 1986) was designed to accurately predict flow and temperature distributions in spent nuclear fuel storage systems. The decay heat generated by the spent fuel in a storage system is removed through a combination of conduction, natural convection, and thermal radiation. In many spent fuel storage systems, thermal radiation is a significant (and sometimes the dominant) mode of heat transfer. Therefore, an accurate numerical model of radiation heat transfer within the system is required to adequately predict the temperature field within the storage system.

The COBRA-SFS program uses radiation exchange factors to define the net amount of energy transferred from each surface to every other surface in an enclosure. This report describes the RADGEN computer routine, which has been developed at Pacific Northwest Laboratory (PNL) (a) for the U.S. Department of Energy to generate radiation exchange factors for a wide variety of spent fuel rod geometries.

Section 2.0 of the report describes the mathematical models used to define radiation heat transfer in spent fuel storage systems. The input instructions for the RADGEN computer program are presented in Section 3.0. The parameters used to dimension the code are described in Section 4.0. Section 5.0 describes the verification of the code using calculated and analytical results for each of the geometry types.

(a) Operated for the U.S. Department of Energy by Battelle Memorial Institute under Contract DE-ACO6-76RLO 1830. 


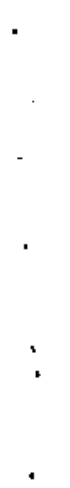

, 


\subsection{PROGRAM DESCRIPTION}

This section describes the mathematical models for radiation heat transfer in spent fuel storage systems. A description of the types of geometries that can be modeled is provided in Section 2.1. The equations and solution procedure used to calculate the radiation exchange factors are presented in Section 2.2, and a discussion of how to combine exchange factors for surface groups is found in Section 2.3.

\subsection{RADIATION SURFACE GEOMETRIES}

Geometries modeled using the RADGEN program are divided into three categories: rods on a square pitch, rods on a triangular pitch, and open channels. Rods on a square pitch are typical of a spent fuel assembly from a commercial nuclear power reactor, while geometries with rods on a triangular pitch represent a consolidated spent fuel canister or an assembly from a liquid metal reactor. Open channels are used where there are no rod bundles and no shadowing of other surfaces. The axial length of each enclosure is assumed to be large compared with the transverse lengths so that the geometry can be modeled using a set of two-dimensional viewfactors.

To model an enclosure, the rod surface areas and surrounding shroud must be divided into discrete radiation surfaces. Each surface acts independently in emitting, absorbing, and reflecting radiant energy. The accuracy of the heat transfer model is sensitive to how the surfaces have been divided because it is assumed that reflected energy, regardless of its source, is uniform over the entire surface. For example, when the typical rod shown in Figure 2.1 a is modeled using one radiation surface, incoming radiation is uniformly reflected in all directions, which is not a physically representative model. In reality, the incident radiation is reflected from, at most, half of the rod surface, and the reflected intensity is dependent on the angle of incidence. Subdivision of the rod into several surfaces results in a more realistic representation of the distribution of reflected energy. For example, the rod in Figure 2.1b is divided into four independent surfaces. 


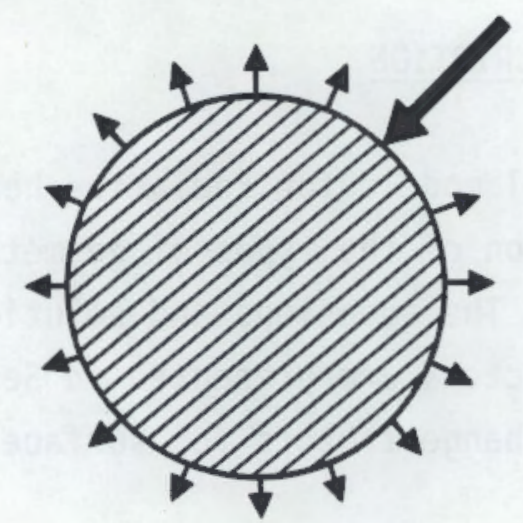

(a)

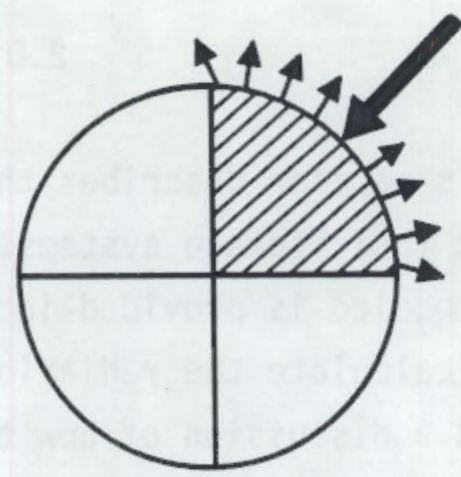

(b)

FIGURE 2.1. Radiation Surface Models for a Typical Spent Fuel Rod

A radiation surface is characterized by blackbody viewfactors that are defined as the fraction of radiation leaving one surface that reaches another surface. Viewfactors are automatically generated in RADGEN using expressions based on nondimensional geometric parameters such as the pitch-to-diameter ratio (PDR). The expressions used in the code for the base viewfactors were developed using the cross-string method (McAdams 1954). An example of how one of these expressions is derived is presented in Appendix A.

For rods on a square pitch, each rod is modeled using four quarter-rod surfaces, and the surface area of the surrounding shroud is also divided into $n$ discrete radiation surfaces, where $n$ is the number of rows plus columns of fuel rods multiplied by four. The radiation surface model used to represent a typical $7 \times 7$ rod bundle is shown in Figure 2.2. The distribution of quarterrod viewfactors for a typical originating surface, s, that sees a total of 15 other surfaces, is shown in Figure 2.3. The farthest surface that can directly receive radiation is assumed to be three rows from the originating surface. The analytical expressions used to calculate the blackbody viewfactors between the originating surface and each of the other surfaces are presented in Table 2.1. The calculated viewfactor from the originating surface to the outermost surface, $h$, includes the viewfactors to all the surfaces beyond surface $h$. This is done to conserve radiant energy. 


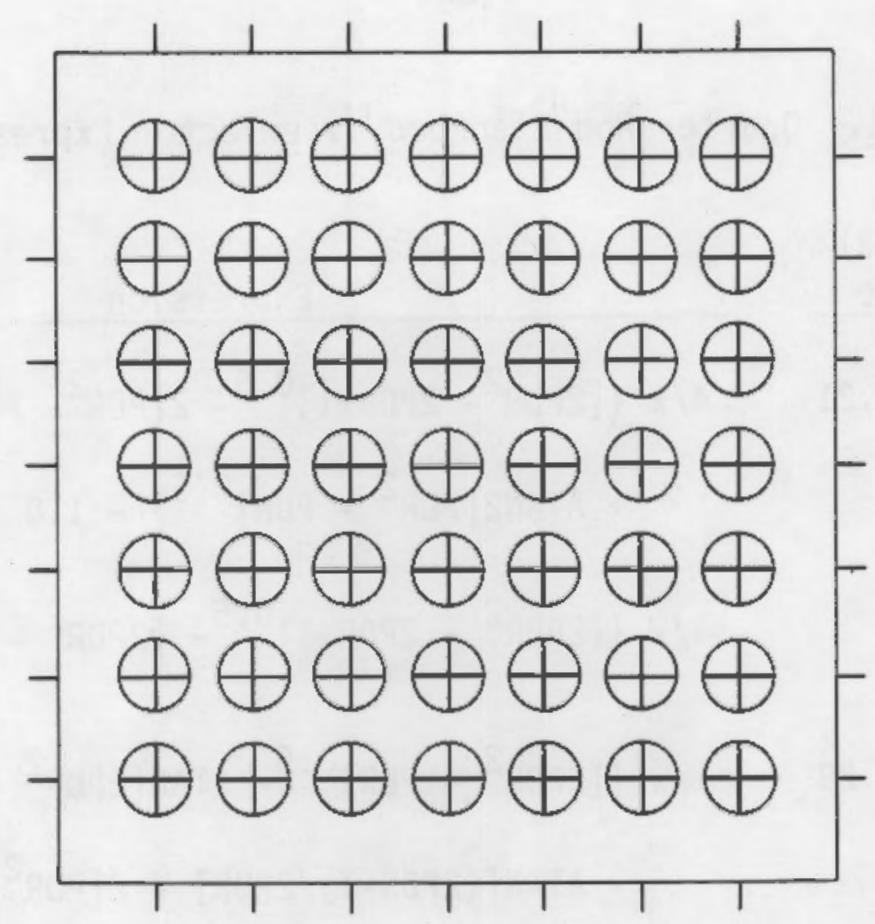

FIGURE 2.2. Radiation Surface Model for a Typical $7 \times 7$ Rod Bundle

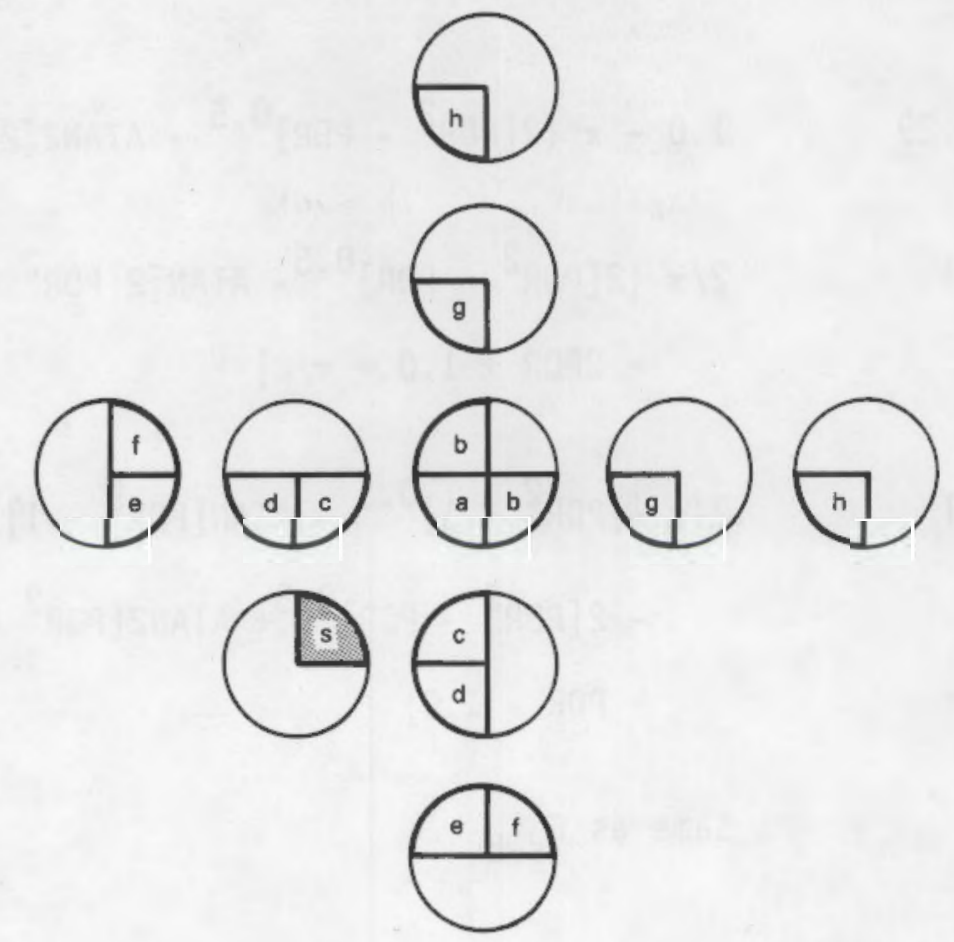

FIGURE 2.3. Blackbody Viewfactor Distribution for Each Quarter Rod 
TABLE 2.1. Quarter Rod Blackbody Viewfactor Expressions

$$
\begin{aligned}
& \text { Blackbody PDR(a) } \\
& \text { Viewfactor Range } \\
& \mathrm{F}_{\mathrm{S}-\mathrm{a}} \quad 1.0-1.21 \quad 4 / \pi\left\{\left[2 \mathrm{PDR}^{2}-2 \mathrm{PDR}+1\right]^{0.5}-2\left[\mathrm{PDR} \mathrm{R}^{2}-\mathrm{PDR}\right]^{0.5}\right. \\
& \left.+\operatorname{ATAN2}\left[P D R^{2}-P D R\right]^{0.5}\right\}-1.0 \\
& >1.21 \\
& 4 / \pi\left\{\left[2 P^{2} R^{2}-2 P D R+1\right]^{0.5}-\left[2 P D R^{2}-2 P D R+0.5\right]^{0.5}\right\}
\end{aligned}
$$

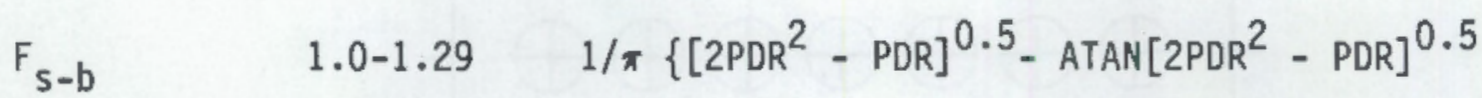

$$
\begin{aligned}
& \text { - } \operatorname{ATAN}[(2 P D R-1) / 2 P D R]-2\left[P D R^{2}-P D R\right]^{0.5} \\
& +\operatorname{ATAN2}[\mathrm{PDR}-\mathrm{PDR}]^{0.5}-2\left[\mathrm{PDR}^{2}-1\right]^{0.5} \\
& \left.+2 \operatorname{ATAN}\left[\operatorname{PDR}^{2}-1\right]^{0.5}\right\}-0.5 * \mathrm{~F}_{\mathrm{S}-\mathrm{a}} \\
& >1.291 .0-\pi\left\{2\left[P_{P R}^{2}-P D R\right]^{0.5}-\operatorname{ATAN}^{2}\left[2 \mathrm{PDR}^{2}-\mathrm{PDR}\right]^{0.5}\right\} \\
& F_{S-C} \quad \text { all } 2 / \pi\left\{2\left[P D R^{2}-P D R\right]^{0.5}-\operatorname{ATAN}\left[2\left(P D R^{2}-P D R\right)^{0.5}\right]\right. \\
& -2 P D R+1.0+\pi / 2\} \\
& F_{S-d} \quad \text { all } 2 / \pi\left\{\left[P D R^{2}-1\right]^{0.5}-\operatorname{ATAN}\left[P D R^{2}-1\right]^{0.5}\right. \\
& -2\left[P D R^{2}-P D R\right]^{0.5}+\operatorname{ATAN2}\left[P D R^{2}-P D R\right]^{0.5} \\
& +P D R-1.0\} \\
& \mathrm{F}_{\mathrm{s}-\mathrm{e}} \quad \text { Same as } \mathrm{F}_{\mathrm{s}-\mathrm{b}}
\end{aligned}
$$

(a) $\quad$ PDR = pitch-to-diameter ratio 
IABLE 2.1. (contd)

\begin{tabular}{|c|c|c|}
\hline $\begin{array}{l}\text { Blackbody } \\
\text { Viewfactor }\end{array}$ & $\begin{array}{l}\text { PDR (a) } \\
\text { Range }\end{array}$ & Expression \\
\hline$F_{s-f}$ & all & 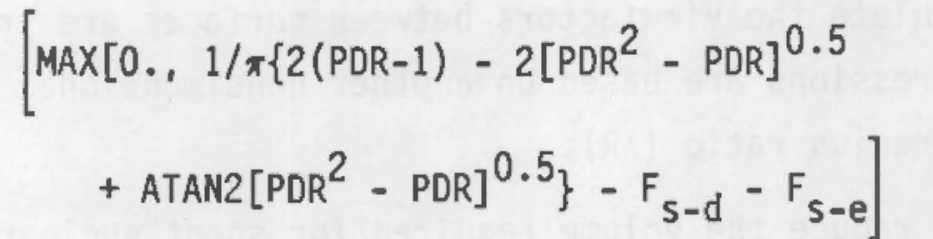 \\
\hline$F_{s-g}$ & all & $\begin{aligned} 2 / \pi & \left\{\left(5 \operatorname{PDR}^{2}-1\right)^{0.5}-\operatorname{ATAN}\left[\left(5 \operatorname{PDR}^{2}-1\right)^{0.5}\right]\right. \\
& -2\left(2 \mathrm{PDR}^{2}-1\right)^{0.5}-\operatorname{ATAN}\left[\left(2 \mathrm{PDR}^{2}-1\right)^{0.5}\right] \\
& +\left(\operatorname{PDR}^{2}-1\right)^{0.5}-\operatorname{ATAN}\left[\left(\mathrm{PDR}^{2}-1\right)^{0.5}\right] \\
& -\operatorname{ATAN}(0.5)\}\end{aligned}$ \\
\hline$F_{s-h}$ & all & $\begin{aligned} 1 / 2 & \left\{1-F_{s-a}-2\left[F_{s-b}+F_{s-c}+F_{s-d}+F_{s-e}\right.\right. \\
& \left.\left.+F_{s-f}+F_{s-g}\right]\right\}\end{aligned}$ \\
\hline
\end{tabular}

(a) $\mathrm{PDR}=$ pitch-to-diameter ratio 
Similar expressions have been developed to calculate the viewfactors from rod surfaces to the surrounding wall surfaces. The distribution of viewfactors to a receiving wall surface, $s$, is shown in Figure 2.4. Each wall surface sees 11 quarter-rod surfaces. The analytical expressions used to calculate the viewfactors between surfaces are presented in Table 2.2. The expressions are based on another nondimensional parameter, the rod-wall gap-to-radius ratio (XR).

To reduce the volume required for spent nuclear fuel storage, spent fuel rods are removed from their assembly structure to form a close-packed triangular array in a canister. Typically, the canister has a square cross section of the approximate dimensions of the original fuel assembly. This process is known as rod consolidation.

A nominal consolidated rod geometry is assumed to consist of a square cross-section canister containing rods on alternating long and short rows. The radiation surface model used to represent a consolidated canister containing 33 rods is shown in Figure 2.5. Figure 2.6 shows the viewfactor distribution for each one-sixth rod surface. A total of 17 surfaces are seen by an originating surface. The expressions used to calculate the blackbody viewfactors from the originating surface to each of the other surfaces are presented in Table 2.3. The distribution of viewfactors to a receiving wall surface, $s$, is shown in Figure 2.7. Each wall surface sees 8 one-sixth rod surfaces. The analytical expressions used to calculate the viewfactors between surfaces are presented in Table 2.4.

After the base viewfactors have been calculated, an array of blackbody viewfactors from every surface $i$ to every surface $j$ in the enclosure $F_{i j}$ is constructed. This array is used in the computation of radiation exchange factors. 


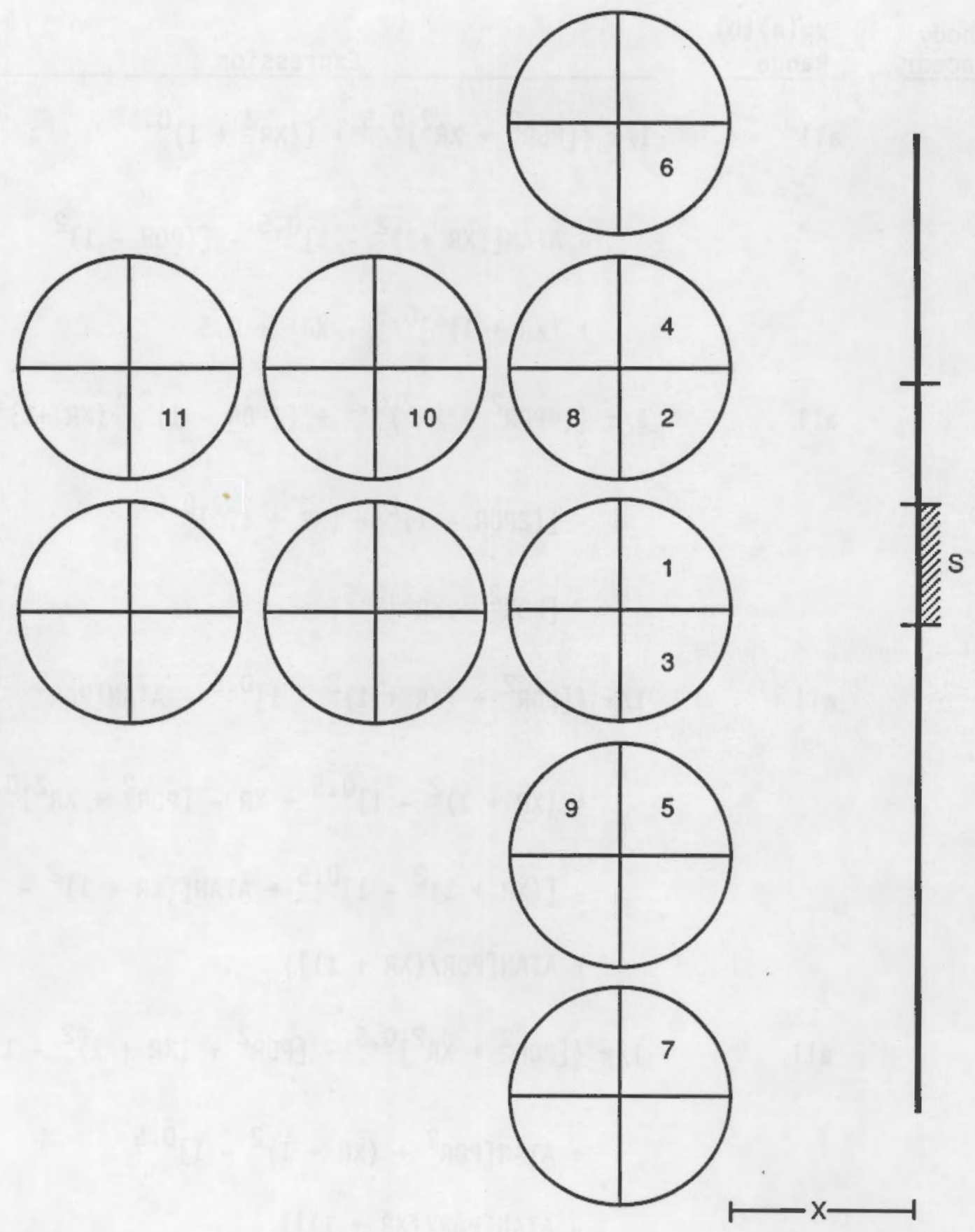

FIGURE 2.4. Viewfactor Distribution from Quarter Rods to Wall Surface 
TABLE 2.2. Rod-to-Wall Viewfactor Expressions for Rods in Square Arrays

$$
\begin{aligned}
& \text { Blackbody } \quad X R(a) \text { (b) } \\
& \text { Viewfactor Range } \\
& F_{1-S} \\
& \text { all } \\
& 1 / \pi\left\{\left[P D R^{2}+X R^{2}\right]^{0.5}+\left[\left(X R^{2}+1\right)^{0.5}\right.\right. \\
& -\operatorname{ATAN}\left[(X R+1)^{2}-1\right]^{0.5}-\left[(P D R-1)^{2}\right. \\
& \left.\left.+(X R+1)^{2}\right]^{0.5}-X R\right\}+0.5 \\
& F_{2-s} \\
& 1 / \pi\left\{\left(4 P D R^{2}+X R^{2}\right)^{0.5}+\left[(P D R-1)^{2}+(X R+1)^{2}\right]^{0.5}\right\} \\
& -\left[(2 P D R-1)^{2}+(X R+1)^{2}\right]^{0.5} \\
& \left.-\left[P D R^{2}+X R^{2}\right]^{0.5}\right\} \\
& F_{3-5} \\
& \text { all } \\
& 1 / \pi\left\{\left[\operatorname{PDR}^{2}+(X R+1)^{2}-1\right]^{0.5}-\operatorname{ATAN}\left[\operatorname{PDR}^{2}\right.\right. \\
& \left.+(X R+1)^{2}-1\right]^{0.5}+X R-\left[P D R^{2}+X R^{2}\right]^{0.5} \\
& -\left[(X R+1)^{2}-1\right]^{0.5}+\operatorname{ATAN}\left[(X R+1)^{2}-1\right]^{0.5} \\
& +\operatorname{ATAN}[P D R /(X R+1)]\} \\
& F_{4-5} \\
& \text { al1 } \\
& 1 / \pi\left\{\left[P D R^{2}+X R^{2}\right]^{0.5}-\left[P D R^{2}+(X R+1)^{2}-1\right]^{0.5}\right. \\
& +\operatorname{ATAN}\left[P D R^{2}+(X R+1)^{2}-1\right]^{0.5} \\
& \text { - } \operatorname{ATAN}[P D R /(X R+1)]\}
\end{aligned}
$$

(a) $\mathrm{PDR}=$ pitch-to-diameter ratio, $\mathrm{XR}=2 \mathrm{X} / \mathrm{D}$
(b) $\mathrm{CI}=(3 \mathrm{PDR}-1) /\left(\mathrm{PDR}^{2}-\mathrm{PDR}\right)^{8}-1, \mathrm{C2}=(4 \mathrm{PDR}-1) /\left(\mathrm{PDR}^{2}-\mathrm{PDR}\right)^{6.5}-1$ 
TABLE 2.2. (contd)

$$
\begin{aligned}
& \text { Blackbody XR(a) (b) } \\
& \text { Viewfactor Range } \\
& \mathrm{F}_{5-\mathrm{S}} \quad<\mathrm{C} 1 \quad 1 / \pi\left\{\left[9 \mathrm{PDR}^{2}+\mathrm{XR}^{2}\right]^{0.5}+\left[(2 \mathrm{PDR}-1)^{2}\right.\right. \\
& \left.+(X R+1)^{2}\right]^{0.5}-\left[P D R^{2}+(X R+1)^{2}-1\right]^{0.5} \\
& +\operatorname{ATAN}\left[P D R^{2}+(X R+1)^{2}-1\right]^{0.5}-\left[(2 P D R-1)^{2}\right. \\
& -1]^{0.5}+\operatorname{ATAN}\left[(2 \mathrm{PDR}-1)^{2}-1\right]^{0.5} \\
& \left.-\left[4 P D R^{2}+X R^{2}\right]^{0.5}-\operatorname{ATAN}[\mathrm{PDR} /(\mathrm{XR}+1)]\right\}-0.5 \\
& >C 1 \\
& 1 / \pi\left\{\left[9 P D R^{2}+X R^{2}\right]^{0.5}+\left[(2 P D R-1)^{2}\right.\right. \\
& \left.+(X R+1)^{2}\right]^{0.5}-\left[(3 P D R-1)^{2}+(X R+1)^{2}\right]^{0.5} \\
& \left.-\left[4 P D R^{2}+X R^{2}\right]^{0.5}\right\} \\
& F_{6-S} \quad<C 1 \quad 1 / \pi\left\{\left[16 P D R^{2}+X R^{2}\right]^{0.5}+\left[P D R^{2}+(X R+1)^{2}-1\right]^{0.5}\right. \\
& -\operatorname{ATAN}\left[P D R^{2}+(X R+1)^{2}-1\right]^{0.5} \\
& +\operatorname{ATAN}[P D R /(X R+1)]-\left[9 P D R^{2}+X R^{2}\right]^{0.5} \\
& +\left[4 P D R^{2}+(X R+1)^{2}-1\right]^{0.5}+\operatorname{ATAN}\left[4 P D R^{2}\right.
\end{aligned}
$$

(a) $\mathrm{PDR}=$ pitch-to-diameter ratio, $\mathrm{XR}=2 \mathrm{X} / \mathrm{D}$
(b) $\mathrm{C1}=(3 \mathrm{PDR}-1) /\left(\mathrm{PDR}^{2}-\mathrm{PDR}\right)^{\mathrm{E}: 5}-1, \mathrm{C2}=(4 \mathrm{PDR}-1) /\left(\mathrm{PDR}{ }^{2}-\mathrm{PDR}\right)^{9.5}-1$ 
TABLE 2.2. (contd)

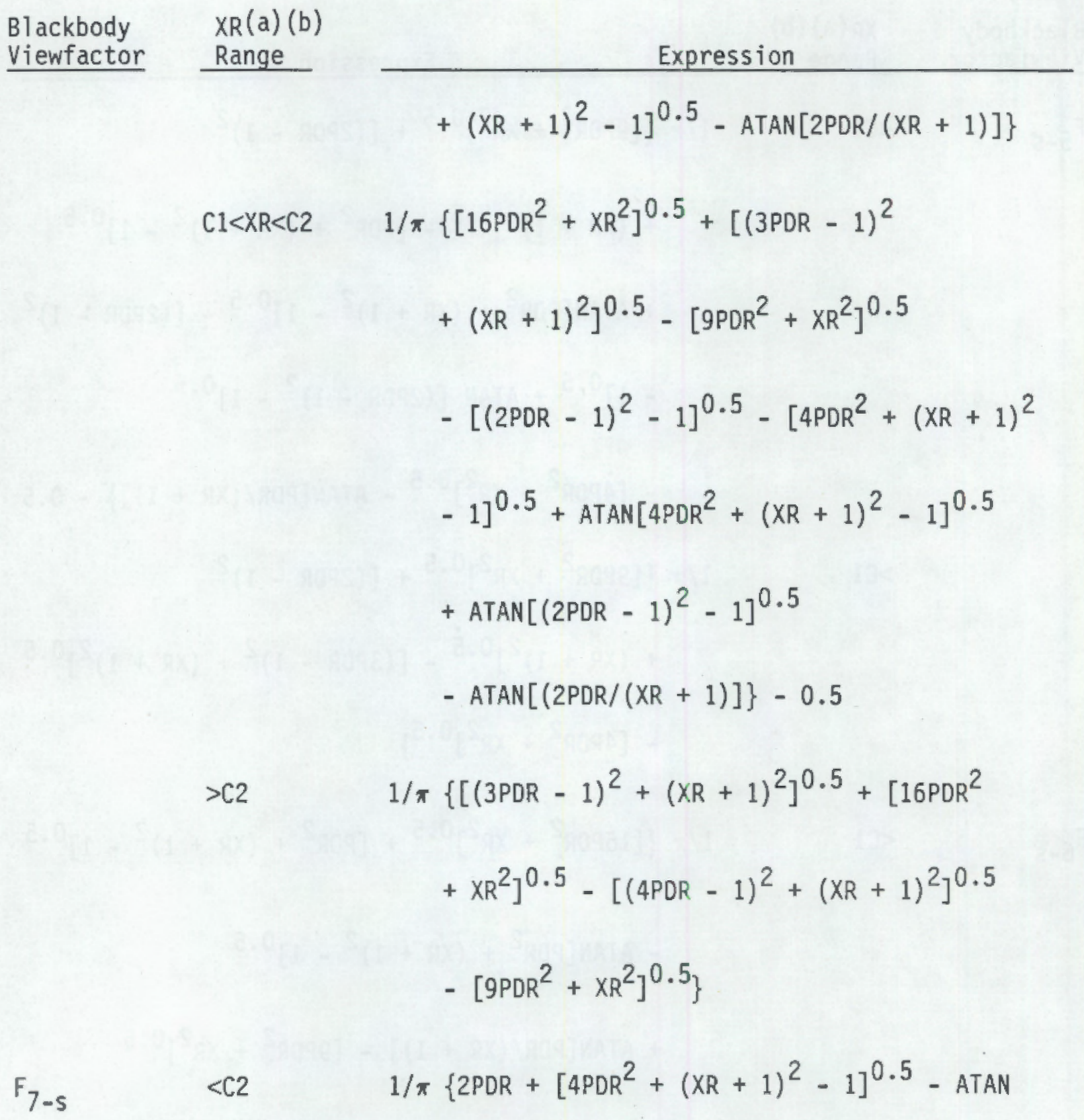

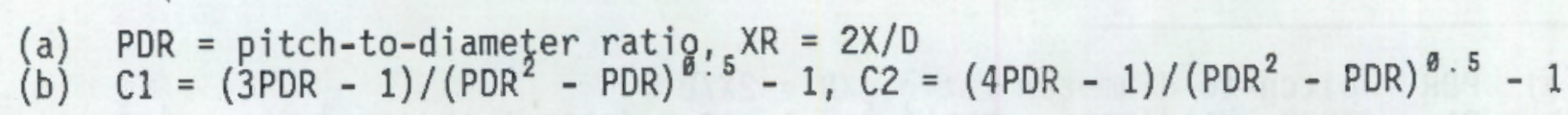




\section{TABLE 2.2. (contd)}

$$
\begin{aligned}
& \text { Blackbody } \quad X R(a) \text { (b) } \\
& \text { Viewfactor Range } \\
& \geq \mathrm{C} 2 \\
& 1 / \pi\left\{2 \mathrm{PDR}+\left[4 \mathrm{PDR}^{2}+(\mathrm{XR}+1)^{2}\right]^{0.5}-\left[(2 \mathrm{PDR}-1)^{2}\right.\right. \\
& \left.-1]^{0.5}+\operatorname{ATAN}[2 \mathrm{PDR}-1)^{2}-1\right]^{0.5} \\
& \left.-\left[16 P D R^{2}+X R^{2}\right]^{0.5}\right\}-0.5 \\
& F_{8-5} \\
& \text { a11 } \\
& 1 / \pi\left\{\left[(2 P D R-1)^{2}+(X R+1)^{2}\right]^{0.5}-\left[4 P^{2} R^{2}\right.\right. \\
& \left.+(X R+1)^{2}-1\right]^{0.5}+\operatorname{ATAN}\left[4 \operatorname{PDR}^{2}+(X R+1)^{2}\right. \\
& \left.-1]^{0.5}+\operatorname{ATAN}[2 \mathrm{PDR} /(\mathrm{XR}+1)]\right\}-0.5 \\
& F_{9-5} \\
& \text { al1 } \\
& 1 / \pi\left\{\left[4 \operatorname{PDDR}^{2}+(\mathrm{XR}+1)^{2}-1\right]^{0.5}-\operatorname{ATAN}\left[4 \mathrm{PDDR}^{2}\right.\right. \\
& \left.+(X R+1)^{2}-1\right]^{0.5}-\operatorname{ATAN}[2 \operatorname{PDR} /(X R+1)] \\
& +\left(2 \mathrm{PDR}^{2}-1\right)^{0.5}-\operatorname{ATAN}\left(2 \mathrm{PDR}^{2}-1\right)^{0.5}
\end{aligned}
$$

(a) $\mathrm{PDR}=$ pitch-to-diameter ratio, $X R=2 X / D$

(b) $\mathrm{Cl}=(3 \mathrm{PDR}-1) /\left(\mathrm{PDR}^{2}-\mathrm{PDR}\right)^{8: 5}-1, \mathrm{C} 2=(4 \mathrm{PDR}-1) /\left(\mathrm{PDR}^{2}-\mathrm{PDR}\right)^{6.5}-1$ 
TABLE 2.2. (contd)

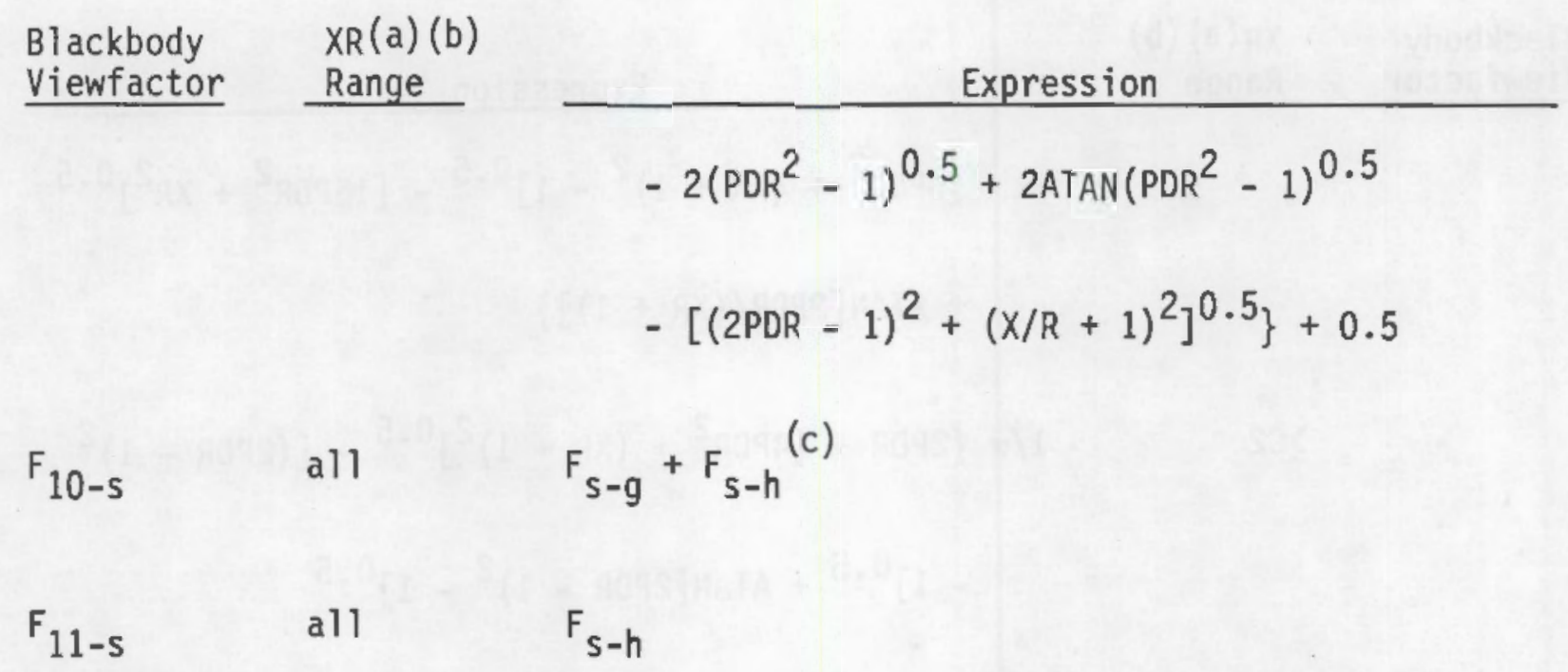

\footnotetext{
(a) $P D R=$ pitch-to-diameter ratio, $X R=2 X / D$

(b) $\mathrm{Cl}=(3 \mathrm{PDR}-1) /\left(\mathrm{PDR}^{2}-\mathrm{PDR}\right)^{8 ! 5}-1, \mathrm{C} 2=(4 \mathrm{PDR}-1) /\left(\mathrm{PDR}^{2}-\mathrm{PDR}\right)^{8.5}-1$

(c) $\mathrm{F}_{\mathrm{s}-\mathrm{g}}$ and $\mathrm{F}_{\mathrm{s}-\mathrm{h}}$ are defined in Table 2.1 .
} 


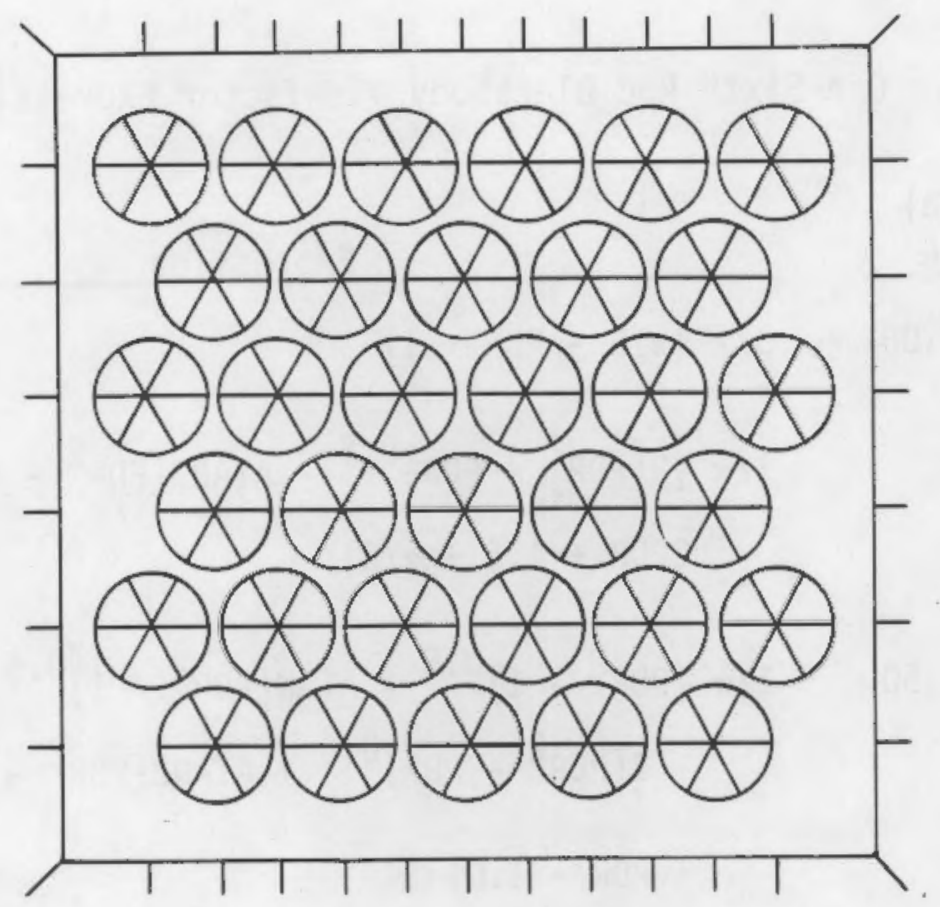

FIGURE 2.5. Radiation Surface Model for a Typical Consolidated Rod Canister
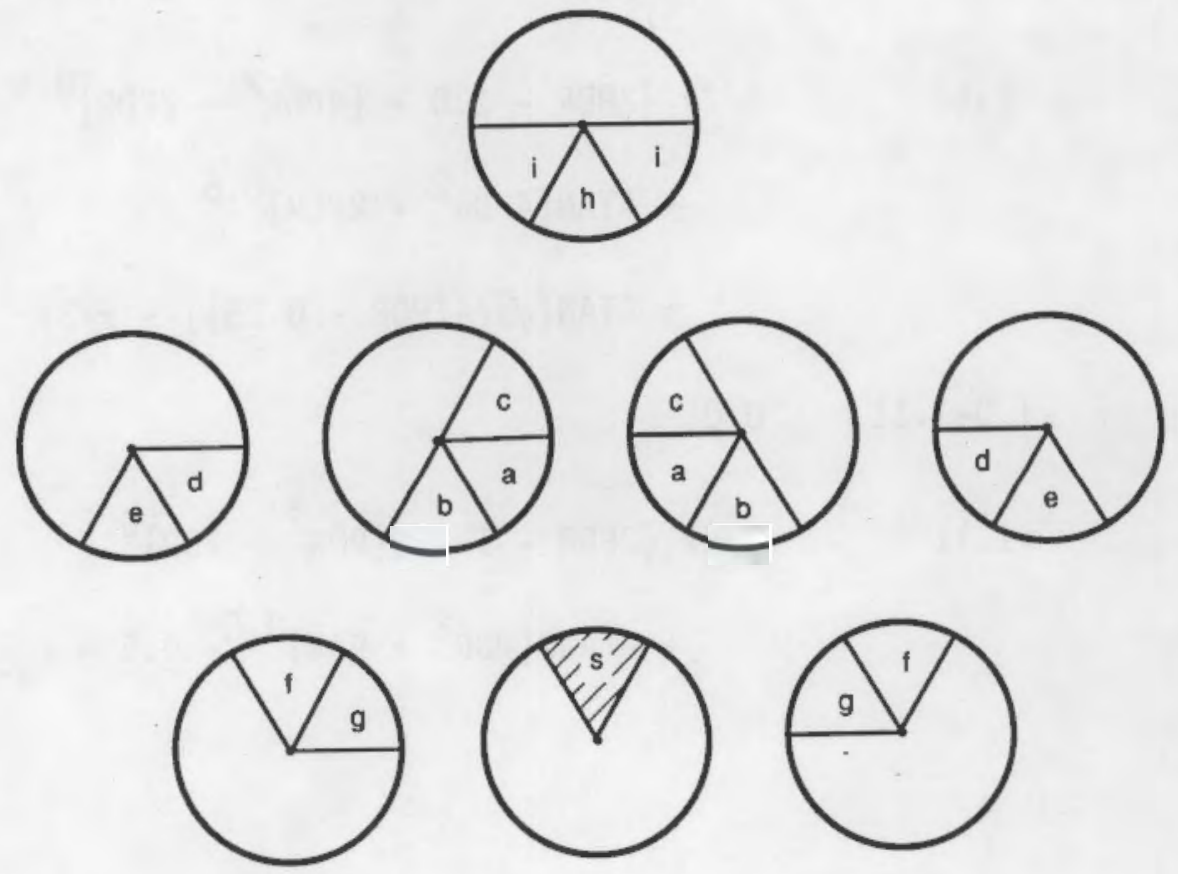

FIGURE 2.6. Blackbody Viewfactor Distribution for Each One-Sixth Rod Surface 
TABLE 2.3. One-Sixth Rod Blackbody Viewfactor Expressions

$$
\begin{aligned}
& \text { Blackbody PDR (a) } \\
& \text { Viewfactor Range } \\
& \mathrm{F}_{\mathrm{S}-\mathrm{a}} \quad 1.0-1.08 \quad 3 / \pi\{\pi / 6-\mathrm{PDR}+1\} \\
& 1.081 / \pi\left\{2\left[P D R^{2}-P D R\right]^{0.5}-\operatorname{ATAN}^{2}\left[P D R^{2}-P D R\right]^{0.5}\right. \\
& 2 \mathrm{PDR}+1.5+\pi / 3\}
\end{aligned}
$$

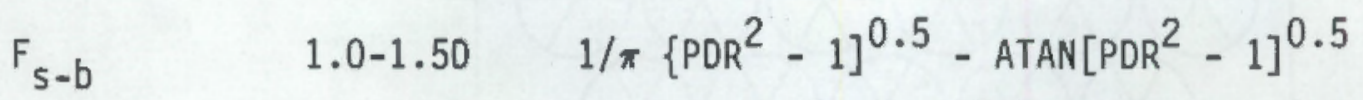

$$
\begin{aligned}
& -2\left[P D R^{2}-P D R\right]^{0.5}+A T A N 2\left[P D R^{2}-P D R\right]^{0.5} \\
& + \text { PDR - } 1.0\} \\
& F_{5-C} \quad 1.0-1.08 \quad 3 / 2 \pi\left\{2\left[P_{D D R}^{2}-P D R\right]^{0.5}-A^{A T A N 2\left[P D R^{2}-P D R\right]^{0.5}}\right. \\
& \left.-2\left[\operatorname{PDR}^{2}-1\right]^{0.5}+2 \operatorname{ATAN}\left[\operatorname{PDR}^{2}-1\right]^{0.5}\right\} \\
& >1.08 \quad 3 / 2 \pi\left\{2 \mathrm{PDR}-1.0-\left[4 \mathrm{PDR}^{2}-2 \mathrm{PDR}\right]^{0.5}\right. \\
& +\operatorname{ATAN}\left[4 P D R^{2}-2 P D R\right]^{0.5} \\
& +\operatorname{ATAN}[\overline{3} / 4(\operatorname{PDR}-0.25)]-\pi / 3\} \\
& \mathrm{F}_{\mathrm{s}-\mathrm{d}} \quad 1.0-1.11 \quad 0.0 \\
& >1.113 / 2 \pi\left\{2 \mathrm{PDR}-1-2\left[\mathrm{PDR}^{2}-\mathrm{PDR}\right]^{0.5}\right. \\
& \left.+ \text { ATAN2 }\left[P D R^{2}-P D R\right]^{0.5}-0.5-F_{S-C}-0.5 F_{s-g}\right\}
\end{aligned}
$$

(a) $P D R=$ pitch-to-diameter ratio 
TABLE 2.3. (contd)

\begin{tabular}{|c|c|c|}
\hline $\begin{array}{l}\text { Blackbody } \\
\text { Viewfactor }\end{array}$ & $\begin{array}{l}\text { PDR (a) } \\
\text { Range }\end{array}$ & Expression \\
\hline$F_{s-e}$ & $\begin{array}{l}1.0-1.11 \\
>1.11\end{array}$ & $\begin{array}{l}0.0 \\
0.5-6 / \pi\left\{\left[P^{2} R^{2}-1\right]^{0.5}-\operatorname{ATAN}\left[P D R^{2}-1\right]^{0.5}-P D R\right\} \\
+3.0-0.5 F_{s-g}-2 * F_{s-f}\end{array}$ \\
\hline$F_{s-f}$ & $\begin{array}{l}1.0-1.11 \\
>1.11\end{array}$ & 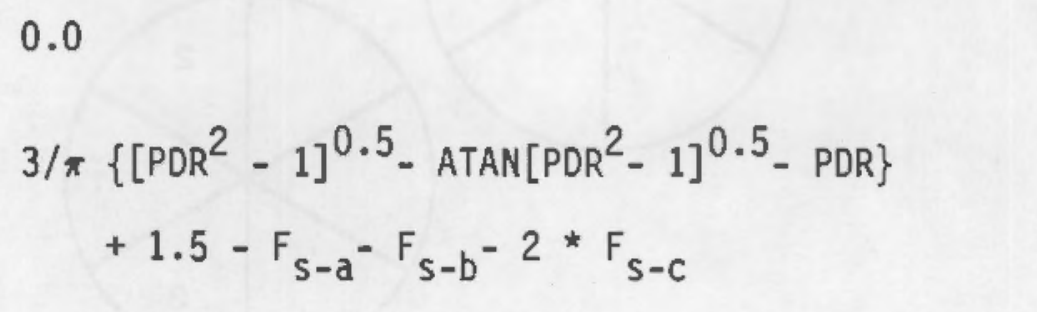 \\
\hline $\mathrm{F}_{\mathrm{S}-\mathrm{g}}$ & & Same as $\mathrm{F}_{\mathrm{s}-\mathrm{c}}$ \\
\hline$F_{s-h}$ & $1.0-1.11$ & $\begin{aligned} & 6 / \pi {\left[\left[3 P D R^{2}-3 P D R+1\right]-2\left[P D R^{2}-P D R\right]^{0.5}\right.} \\
&\left.+\operatorname{ATAN2}\left[P D R^{2}-P D R\right]-\pi / 3\right\} \\
& 6 / \pi\left\{\left[P D R^{2}-1\right]^{0.5}-\operatorname{ATAN}\left[P D R^{2}-1\right]^{0.5}\right\}\end{aligned}$ \\
\hline$F_{s-i}$ & & Same as $F_{s-c}$ \\
\hline
\end{tabular}

(a) $\mathrm{PDR}=$ pitch-to-diameter ratio 


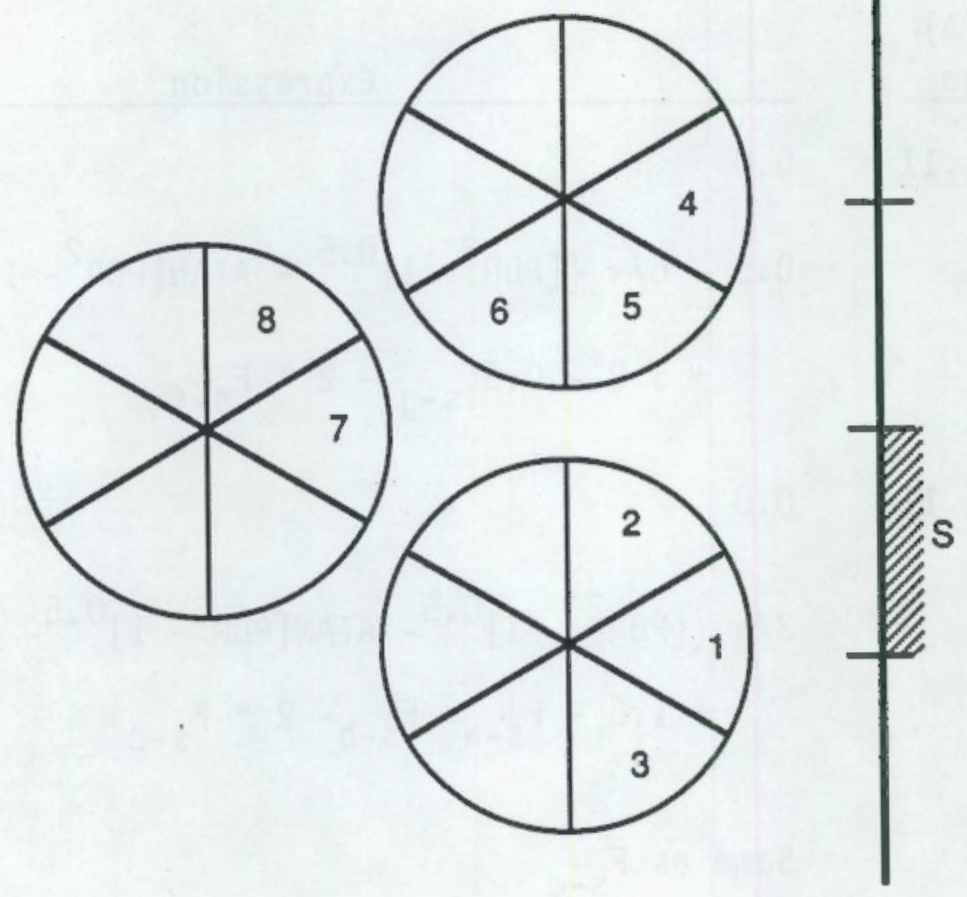

FIGURE 2.7. Blackbody Viewfactor Distribution from One-Sixth Rods to Wall Surface

\subsection{RADIATION EXCHANGE FACTORS}

In COBRA-SFS, the radiation heat transfer between surfaces in an enclosure is modeled using radiation exchange factors where the net rate of radiant energy outflow from surface $i$ to surface $j, Q_{i j}$, is defined in terms of an exchange factor, $F_{i j}$, as

$$
Q_{i j}=A_{i} F_{i j} \sigma\left(T_{i}^{4}-T_{j}^{4}\right)
$$

The quantity $F_{i j}$ specifies the total amount of radiant energy emitted from surface $i$ that reaches surface $j$ and is absorbed. This includes all the paths by which radiation may reach surface $j$ from surface $i$; that is, the direct 
TABLE 2.4. Rod-to-Wall Viewfactor Expressions for Rods in Triangular Arrays

$$
\begin{aligned}
& \text { Blackbody } \quad X R(a)(b) \\
& \text { Viewfactor Range } \\
& F_{1-5} \quad<C 1 \quad 3 / 2 \pi\left\{\left[\text { PDR }^{2}+(X R+1)^{2}-1\right]^{0.5}-\operatorname{ATAN}^{2} \operatorname{PDR}^{2}\right. \\
& \left.+(\mathrm{XR}+1)^{2}-1\right]^{0.5}+\operatorname{ATAN}[\mathrm{POR} /(\mathrm{XR}+1)] \\
& \left.-\left[(X R+1-3 / 2)^{2}+(P D R-0.5)^{2}\right]^{0.5}\right\}+0.25 \\
& >C 1 \quad 3 / 2 \pi\left\{\left[(X R+1-3 / 2)^{2}+(P D R+0.5)^{2}\right]^{0.5}\right. \\
& \left.-\left[(X R+1-3 / 2)^{2}+(P D R-0.5)^{2}\right]^{0.5}\right\} \\
& F_{2-S} \quad<C 2 \quad 3 / 2 \pi\left\{\left[(X R+1-3 / 2)^{2}+(P D R-0.5)^{2}\right]^{0.5}\right. \\
& \left.-\left[(S R+1)^{2}+(P D R-1)^{2}\right]^{0.5}\right\}+0.5 \\
& >\mathrm{C} 2 \\
& 3 / 2 \pi\left\{\left[(X R+1-3 / 2)^{2}+(P D R-0.5)^{2}\right\}^{0.5}\right. \\
& +\left[(X R+1)^{2}-1\right]^{0.5}-\operatorname{ATAN}\left[(X R+1)^{2}-1\right]^{0.5} \\
& -\left[(X R+1)^{2}+(P D R-1)^{2}\right]^{0.5}-[(X R+1 \\
& \left.\left.-3 / 2)^{2}+0.25\right]^{0.5}\right\}+0.75
\end{aligned}
$$
(a) $\mathrm{PDR}=$ pitch-to-diameter ratio, $X R=2 X / D$
(b) $\mathrm{Cl}=(\mathrm{PDR}+0.5) / \sqrt{3}+1-\sqrt{3} / 2$ 


\section{TABLE 2.4. (contd)}

$$
\begin{aligned}
& \text { Blackbody } \quad X R(a)(b) \\
& \frac{\text { Viewfactor }}{F_{3-5}} \frac{\text { Range }}{A 11} \quad \frac{\text { Expression }}{3 / 2 \pi\left\{\left[(X R+1-3 / 2)^{2}+0.25\right]^{0.5}-\left[(X R+1)^{2}\right.\right.} \\
& \left.-1]^{0.5}+\operatorname{ATAN}\left[(X R+1)^{2}-1\right]^{0.5}\right\}-0.25 \\
& \mathrm{~F}_{4-\mathrm{S}} \quad \mathrm{CC} \quad 3 / 2 \pi\left\{2 \mathrm{PDR}+\left[(\mathrm{XR}+1-3 / 2)^{2}+(\mathrm{PDR}-0.5)^{2}\right]^{0.5}\right. \\
& -\left[(2 P D R-0.5)^{2}-0.25\right]^{0.5}+\operatorname{ATAN}[(2 P D R \\
& \left.-0.5)^{2}-0.25\right]^{0.5}+\operatorname{ATAN}[3 / 2(2 \mathrm{PDR}-0.5)] \\
& -\left[P D R^{2}+(X R+1)^{2}-1\right]^{0.5}+\operatorname{ATAN}\left[P D R^{2}\right. \\
& \left.\left.+(X R+1)^{2}-1\right]^{0.5}-\operatorname{ATAN}[\operatorname{PDR} /(X R+1)]\right\} \\
& -0.75 \\
& >C 1 \quad 3 / 2 \pi\left\{2 P D R+\left[(X R+1-3 / 2)^{2}+(P D R-0.5)^{2}\right]^{0.5}\right. \\
& -\left[(2 \mathrm{PDR}-0.5)^{2}-0.25\right]^{0.5}+\operatorname{ATAN}[(2 \mathrm{PDR} \\
& \left.-0.5)^{2}-0.25\right]^{0.5}+\operatorname{ATAN}[3 / 2(2 \mathrm{PDR}-0.5)] \\
& \left.-\left[(X R+1-3 / 2)^{2}+(P D R+0.5)^{2}\right]^{0.5}\right\}-0.5
\end{aligned}
$$

(a) $\mathrm{PDR}=$ pitch-to-diameter ratio, $X \mathrm{XR}=2 \mathrm{X} / \mathrm{D}$

(b) $\mathrm{Cl}=(\mathrm{PDR}+0.5) / \sqrt{3}+1-\sqrt{3} / 2$ 
TABLE 2.4. (contd)

$$
\begin{aligned}
& \text { Blackbody } \quad \text { XR(a) (b) } \\
& \text { Viewfactor Range } \\
& \mathrm{F}_{5-\mathrm{S}} \\
& \text { A11 } \\
& 3 / 2 \pi\left\{\left[(X R+1)^{2}+(P D R-1)^{2}\right]^{0.5}+[(2 P D R\right. \\
& \left.-0.5)^{2}-0.25\right]^{0.5}-\operatorname{ATAN}\left[(2 \mathrm{PDR}-0.5)^{2}\right. \\
& -0.25]^{0.5}-\operatorname{ATAN}[3 / 2(2 \mathrm{PDR}-0.5)] \\
& -\left[(X R+1-3 / 2)^{2}+(P D R-0.5)^{2}\right]^{0.5} \\
& -\left[(2 \mathrm{PDR}-1)^{2}-1\right]^{0.5}+\operatorname{ATAN}\left[(2 \mathrm{PDR}-1)^{2}\right. \\
& \left.-1]^{0.5}\right\} \\
& F_{6-5} \\
& \text { A } 11 \\
& 3 / 2 \pi\left\{\left[(2 \mathrm{PDR}-1)^{2}-1\right]^{0.5}-\operatorname{ATAN}\left[(2 \mathrm{PDR}-1)^{2}\right.\right. \\
& -1]^{0.5}-2\left[\mathrm{PDR}^{2}-1\right]^{0.5}+2 \operatorname{ATAN}\left[\mathrm{PDR}^{2}\right. \\
& \left.-1]^{0.5}\right\} \\
& \text { F 7-s } \\
& \text { Al1 } \\
& 0.5 * F_{s-g}+F_{s-h}
\end{aligned}
$$

(a) $\mathrm{PDR}=$ pitch-to-diameter ratio, $X R=2 X / D$

(b) $\mathrm{C} 1=(\mathrm{PDR}+0.5) / \sqrt{3}+1-\sqrt{3} / 2$

(c) $F_{s-d}, F_{s-g}$ and $F_{s-h}$ are defined in Table 2.3. 
path, paths by means of one reflection, and paths by multiple reflections. For all black surfaces $(\epsilon=1.0)$, the two viewfactors and exchange factors are identical.

The radiation exchange factors, $F_{i j}$, are calculated from the geometry of the problem and the emissivities of the participating surfaces using the set of equations ( $\operatorname{Cox} 1977$ )

$$
\sum_{i=1}^{n}\left(F_{k i} \frac{1-\epsilon_{i}}{\epsilon_{i}}-\frac{\delta_{k i}}{\epsilon_{i}}\right) F_{i j}=F_{k j} \epsilon_{j} ; j=1, \ldots, n ; k=1, \ldots, n
$$

where $\mathrm{F}_{\mathrm{kj}}$ and $\mathrm{F}_{\mathrm{kj}}$ are the blackbody view factors, $\epsilon \mathrm{j}$ is the emissivity of surface $i, \delta_{k i}$ is the Kronecker delta, and $n$ is the total number of surfaces in an enclosure. The following assumptions were made in developing this equation:

- nonparticipating media

- isothermal, gray surfaces

- reflected and emitted radiation diffusely distributed

- uniform radiosity over each defined surface.

When a complete set of blackbody viewfactors and surface emissivities is used with Equation (2.2), a set of $n^{2}$ equations results. These equations are solved iteratively using the method of successive over-relaxation. An acceleration factor of 1.1 is used, and the solution is assumed to be converged when the maximum change in any exchange factor from one iteration to the next is less than $1 \times 10^{-6} \%$.

\subsection{COMBINING EXCHANGE FACTORS}

After the $n^{2}$ equation set is solved, the resulting set of quarter-rod gray body exchange factors is combined to obtain full-rod gray body exchange factors. The exchange factors are combined so that the total heat transferred from rod $i$ to rod $j, Q_{i j}$, is equal to the sum of heat transfer from each quarter rod, $n$, of rod $i$ to each quarter rod, $m$, of $\operatorname{rod} j$ : 


$$
Q_{i j}=\sum_{n=1}^{4} \sum_{m=1}^{4} Q_{n m}
$$

The heat transferred from one quarter rod to another by radiation is

$$
Q_{n m}=A \sigma F_{n m}\left(T_{n}^{4}-T_{m}^{4}\right)
$$

where $F_{\mathrm{nm}}$ are the quarter rod exchange factors. Assuming that rods $i$ and $j$ are isothermal and of equal diameter, the total heat transfer from rod $i$ to rod $j$ is written as

$$
\begin{aligned}
Q_{i j} & =\sum_{n=1}^{4} \sum_{m=1}^{4} \Delta x \frac{\pi d}{4} \sigma F_{n m}\left(T_{i}^{4}-T_{j}^{4}\right) \\
& =\Delta x \frac{\pi d}{4} \sigma\left(T_{i}^{4}-T_{j}^{4}\right) \sum_{n=1}^{4} \sum_{m=1}^{4} F_{n m}
\end{aligned}
$$

Recall that the total heat transfer from rod $i$ to rod $j$ is defined as

$$
Q_{i j}=A \sigma F_{i j}\left(T_{i}^{4}-T_{j}^{4}\right)
$$

Equating Equations (2.5) and (2.1), the rod-to-rod radiation exchange factor $F_{i j}$ is

$$
F_{i j}=\frac{1}{4} \sum_{n=1}^{4} \sum_{m=1}^{4} F_{n m}
$$

The final set of exchange factors is written to a file to be used as input to the COBRA-SFS code. This approach creates a mode 1 in COBRA-SFS that assumes 
an isothemal rod surface temperature while allowing the radiosity to vary around the rod.

The idea of combining surfaces with similar temperatures can be extended to groups of rods or other surfaces. For example, if a rod bundle has a temperature distribution which is symmetric about its diagonal, the full-rod exchange factors for the full assembly may be combined to give a set of exchange factors for the half bundle. This procedure of combining exchange factors is possible when it can be assumed that the temperatares of the surfaces in each group are nearly equal. 


\subsection{INPUT INSTRUCTIONS}

This section provides the input instructions for the RADGEN computer routine. The input is read either interactively or through a batch input file. When input is read interactively, questions are answered directly using a computer terminal. During the interactive session, a batch input file is created that can be used or modified for future runs.

The discussion of input is divided into five sections. The input required to set up the problem is described in Section 3.1. In this section, the type of geometry for the problem is selected. If the geometry involves a rod bundle, the geometry input is described in Section 3.2. If an open channel geometry is specified, the geometry input is described in Section 3.3. The surface emissivity input for the various surfaces is described in Section 3.4. If the exchange factors for the individual surfaces will be combined to simplify the model, the required input is described in section 3.5 .

The general input instruction format describes the format for each section of input for the interactive and batch modes and gives a complete description of the variables used.

Some input lines are repeated, and some groups of 1 ines are repeated in a set sequence. These repetitive patterns are called out in the instructions, both in the format for the line and in the text accompanying the input. In many instances, input will depend on values specified in previous input lines. These variables are noted on the input line, with a reference to the line where the variable was defined. For example, the variable for the type of geometry to be modeled, IGEOM, is read on input line RADGEN.3. In all subsequent instructions that refer to IGEOM, the origin of this variable is directed by specifying the variable as IGEOM[RADGEN.3].

\subsection{PROBLEM INITIATION}

The input required to set up the problem includes the method of reading input, the mode of operation, the title of the problem, and the type of geometry desired. 
The answer to the first interactive question determines if the interactive or batch input file is used. When input is read interactively, a batch input file is created that may be used or modified for future runs. If the batch mode is selected, the input file is read from I/0 Unit 5 .

The RAOGEN computer program may be operated in two different modes. The primary mode (IMODE=0) generates new radiation exchange factors given geometry and emissivity information. These exchange factors may be combined to give exchange factors from one surface group to another. The base and combined exchange factors are both written to I/0 Unit 10.

The majority of the cost of a typical RADGEN run is generating the base exchange factors. If a new set of combined exchange factors is required, IMODE = 1 avoids the need to recalculate the base factors if they have previously been calculated and saved. Therefore, an additional operating mode ( $I M O D E=1$ ) was added that reads base exchange factors from an existing file (on I/0 Unit 11) before combining them. If this mode is selected, the input skips to Section 3.3 .

Three types of geometries are modeled by the RADGEN code: rods on a square pitch, rods on a triangular pitch, and open channels. Geometries with rods on a square pitch (IGEOM=0) are for unconsolidated spent fuel assemblies. Geometries with rods on a triangular pitch (IGEOM=1) are used for consolidated spent fuel rods in a canister. Open channels geometries (IGEOM=2) are channels that do not contain a rod bundle and are limited to channels with no shadowing, i.e., where the view from each surface to another is not blocked by a third surface.

The interactive and batch formats for the problem initiation input are presented below. In the interactive mode description, sentences presented in all capital letters are the questions asked by the routine. Explanations in lowercase letters enclosed in parentheses define the code variable being requested. The user-supplied answer follows the question mark. 
Interactive Format:

INPUT FROM TTY? IF NOT, THEN READ FROM TAPES: (code variabie READIN) (Y/YES, RET/NO)

? y

SPECIFY MOOE OF OPERATION (code variable IMODE)

0 - GENERATE NEW EXCHANGE FACTORS

? 0

1 - LUMP EXISTING EXCHANGE FACTORS (TO BE READ FROM TAPE11)

ENTER TITLE FOR PROBLEM (UP TO 68 CHARACTERS) (code variable TEXT)

? sample problem

TYPE OF GEOMETRY DESIRED (code variable IGEOM)

0 - RODS ON SQUARE PITCH

1 - RODS ON TRIANGULAR PITCH

? 0

2 - OPEN CHANNEL

Batch Format:

RADGEN.1 IMODE

FORMAT (I5)

Columns Variable

Description

$1-5 \quad$ IMODE

Mode of operation:

0 - Generate new exchange factors given geometry and emissivity information

1 - Combine existing exchange factors that are read from I/0 Unit 11

$\star \star \star \star \star$ If IMODE $=1$, go to RADGEN. 12

RADGEN.2 TEXT

FORMAT (16A4)

Columns Variable

Description

$1-64$ TEXT

Title for problem identification (first line of the output and TAPE 10 files; maximum of 64 characters)

RADGEN.3 IGEOM

FORMAT (I5) 
Columns Variable

$1-5 \quad$ IGEOM
Description

Flag for type of geometry:

0 - rods on square pitch

1 - rods on triangular pitch

2 - open channel, no rods

$\star \star \star \star \star$ If IGEOM $=2$, go to RADGEN.7

\subsection{ROD BUNDLE GEOMETRY}

This section describes the geometry parameters that define a rod bundle, whether the rods are on a square (IGEOM=0) or triangular (IGEOM=1) pitch. This input is not read when an open channel geometry is specified (IGEOM=2).

Rod bundle geometries are divided into two categories: standard and user-specified. Examples of standard geometries for rods on square and triangular pitch are shown in Figures 3.1 and 3.2, respectively. For rods on a square pitch, a standard geometry is defined as a square or rectangular array of rods in a square or rectangular canister. For rods on a triangular pitch, a standard geometry is defined as an array of rods arranged on alternating long and short rows differing in length by one rod, surrounded by a square or rectangular canister.

Any rod geometries that do not conform to the standard geometry definitions given above must be user-specified. Examples of user-specified geometries for rods on square and triangular pitch are shown in Figures 3.3 and 3.4, respectively. In both of these cases, the starting point of the rod rows, the length of the rows, and the shape of the surrounding canister are different from the standard case.

The input in this section is divided into three categories: rod bundle parameters, rod location information, and canister geometry input. Each of these categories is discussed in more detail below.

\subsubsection{Rod Bundle Parameters}

The basic parameters required to define a rod bundle, whether it is a standard or user-specified geometry, include the pitch-to-diameter ratio, the 


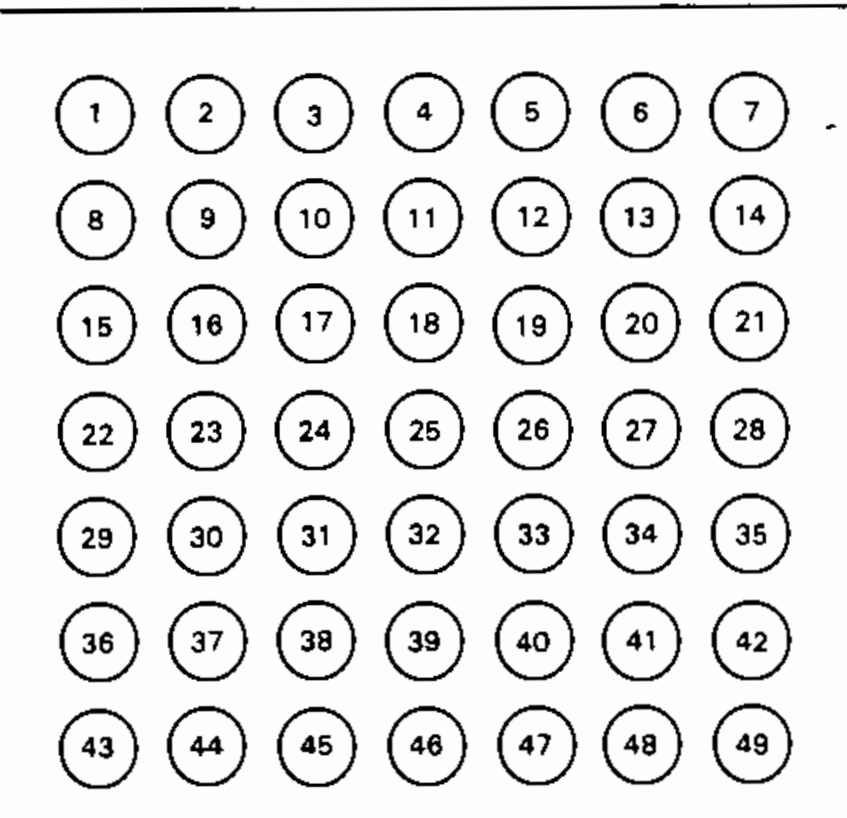

FIGURE 3.1. Typical Standard Geometry for Rods on a Square Pitch

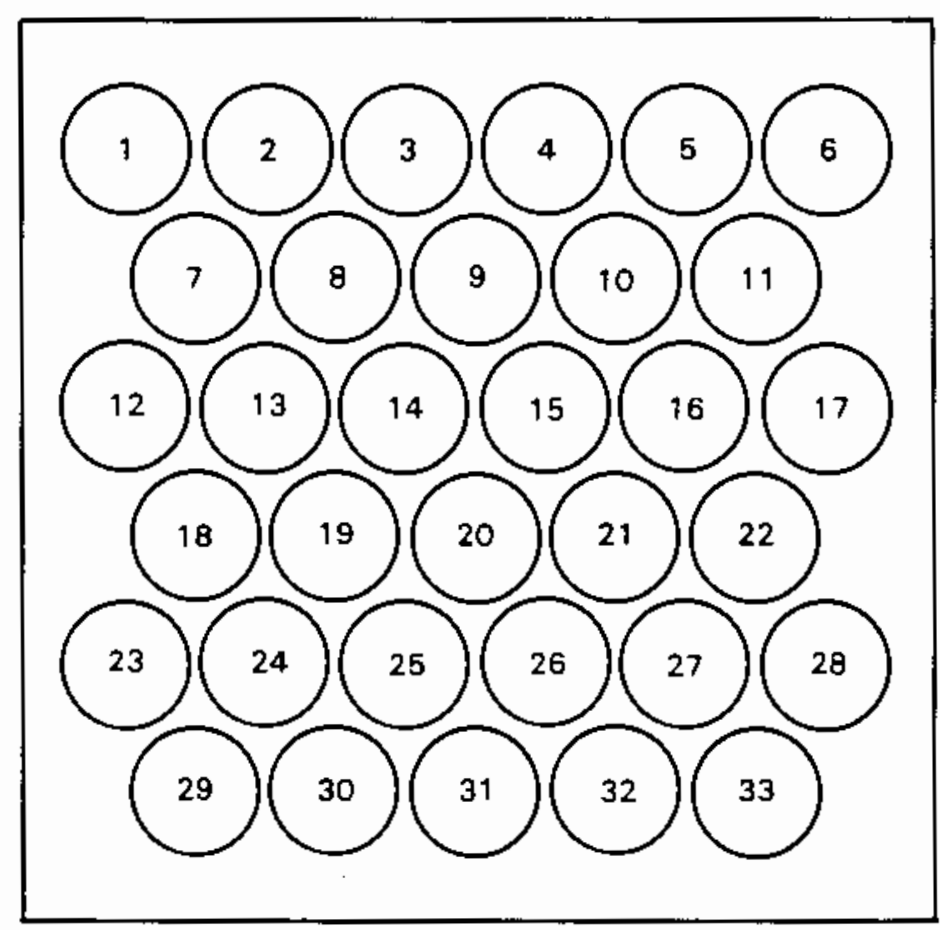

FIGURE 3.2. Typical Standard Geometry for Rods on a Triangular Pitch 


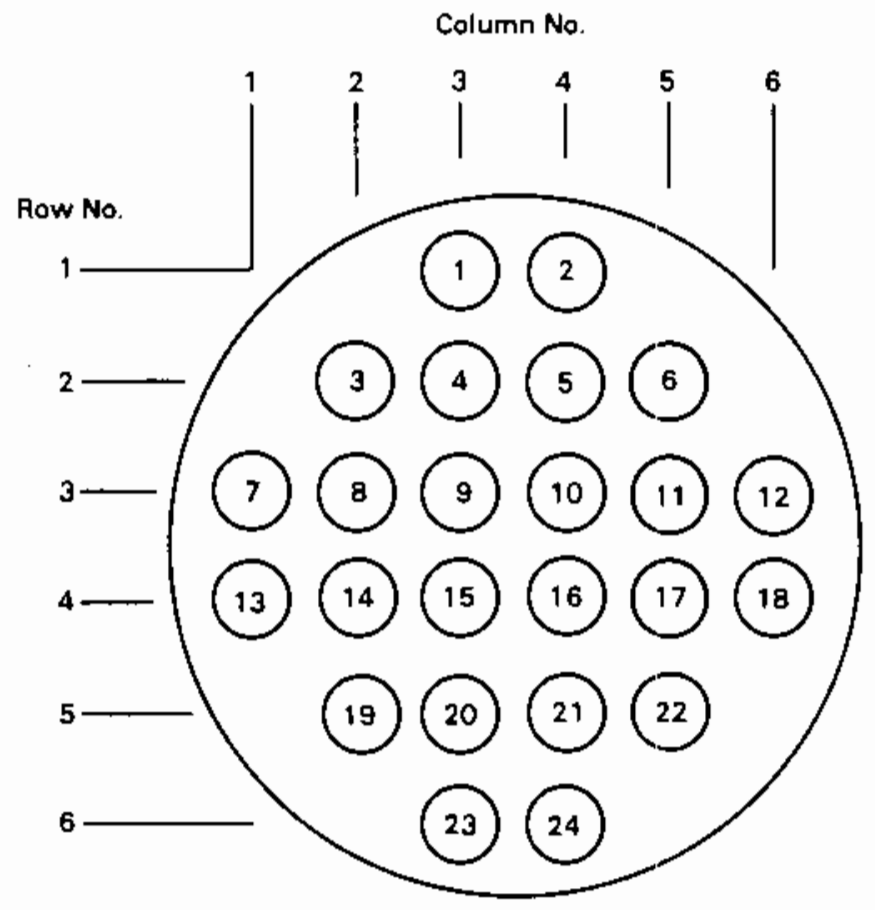

FIGURE 3.3. User-Specified Geometry for Rods on a Square Pitch

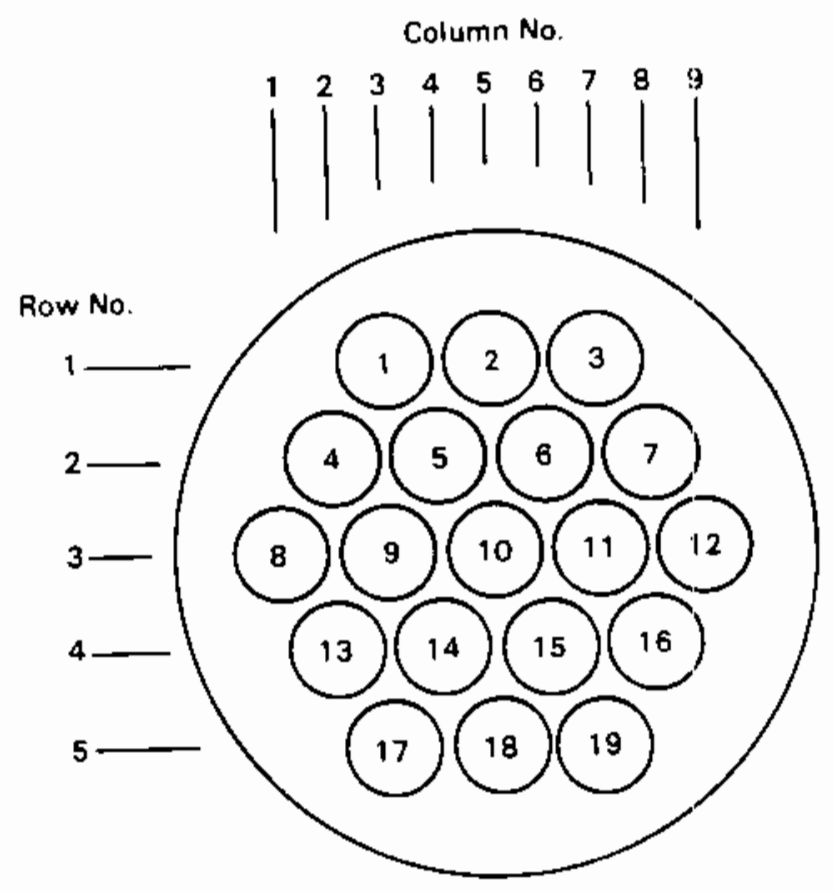

FIGURE 3.4. User-Specified Geometry for Rocs on a Triangular Pitch 
number of rows of rods, the number of rods in each row (if a standard geometry), and the arrangement of rows (if a standard triangular pitch geometry). If the number of rods in each row is not specified ( $\mathrm{NCOL}=0)$, then the rod location information is read according to the input described in Section 3.2.2.

The interactive and batch formats for the rod bundle parameters are presented below. The interactive input corresponds to the standard geometry for rods on a triangular pitch shown in Figure 3.2 .

Interactive Format:

ROD PITCH-TO-DIAMETER RATIO (code variable PDR)

$? 1.05$

NUMBER OF ROWS OF RODS (code variable NROWS)

? 6

NUMBER OF RODS IN EACH ROW (code variable NCOL)

(FOR TRIANGULAR ARRAYS IN A SQUARE CANISTER, ENTER THE LARGER NUMBER OF RODS PER ROW)

(IF THE NUMBER OF RODS IS TO BE SPECIFIED FOR EACH ROW, RETURN)

? 6

RODS IN A SQUARE CANISTER ARE ASSUMED TO BE ARRANGED IN ALTERNATING

LONG AND SHORT ROWS

INDICATE WHETHER THE TOP ROW IS LONG OR SHORT (code variable IFIRST)

+1 - LONG ROW

? 1

-1 - SHORT ROW

Batch Format:

RADGEN.4 PDR, NROWS, NCOL, IFIRST

FORMAT $(F 5.3,3 \mathrm{I} 5)$

$\underline{\text { Variable }}$

Description

PDR

Rod pitch-to-diameter ratio

NROWS

Number of rows of rods

NCOL

Number of rods in each row. Leave blank if the number of rods is to be specified for each row. 
IFIRST

For standard triangular pitch geometries, indicates whether

the top row is long or short

+1 - long rows

-1 - short rows

$\star \star \star \star \star$ If NCOL $>0$, go to RADGEN. 6

\subsubsection{Rod Location Information}

A user-specified geometry (NCOL[RADGEN.4]=0) requires input that defines the rod locations. If a standard geometry has been specified (NCOL[RADGEN.4]>0), the input skips to Section 3.2.3.

Rod location information is specified in terms of rod rows. Each row is defined by the beginning rod location, JBEG, and the number of rods in that row, NLINE. The beginning location is specified by the number of columns from the leftmost rod. Examples of rods on a square and triangular pitch are shown in Figures 3.3 and 3.4, respectively. In Figure 3.3, the first row begins in column three and has a length of two rods. In Figure 3.4, the first row begins in column three and has a length of three rods.

The interactive and batch formats for the rod location information are presented below. The input used in the interactive format example corresponds to the geometry in Figure 3.3.

Interactive Format:

NUMBER OF RODS IN EACH ROW (code variable NCOL) ?

(IF THE NUMBER OF RODS IS TO BE SPECIFIED FOR EACH ROW, RETURN)

USER SPECIFIED GEOMETRY

FOR EACH ROW, ENTER THE BEGINNING LOCATION AND NUMBER OF RODS

FOR ROW NO. 1 (BEGINNING LDCATION, NUMBER OF RCDS) (code variables JBEG( 1$)$ and $\operatorname{NLINE}(1)$ )

? 3,2

FOR ROW NO. 2 (BEGINNING LOCATION, NUMBER OF ROCS)

? 2,4 (code variables JBEG( 2) and $\operatorname{NLINE}(2)$ )

FOR ROW NO. 3 (BEGINNING LOCATION, NUMBER OF ROCS)

? 1,6 (code variables JBEG (3) and $\operatorname{NLINE}(3)$ )

FOR ROW NO. 4 (BEGINNING LOCATION, NUMBER OF ROCS) (code variables JBEG(4) and NLINE( 4) 
$? 1,6$

FOR ROW NO. 5 (BEGINNING LOCATION, NUMBER OF RODS)

? 2,4

(code variables JBEG (5) and $\operatorname{NLINE}(5)$ )

FOR ROW NO. 6 (BEGINNING LOCATION, NUMBER OF RODS)

(code variables JBEG( 6) and $\operatorname{NLINE}(6)$ )

? 3,2

Batch Format:

RADGEN.5 (JBEG(I), (NLINE(I), I=1, NROWS[RADGEN.4])

FORMAT (2I5)

Columns Variable

Description

$1-5 \quad J B E G(1)$

Column in which the first rod in row I exists

$6-10 \quad$ NLINE(I)

Number of rods in row I

*** RADGEN.5 is read in NROWS [RADGEN.4] times

*** RADGEN.5 is read on ly if NCOL[RADGEN.4] $=0$

\subsubsection{Canister Geometry Input}

This section describes the input that defines the canister geometry for a standard rod bundle geometry (NCOL[RADGEN.4]>0). The rods in a standard geometry are surrounded by a square or rectangular canister. The size of the canister and the location of the rod bundle within the canister are defined by specifying the distance between the edge of the rods and the canister wall on all four sides. This allows the user to model the effect of eccentric bundle placement within the canister. The rod outside diameter is required to specify the distances in terms of rod diameters to calculate the base viewfactors. The interactive and batch formats for the canister geometry input are presented below.

Interactive Format:

ROD OUTSIDE DIAMETER (IN.) (code variable DIA)

$? .422$

DIAMETER BETWEEN THE EDGE OF THE RODS AND THE CANISTER WALL (IN.)

AT THE TOP (code variable XR(1)) 


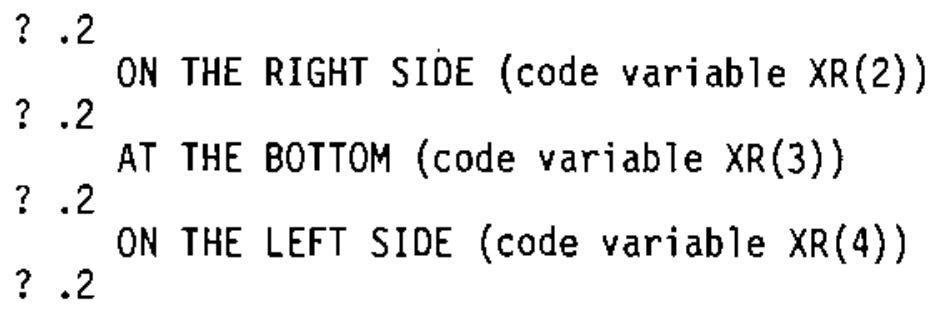

\section{RADGEN. 6 only if NCOL[RADGEN. 4$]>0$}

\subsection{OPEN CHANNEL GEOMETRY}

The input required to define an open channel geometry (IGEOM[RADGEN.3] =2) is described below. An open channel is defined as a channel with uniform cross section that contains no rods. Open channel geometries are limited to channels with no shadowing, i.e., where the view from each surface to another is not blocked by a third surface.

Surfaces around the channel are defined by their startpoints and perimeter length. An example of an open channel geometry is shown in Figure 3.5. The coordinates for the startpoint and the length are read for each surface. The surfaces are read in consecutive order around the channel (in this case from surfaces 1 to 6 ). The endpoint for the final surface (surface 6 ) is assumed to be the first startpoint read (point 1). If no length is specified, then it is calculated based on a straight 1 ine between the startpoint and endpoint. In the example, the lengths for surfaces $1,2,5$, and 6 are calculated automatically but the lengths for surfaces 3 and 4 must be input. 


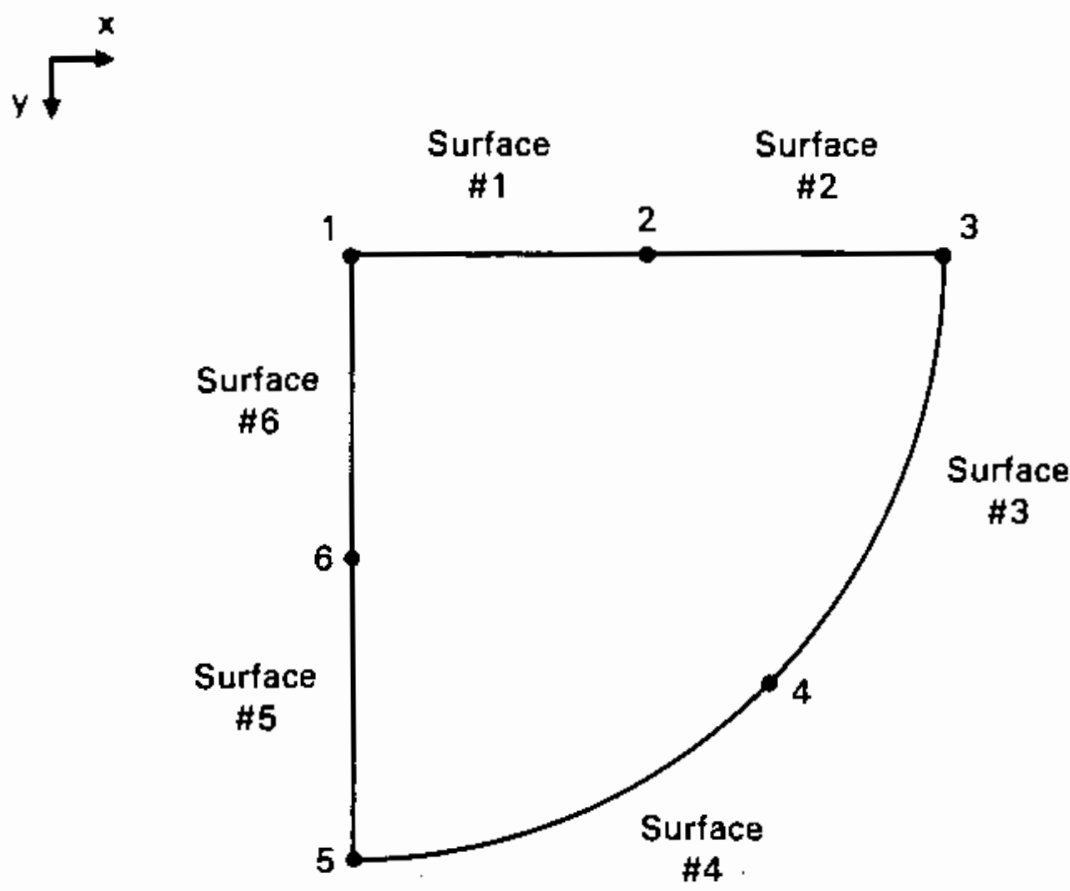

FIGURE 3.5. Typical Open Channel Geometry

The interactive and batch formats for the open channel geometry input are presented below. The input used in the interactive format example corresponds to the geometry shown in Figure 3.5.

\section{Interactive Format:}

NUMBER OF RADIATION SURFACES SURROUNDING THE CHANNEL (code variable NWALL)

? 6

FOR EACH SURFACE, ENTER THE $X$ AND $Y$ COORDINATES FOR THE STARTPOINT

AND THE SURFACE LENGTH (IN.) (ENTER ZERO FOR A STRAIGHT LINE)

- READ IN CONSECUTIVE ORDER AROUND THE CHANNEL

- THE ENDPOINT FOR THE FINAL SURFACE IS ASSUMED TO BE THE FIRST POINT READ

STARTPOINT COORDINATES AND LENGTH FOR SURFACE NO. 1 (code variables $X(1), Y(1)$ and PERIM( 1$)$ )

? D.,0.,0.

STARTPOINT COORDINATES AND LENGTH FOR SURFACE NO. 2 (code variables $X(2), Y(2)$ and PERIM( 2))

? $1 ., 0 ., 0$.

STARTPOINT COORDINATES AND LENGTH FOR SURFACE NO. 3 (code variables $X(3), Y(3)$ and $\operatorname{PERIM}(3)$ )

? 2.,0, 1.571 
STARTPOINT COORDINATES AND LENGTH FOR SURFACE NO. 4

(code variables $X(4), Y(4)$ and PERIM (4))

? $1.414,1.414,1.571$

STARTPOINT COORDINATES AND LENGTH FOR SURFACE NO, 5

(code variables $X(5), Y(5)$ and $\operatorname{PERIM}(5)$ )

? $0 ., 2,0$.

STARTPOINT COORDINATES AND LENGTH FOR SURFACE NO. 6 (code variables $X(6), Y(6)$ and PERIM( 6))

? $0 ., 1,0$.

Batch Format:

RADGEN.7 NWALL

FORMAT (I5)

Columns $\quad$ Variable

1 - 5 NWALL Number of radiation surfaces surrounding the channel

RADGEN.8 (X(I),Y(I),PERIM(I), I=1, NWALL)

FORMAT (3F5.3)

Columns Variable

$1-5 \quad X(I)$

$6-10 \quad Y(I)$

$11-15 \quad$ PERIM(I)
Cescription

The $x$-coordinate of the startpoint for surface I

The $y$-coordinate of the startpoint for surface I

Perimeter length for surface I (in.). If set equal to zero, the length is calculated based on a straight line between endpoints.

$\star \star *$ RADGEN.8 is read in NWALL[RADGEN.7] times

$\star \star \star$ RADGEN.7 through 8 are read only if IGEOM[RADGEN. 3$]=2$.

\subsection{SURFACE EMISSIVITY}

Once the radiation surface geometry has beer established, the emissivities for each surface must be specified. These emissivities are assumed to be constant over the surface and independent of temperature. All rod surfaces 
are assumed to have the same emissivity. The wall surfaces may have the same emissivity or have different emissivities, which are specified for each surface. This is accomplished by specifying a zero for the base wall emissivity (EMWALL[RADGEN.9]=0) and then specifying the number of wall surfaces. The interactive and batch formats for the surface emissivity input are presented below.

Interactive Format:

ROD EMISSIVITY (code variables EMROD)

?.8 WALL EMISSIVITY (ENTER ZERO IF VALUES ARE TO BE READ FOR EACH WALL) ? 0.0 (code variable EMWALL)

? 8 NUMBER OF WALL SURFACES (code variable NHALL) EMISSIVITY FOR WALL NO. 1 (code variable EMH( 1)) ? 0.2

EMISSIVITY FOR WALL NO. 2 (code variable EMW(2)) ? 0.2 EMISSIVITY FOR WALL NO. 3 (code variable EMW(3)) ? 0.6 EMISSIVITY FOR WALL NO. 4 (code variable EMW(4))

? 0.6 EMISSIVITY FOR WALL NO. 5 (code variable EMW( 5)) ? 0.6 EMISSIVITY FOR WALL NO. 6 (code variable EMW( 6)) ? 0.6 EMISSIVITY FOR WALL NO. 7 (code variable EMW( 7)) ? 0.2 EMISSIVITY FOR WALL NO. 8 (code variable EMW( 8 )) ? 0.2

Batch Format:

RADGEN.9 EMROD, EMWALL FORMAT (2F5.3)

\begin{tabular}{|c|c|}
\hline Columns & Variable \\
\hline $1-5$ & EMROD \\
\hline $6-10$ & EMWALL \\
\hline
\end{tabular}
Description Rod emissivity. If zero, no rods in enclosure. Base wall emissivity. If set equal to zero, emissivities are read for each wall surface. 
RAOGEN.10 NWALL

FORMAT (I5)

Columns Variable

Description

$1-5$

NWALL

Number of radiation surfaces surrounding the rod bundle

*\#* RADGEN is read only if IGEOM[RADGEN.3] $<2$

RADGEN.11 (EMW(I), I=1, NWALL)

FORMAT (12F5.3)

Columns variable

$1-5 \quad \operatorname{EMW}(\mathrm{I})$

$6-10$

etc.
Description

Emissivity for individual wall radiation surface I

*** RADGEN.10 and 11 are read only if EMWALL[RADGEN.9] $=0.0$.

\subsection{EXCHANGE FACTOR LUMPING OPTIONS}

In a detailed COBRA-SFS rod bundle model, each fuel rod is treated as an individual radiation surface. In many cases, it is possible to reduce the size of the model by combining or Tumping individual surfaces into surface groups. Exchange factors must then be combined to correspond to the surface groups. This lumping can be accomplished by either of two methods--by specifying an automatic exchange factor lumping option or by using the userspecified lumping option.

The automatic lumping options are used when problem symmetry allows exchange factors about the axis of symmetry to be combined or folded. For example, an $8 \times 8$ rod bundle is shown in Figure 3.6. When there is symmetry about the diagonal, the model may be reduced to a half-bundle model as shown in Figure 3.7. A $15 \times 15$ rod bundle with one-eighth symmetry may be reduced to the model presented in Figure 3.8. For rods on a triangular pitch, a hexagonal array, such as that shown in Figure 3.9, can be reduced with onesixth symmetry to the model presented in Figure 3.10 . 


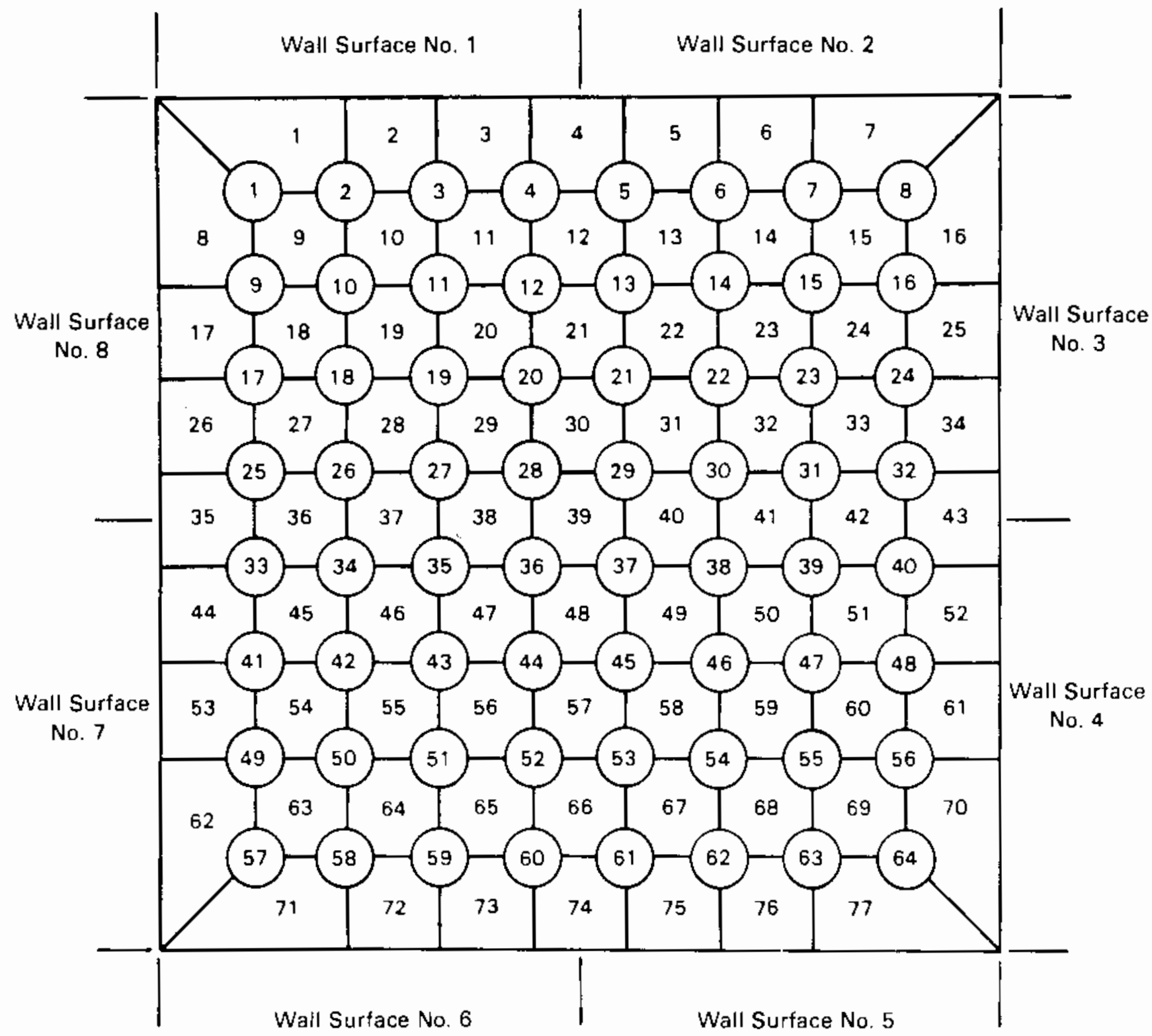

FIGURE 3.6. Radiation Surface Locations for a Full $8 \times 8$ Rod Bundle 


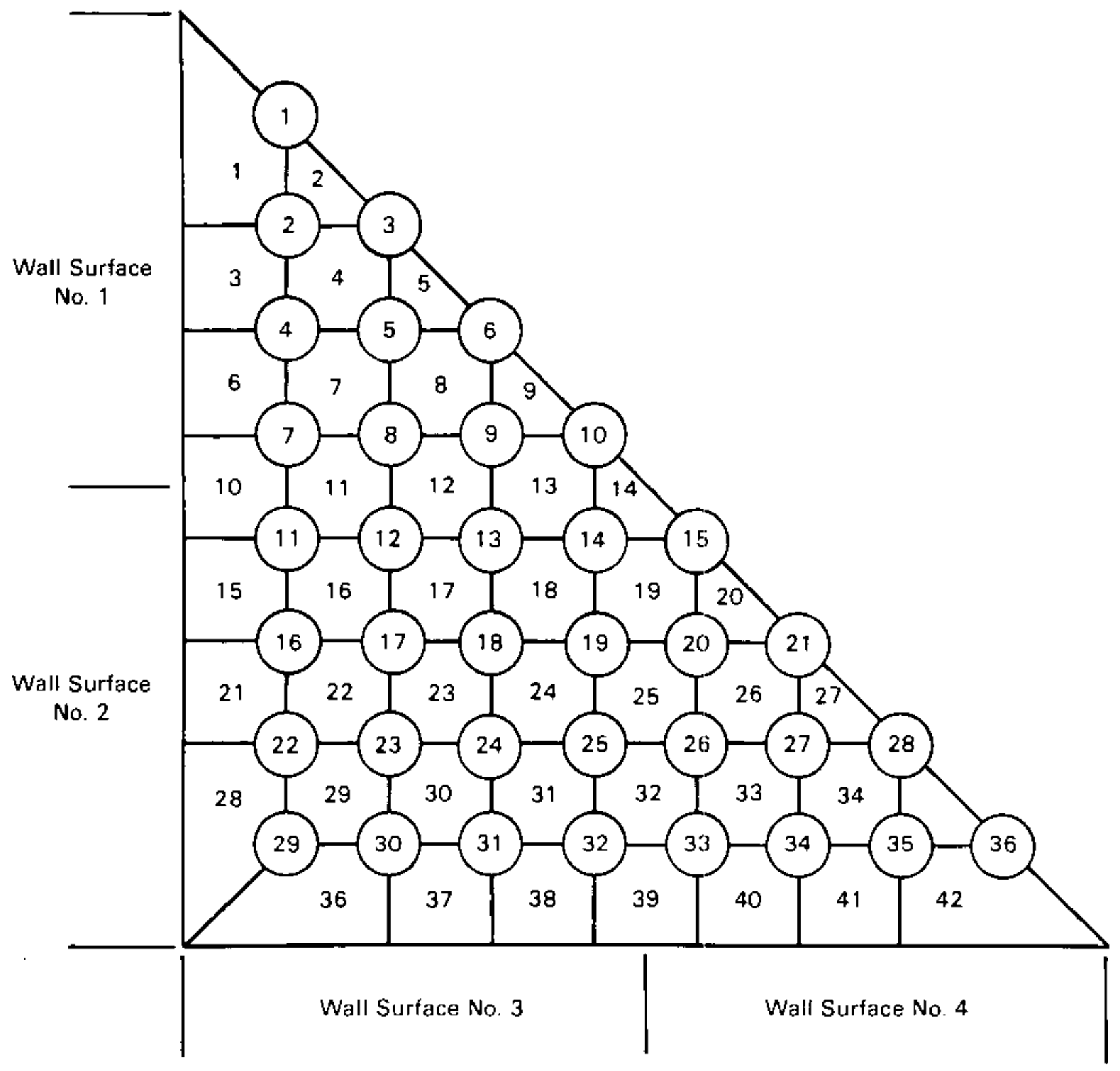

FIGURE 3.7. Radiation Surface Locations for a Half $8 \times 8$ Rod Bundle with Symmetry along the Diagonal 


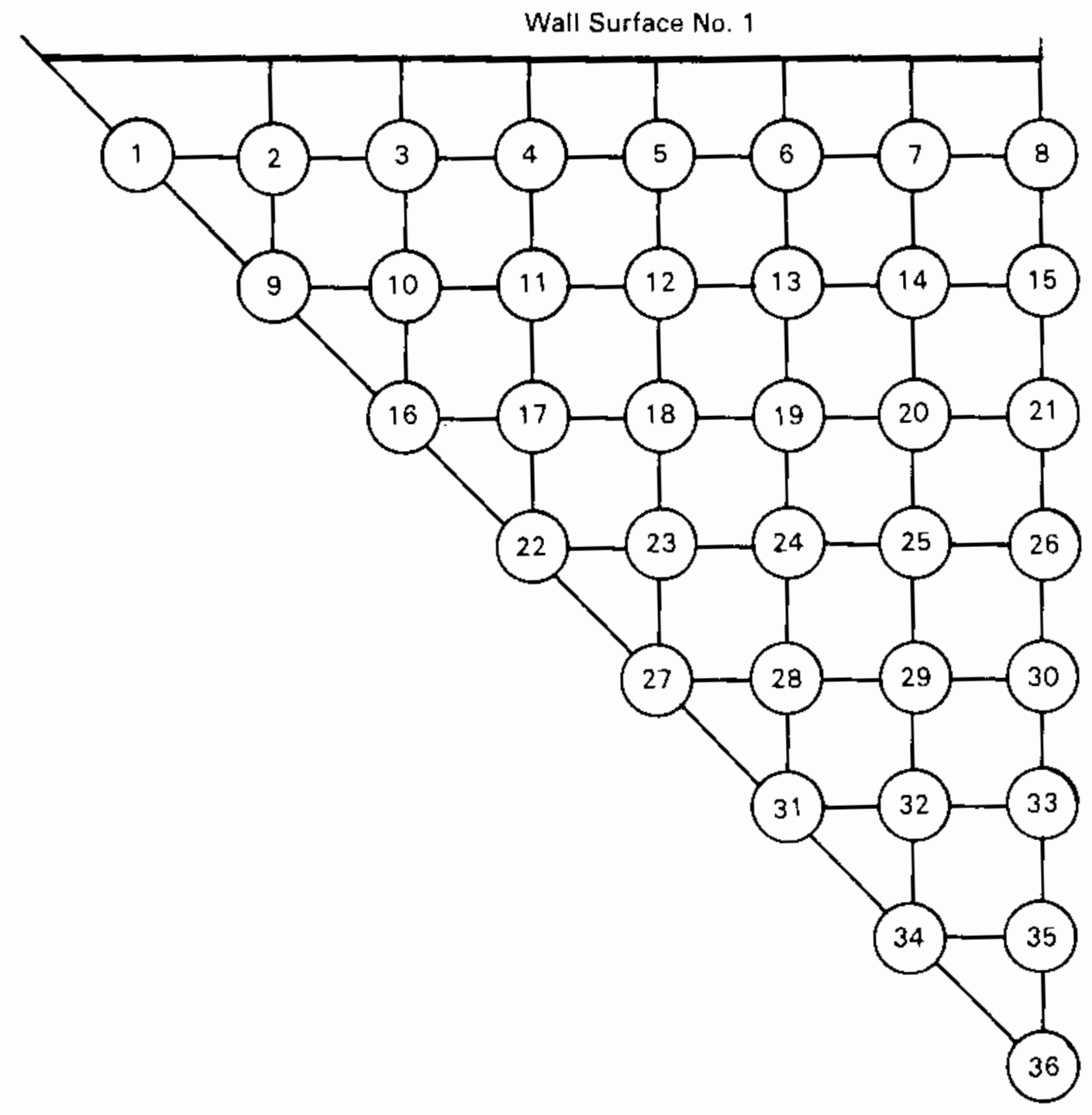

FIGURE 3.8. Radiation Surface Locations for a $15 \times 15$ Rod Bundle with One-Eighth Symmetry 


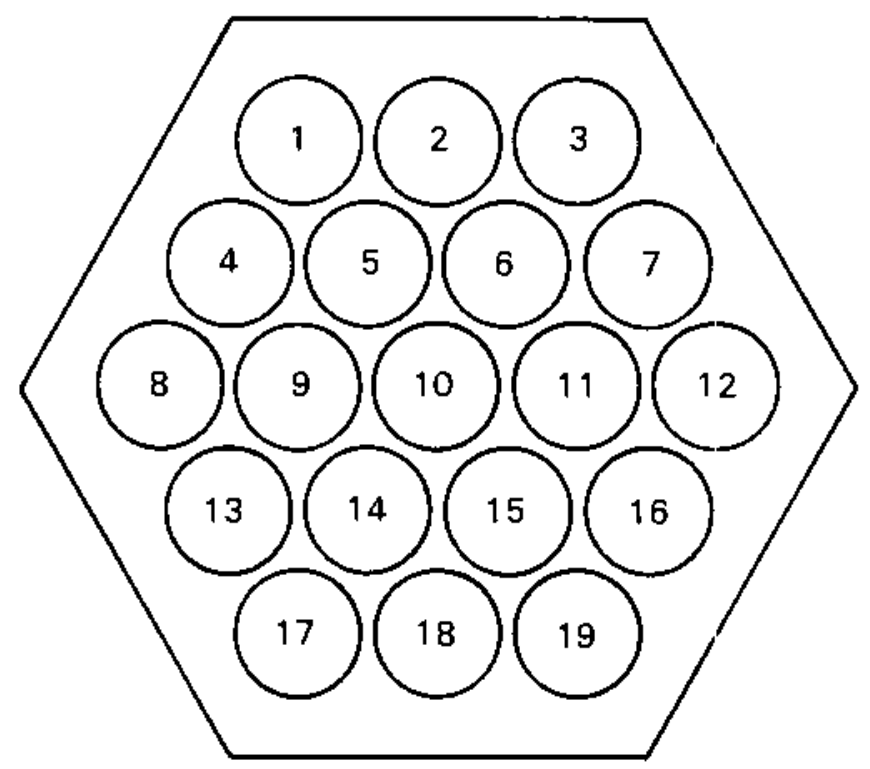

FIGURE 3.9. Radiation Surface Locations for a Hexagonal Rod Bundle

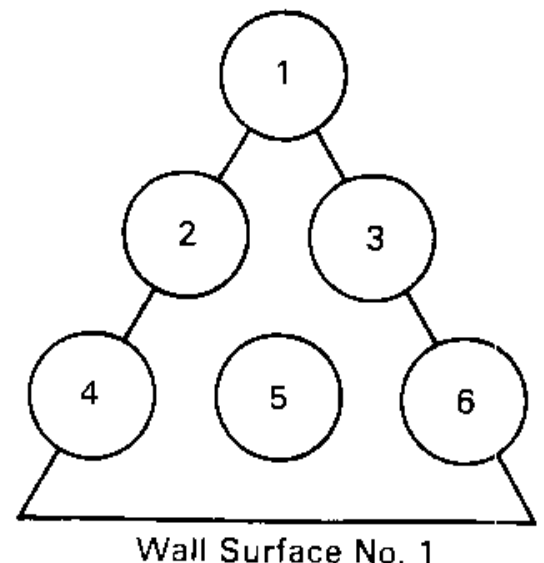

FIGURE 3.10. Radiation Surface Locations for a Hexagonal Bundle with OneSixth Symmetry 
For cases where the automatic lumping options do not apply, the user may specify how the exchange factors should be combined. First, the number of radiation surface groups must be specified. Then, the surfaces or portions of surfaces are 1 isted for each group. For example, a typical $7 \times 7$ rod bundie can be represented by the model presented in Figure 3.11. Note that an individual radiation surface may belong to more than one surface group. When this occurs, a fraction of the surface is assigned to each group.

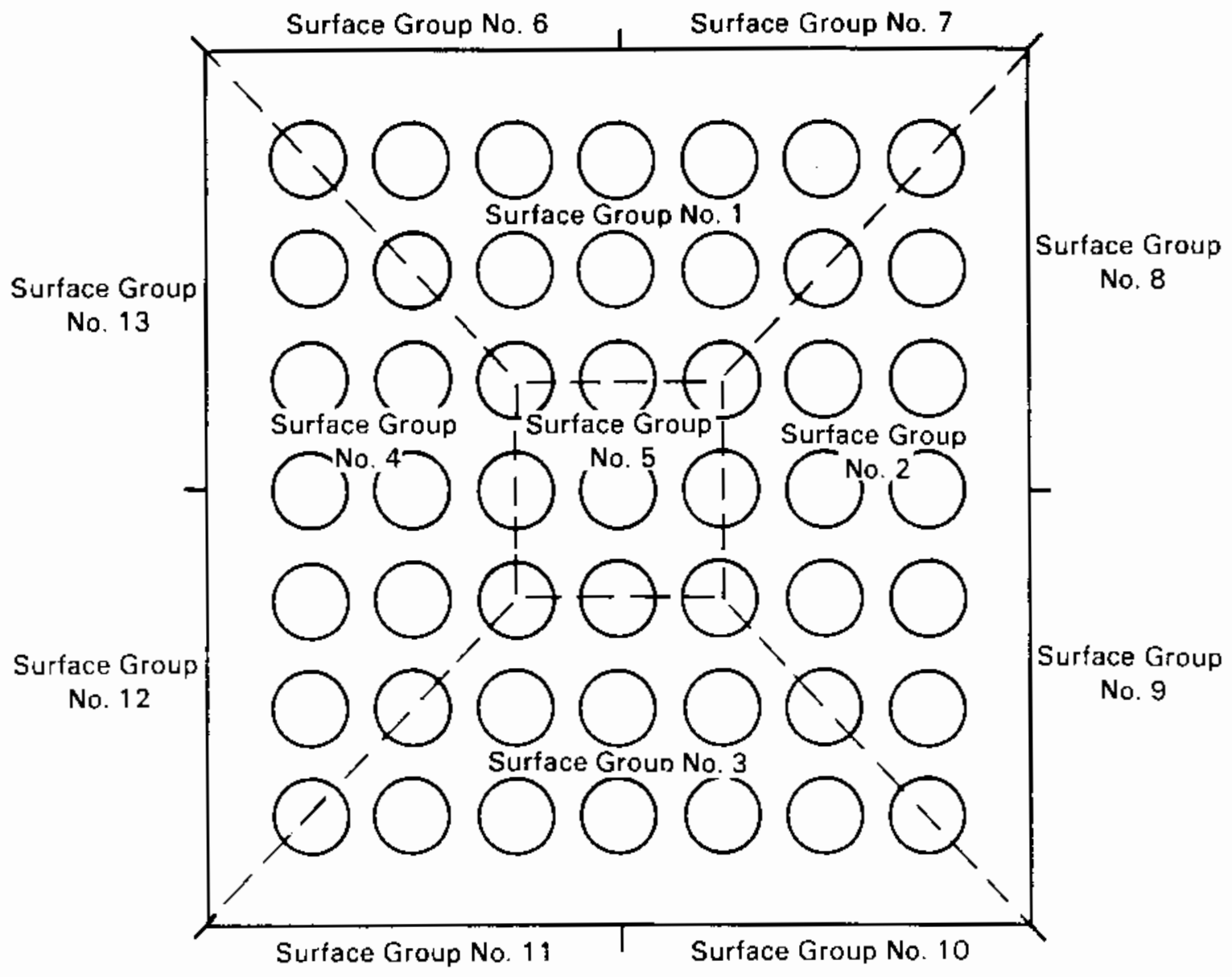

FIGURE 3.11. Lumped Model Representing a Typical $7 \times 7$ Rod Bundle 
When user-specified lumping is used, all individual rod and wall radiation surfaces must be assigned to a surface group. The wall surfaces are numbered consecutively after the rod surface numbers. For example, for a bundle with 49 rods, the first wall surface is assigned number 50 . The algorithm for lumping radiation exchange factors is described in Section 2.3.

The interactive and batch formats for the exchange factor lumping information are presented below. The input used in the interactive format example corresponds to the model presented in Figure 3.11 .

Interactive Format:

INOICATE AUTOMATIC EXCHANGE FACTOR LUMPING OPTIONS (code variable ILUMP)

0 - NO AUTOMATIC LUMPING

1 - HALF SYMMETRY ALONG DIAGONAL (SQUARE PITCH)

2 - EIGHTH SYMMETRY (SQUARE PITCH)

3 - SIXTH SYMMETRY (TRIANGULAR PITCH)

? 0

NUMBER OF GROUPS FOR USER-SPECIFIED LUMPING (code variable NGRP)

(ENTER ZERO IF LUMPING IS NOT DESIRED)

? 13

NUMBER OF WHOLE SURFACES IN GROUP 1 (code variable NWHOLE)

? 8

LIST THE WHOLE SURFACE NUMBERS

? $2,3,4,5,6,10,11,12$

NUMBER OF PARTIAL SURFACES IN GROUP I (code variable NPART)

? 7

LIST THE SURFACE NUMBERS AND FRACTION OF SURFACE FOR EACH

? $1,0.5,9,0.5,17,0.375,18,0.5,19,0.375,13,0.5,7,0.5$ NUMBER OF WHOLE SURFACES IN GROUP 2 (code variable NWHOLE)

? 8

LIST THE WHOLE SURFACE NUMBERS

? $14,20,21,27,28,34,35,42$ NUMBER OF PARTIAL SURFACES IN GROUP 2 (code variable NPART)

? 7

LIST THE SURFACE NUMBERS AND FRACTION OF SURFACE FOR EACH

? $7,0.5,13,0.5,19,0.375,26,0.5,33,0.375,41,0.5,49,0.5$ NUMBER OF WHOLE SURFACES IN GROUP 3 (code variable NWHOLE)

? 8

LIST THE WHOLE SURFACE NUMBERS

? $38,39,40,44,45,46,47,48$

NUMBER OF PARTIAL SURFACES IN GROUP 3 (code variable NPART)

? 7

LIST THE SURFACE NUMBERS AND FRACTION OF SURFACE FOR EACH

? $43,0.5,37,0.5,31,0.375,32,0.5,33,0.375,41,0.5,49,0.5$

NUMBER OF WHOLE SURFACES IN GROUP 4 (code variable NWHOLE) 
? 8

LIST THE WHOLE SURFACE NUMBERS

? $8,15,16,22,23,29,30,36$

NUMBER OF PARTIAL SURFACES IN GROUP 4 (code variable NPART)

? 7

LIST OF THE SURFACE NUMBERS AND FRACTION OF SURFACE FOR EACH

? $1,0.5,9,0.5,17,0.375,24,0.5,24,0.5,31,0.375,37,0.5,43,0.5$ NUMBER OF WHOLE SURFACES IN GROUP 5 (code variable NWHOLE)

? 1

LIST THE WHOLE SURFACE NUMBERS

? 25 NUMBER OF PARTIAL SURFACES IN GROUP 5 (code variable NPART) ? 8 LIST THE SURFACE NUMBERS AND FRACTION OF SURFACE FOR EACH

? $17,0.25,18,0.5,19,0.25,26,0.5,33,0.25,32,0.5,31,0.25,24,0.5$ NUMBER OF WHOLE SURFACES IN GROUP 6 (code variable NWHOLE)

? 1

? 50

LIST THE WHOLE SURFACE NUMBERS

NUMBER OF PARTIAL SURFACES IN GROUP 6 (code variable NPART)

? 0

NUMBER OF WHOLE SURFACES IN GROUP 7 (code variable NWHOLE)

? 1

LIST THE WHOLE SURFACE NUMBERS

? 51

NUMBER OF PARTIAL SURFACES IN GROUP 7 (code variable NPART)

? 0

NUMBER OF WHOLE SURFACES IN GROUP 8 (code variable NWHOLE)

? 1

LIST THE WHOLE SURFACE NUMBERS

? 52

NUMBER OF PARTIAL SURFACES IN GROUP 8 (code variable NPART) ? 0

NUMBER OF WHOLE SURFACES IN GROUP 9 (code variable NWHOLE) ? 1

LIST THE WHOLE SURFACE NUMBERS

? 53

NUMBER OF PARTIAL SURFACES IN GROUP 9 (code variable NPART)

? 0

NUMBER OF WHOLE SURFACES IN GROUP 10 (code variable NWHOLE)

? 1

LIST THE WHOLE SURFACE NUMBERS

? 54

NUMBER OF PARTIAL SURFACES IN GROUP 10 (code variable NPART)

? 0

NUMBER OF WHOLE SURFACES IN GROUP 11 (code variable NWHOLE)

? 1

LIST THE WHOLE SURFACE NUMBERS

? 55 
? 0

NUMBER OF PARTIAL SURFACES IN GROUP 11 (code vâriable NPART) 0

NUMBER OF WHOLE SURFACES IN GROUP 12 (code variable NWHOLE) ? 1

LIST THE WHOLE SURFACE NUMBERS

? 56

NUMBER OF PARTIAL SURFACES IN GROUP 12 (code variable NPART) ? 0

NUMBER OF WHOLE SURFACES IN GROUP 13 (code variable NWHOLE)

? I

? 57

IST THE WHOLE SURFACE NUMBERS

NUMBER OF PARTIAL SURFACES IN GROUP 13 (code variable NPART) ? 0

Batch Format:

RADGEN.12 ILUMP

FORMAT (I5)

Columns Variable

Description

$1-5 \quad$ ILUMP

Automatic exchange factor lumping options

0 - no autonatic lumping

1 - half symmetry along diagonal (square pitch)

2 - eighth symmetry (square pitch)

3 - sixth symmetry (triangular pitch)

RADGEN.13 NGRP

FORMAT(I5)

Columns Variable

Description

$1-5 \quad$ NGRP

Number of surface groups to be used for userspecified lumping. Enter zero if user-specified lumping is not desired.

RADGEN . $14 \quad$ I, NTOT

FORMAT(2I5) 


\begin{tabular}{|c|c|c|}
\hline Columns & Variable & Description \\
\hline $1-5$ & I & Surface group identification number \\
\hline $6-10$ & NTOT & $\begin{array}{l}\text { Number of individual radiation surfaces in surfa } \\
\text { group I }\end{array}$ \\
\hline RADGEN . 15 & $\begin{array}{l}(\operatorname{LLOC}(\mathrm{J}), \operatorname{PHI}(\mathrm{J}), \mathrm{J}=1 \\
\operatorname{FORMAT}(6(\mathrm{I} 5, \mathrm{F5} .3))\end{array}$ & (, NTOT)) \\
\hline Columns & Variable & Description \\
\hline $\begin{array}{l}1-5 \\
11-15 \\
\text { etc. }\end{array}$ & $\operatorname{LLOC}(\mathrm{J})$ & $\begin{array}{l}\text { Identification number of individual surface } \\
\text { belonging to surface group I }\end{array}$ \\
\hline $\begin{array}{l}6-10 \\
16-20 \\
\text { etc. }\end{array}$ & $\mathrm{PHI}(\mathrm{J})$ & $\begin{array}{l}\text { Fraction of surface LLOC }(\mathrm{J}) \text { that belongs to } \\
\text { surface group I }\end{array}$ \\
\hline
\end{tabular}





\subsection{DIMENSION PARAMETERS}

The dimensions of the arrays in RADGEN are defined with PARAMETER statements. The required values for the dimensions on the various arrays in the code are problem-dependent, and the user can change the dimensions by changing the PARAMETER statements via UPDATE. There are seven dimension parameters that must be specified by the user (or, the user must verify that the existing value in the PARAMETER statement is adequate for the given problem). These parameters are listed below with their definitions and standard values. Error checks are included in the subroutines that process the input stream and look for dimension errors, but these checks can catch only the errors that the code developers were able to anticipate.

In addition to the user-specified parameters listed below, some parameters are calculated by the code to dimension solution arrays. DO NOT MAKE CHANGES TO CODE-CALCULATED PARAMETERS.

The user-specified dimension parameters for RADGEN are defined as follows:

NR - Maximum number of rows or columns of rods. (For rods on a triangular pitch, the number of columns includes the staggered rods. For example, the number of columns in the array in Figure 3.2 is 11.)

NP - Maximum number of rods in an array.

NW - Maximum number of surrounding wall surfaces. (If the geometry is not user-specified, $\mathrm{NW}$ is the sum of the number of rows and columns multiplied by four. For a user-specified geometry, $N W$ is dependent on the options selected.)

ND - Number of surfaces into which each rod is divided. (For rods on a square

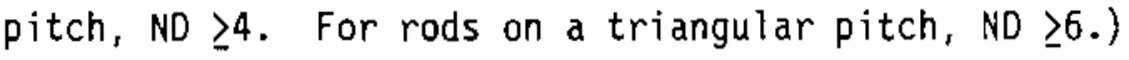

NL - Maximum number of surface groups when exchange factors are combined.

NX - Maximum number of surfaces that each surface sees directly. (If the geometry is not user-specified, NX $\geq 16$ for rods on a square pitch and NX $\geq 18$ for rods on a triangular pitch.) 
NF - Maximum number of combined surface groups to which an individual surface can belong. 


\subsection{CODE VERIFICATION}

The RADGEN computer program is capable of generating radiation exchange factors for a wide range of geometries. To verify that the geometries are modeled correctly, code results were compared with both calculated and/or analytical results for each of the geometry types.

\subsection{RODS ON A SQUARE PITCH}

The methods used to develop the quarter-rod viewfactor expressions were an extension of the work performed by Cox (1977) for whole rods on a square pitch. The arrangements of rods used for whole rod analysis are shown in Figure 5.1. The viewfactor expressions for these rod locations are listed in Table 5.1 .

To be correct, the calculated quarter-rod viewfactors must be consistent with the whole rod viewfactors calculated by Cox. The expressions relating the quarter-rod to whole rod viewfactors are

$$
\begin{aligned}
& F_{S-A}=1 / 2\left[F_{S-c}+F_{S-d}\right] \\
& F_{S-B}=1 / 4\left[F_{S-a}+2\left(F_{a-b}+F_{S-e}+F_{S-f}-F_{C o r}\right)\right] \\
& F_{S-C}=1 / 4 F_{S-g} \\
& F_{S-D}=1 / 4\left(F_{S-h}+F_{\text {Cor }}\right)
\end{aligned}
$$

The term $F_{\text {cor }}$ corresponds to the viewfactor from quarter-rod surface $s$ to the gap between rods shown in Figure 5.2. For the whole-rod model, the viewfactor for this gap is included in the viewfactor to the outermost rod, $F_{S-d}$. For the quarter-rod model, the gap viewfactor is included in the viewfactors to the rod behind the originating surface $S, F_{S-B}$ (which includes $F_{5-e}$ and $\left.F_{S-f}\right)$. The expression for calculating the value of $F_{C o r}$ for all pitch-todiameter ratios is 


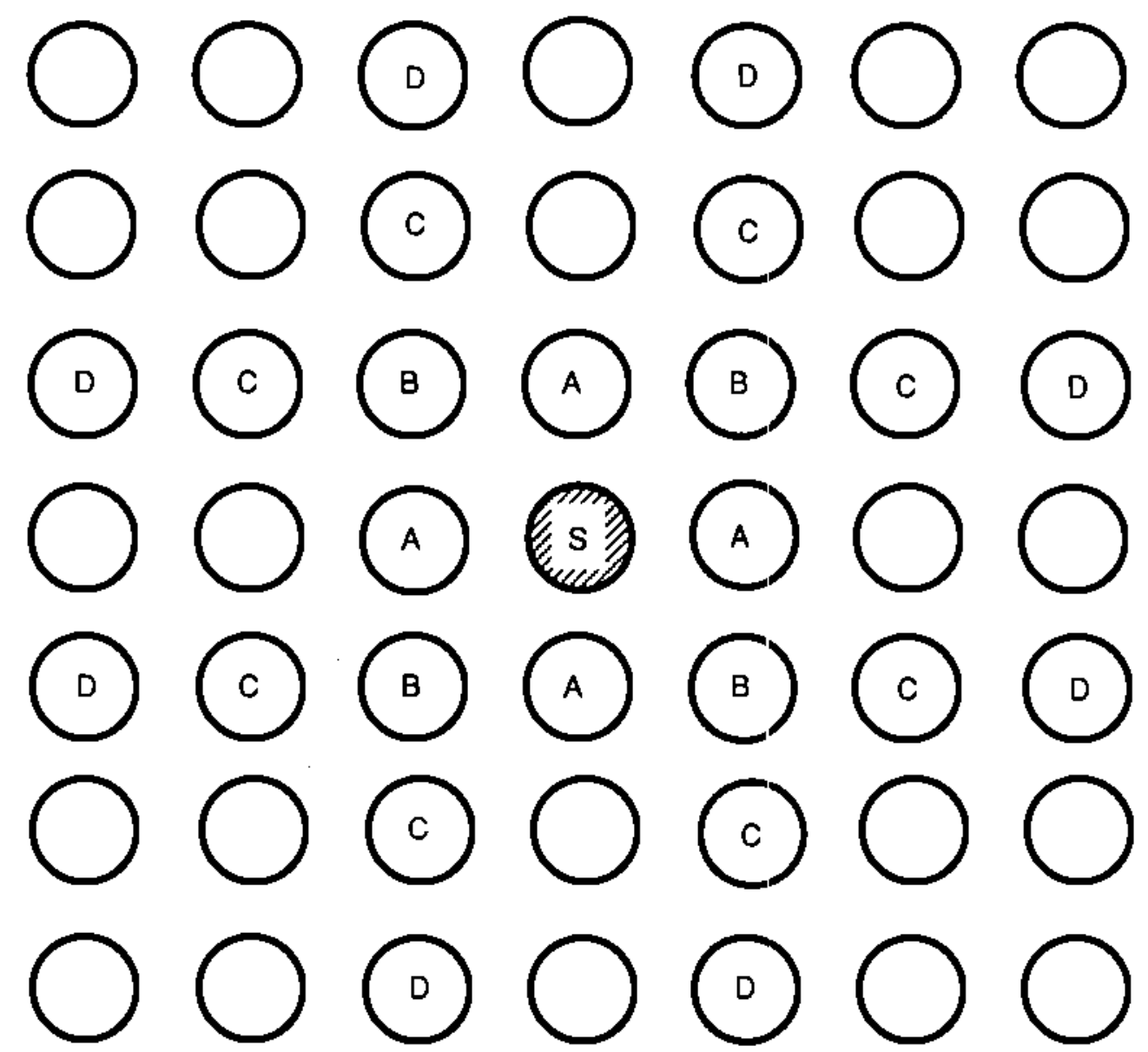

FIGURE 5.1. Whole-Rod Locations for Rods on a Square Pitch

$$
\begin{aligned}
& F_{\text {cor }}=1 / \pi\left\{2\left[P_{D R}^{2}+(P D R-1)^{2}\right]^{0.5}-2\left[2 P^{2}-P D R R^{0.5}\right.\right. \\
&\left.+\operatorname{ATAN2}\left[2 P D R^{2}-P D R\right]^{0.5}+\operatorname{ATAN}\left(\frac{2 P D R-1}{2 P D R}\right)-\pi / 2\right\}
\end{aligned}
$$

The whole-rod viewfactors that are calculated using Equations (5.1) through (5.4) are compared with the viewfactors calculated from the expressions in Table 5.1. The results of the comparison are presented in Table 5.2. In all cases, the viewfactors compare identically, indicating that the partial rod viewfactors and whole rod viewfactors are consistent with each other. 
TABLE 5.1. Blackbody Viewfactor Expressions for Whole Rods on a Square Pitch

$$
\begin{aligned}
& \text { Blackbody PDR(a) } \\
& \text { Viewfactor Range Expression } \\
& F_{S-A} \quad \text { all } 1 / \pi\left\{\left(P^{2}-1\right)^{0.5}-\operatorname{ATAN}\left(P^{2} R^{2}-1\right)^{0.5}\right. \\
& -\mathrm{PDR}+\pi / 2\} \\
& \mathrm{F}_{\mathrm{S}-\mathrm{B}} \quad 1.0-1.41 \quad 1 / \pi\left\{\left(2 \mathrm{PDR}^{2}-1\right)^{0.5}-\operatorname{ATAN}\left(2 \mathrm{PDR}^{2}-1\right)^{\mathrm{D} .5}\right. \\
& \left.-2\left(\operatorname{PDR}^{2}-1\right)^{0.5}+2 \operatorname{ATAN}\left(\mathrm{PDR}^{2}-1\right)^{0.5}\right\} \\
& >1.411 / \pi\left\{\left(2 \mathrm{PDR}^{2}-1\right)^{0.5}-\operatorname{ATAN}\left(2 \mathrm{POR}^{2}-1\right)^{0.5}\right. \\
& -\sqrt{2} P D R+\pi / 2\} \\
& \mathrm{F}_{\mathrm{S}-\mathrm{C}} \quad 1.0-1.41 \quad 1 / \pi\left\{\left(5 \mathrm{PDR}^{2}-1\right)^{0.5}-\operatorname{ATAN}\left(5 \mathrm{PDR}^{2}-1\right)^{0.5}\right. \\
& -2\left(2 \mathrm{PDR}^{2}-1\right)^{0.5}+2 \operatorname{ATAN}\left(2 \mathrm{PDR}^{2}-1\right)^{0.5} \\
& +\left(\operatorname{PDR}^{2}-1\right)^{0.5}-\operatorname{ATAN}\left(\mathrm{PDR}^{2}-1\right)^{0.5} \\
& -\operatorname{ATAN}(0.5)\} \\
& >1.41 \\
& 1 / \pi\left\{\left(5 P^{2} R^{2}-1\right)^{0.5}-\operatorname{ATAN}\left(5 P D R^{2}-1\right)^{0.5}\right. \\
& -\left(2 \mathrm{PDR}^{2}-1\right)^{0.5}+\operatorname{ATAN}\left(2 \mathrm{PDR}^{2}-1\right)^{0.5} \\
& \left.-\left(\mathrm{PDR}^{2}-1\right)^{0.5}+\operatorname{ATAN}\left(\mathrm{PDR}^{2}-1\right)^{0.5}-\pi / 4\right\} \\
& F_{S-D} \quad \text { all } \\
& \frac{1.0-4\left(F_{S-A}+F_{S-B}\right)-8 F_{S-C}}{8}
\end{aligned}
$$

(a) $P D R=$ pitch-to-diameter ratio 


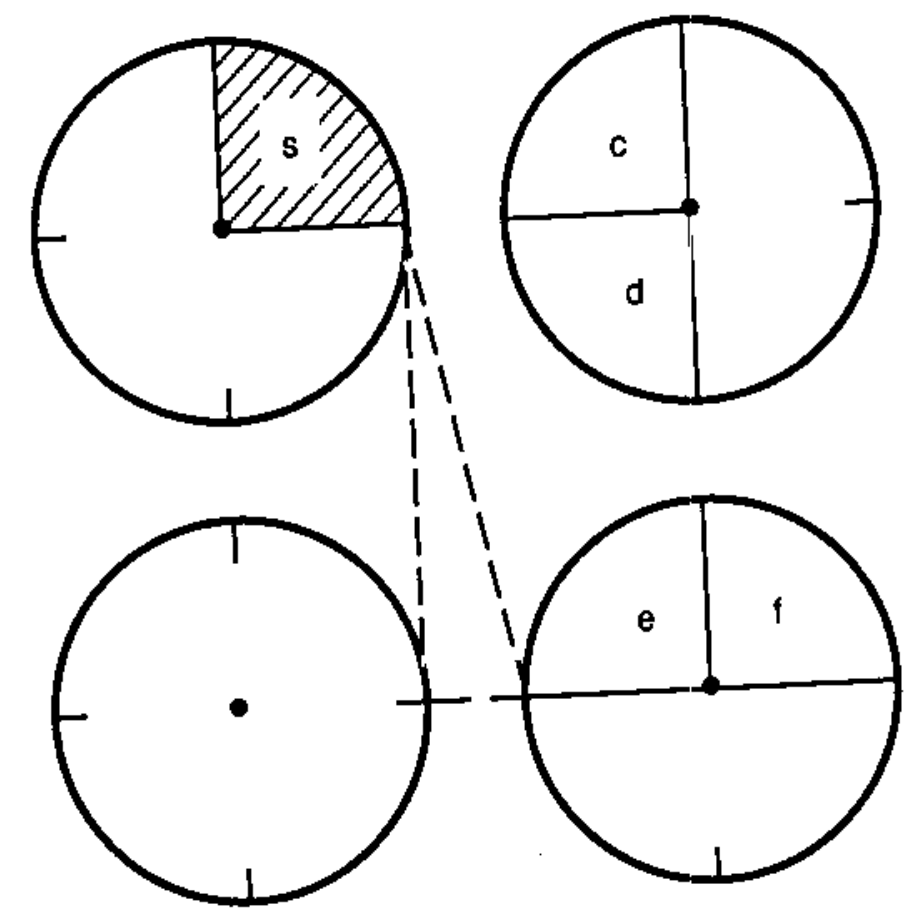

FIGURE 5.2. Viewfactor Geometry Corresponding to $F_{\text {cor }}$

TABLE 5.2. Whole-Rod Viewfactor Comparison for Rods on a Square Pitch

\begin{tabular}{|c|c|c|c|c|c|}
\hline$P D R(a)$ & Method & $\mathrm{FS}_{\mathrm{S}-\mathrm{A}}$ & FS-B & $\mathrm{FS}_{\mathrm{S}-\mathrm{C}}$ & FS-D \\
\hline \multirow{2}{*}{1.0} & Cox & 0.18169 & 0.06831 & 0 & 0 \\
\hline & RADGEN & 0.18169 & 0.06831 & 0 & 0 \\
\hline \multirow{2}{*}{1.1} & $\operatorname{Cox}$ & 0.15895 & 0.08337 & 0.00350 & 0.00034 \\
\hline & RADGEN & 0.15895 & 0.08337 & 0.00350 & 0.00034 \\
\hline \multirow{2}{*}{1.2} & $\operatorname{Cox}$ & 0.14274 & 0.08760 & 0.00861 & 0.00122 \\
\hline & RADGEN & 0.14274 & 0.08760 & 0.00861 & 0.00122 \\
\hline \multirow{2}{*}{1.3} & Cox & 0.12997 & 0.08659 & 0.01427 & 0.00246 \\
\hline & RADGEN & 0.12997 & 0.08659 & 0.01427 & 0.00246 \\
\hline \multirow{2}{*}{1.4} & $\operatorname{Cox}$ & 0.11949 & 0.08221 & 0.02018 & 0.00396 \\
\hline & RADGEN & 0.11949 & 0.08221 & 0.02018 & 0.00396 \\
\hline
\end{tabular}

(a) $P D R=$ pitch-to-diameter ratio 
Another method used to verify the quarter-rod blackbody viewfactor expressions is to measure the lengths from a scale drawing of the geometry and calculate a set of viewfactors using the cross-string formula. Rather than measure the lengths by hand, a computer program (VIEW) was written to digitize the information from a plotter and calculate the lengths automatically. Program VIEW was written for a Hewlett-Packard Series 85 computer. A listing of this program is presented in Appendix B.

The blackbody viewfactor results from program VIEW are compared with those calculated by RADGEN in Table 5.3 for a pitch-to-diameter ratio of 1.25. The accuracy of the viewfactor calculated by program VIEW depends on the accuracy of the scale drawing of the geometry and the level of detail used in digitizing the lengths, especially for curved surfaces. This is especially true for viewfactors with small values that are based on small differences between large lengths. For this reason, viewfactors $F_{s-f}$ and $F_{s-h}$ are not included in the comparison because of a lack of repeatability in the calculated values.

\subsection{RODS ON A TRIANGULAR PITCH}

The methods used to develop the one-sixth rod viewfactor expressions were an extension of the work performed by Cox (1977) for whole rods on a triangular pitch. The arrangement of rods used for whole-rod analys is is shown in Figure 5.3. The viewfactor expressions for these rod locations are listed in Table 5.4 .

To be correct, the calculated one-sixth rod viewfactors must be consistent with the whole-rod viewfactors calculated by Cox. The expressions relating the one-sixth to whole-rod viewfactors are

$$
\begin{aligned}
& F_{s-A}=1 / 3\left[F_{s-a}+F_{s-b}+F_{s-c}+F_{s-f}+F_{s-g}\right] \\
& F_{s-B}^{*}=1 / 6\left[F_{s-h}+2\left(F_{s-d}+F_{s-e}+F_{s-i)}\right]\right.
\end{aligned}
$$


TABLE 5.3. Comparison of One-Quarter Rod Viewfactors to Program VIEW Results $(P D R=1.25)$

\begin{tabular}{|c|c|c|c|}
\hline viewfactor & RADGEN & Program VIEW & $\%$ Error \\
\hline$F_{5-a}$ & $2.726 e-1$ & $2.724 \mathrm{e}-1$ & 0.0 \\
\hline$F_{s-b}$ & $1.889 e-2$ & $1.915 \mathrm{e}-2$ & 1.4 \\
\hline $\mathrm{F}_{\mathrm{S}-\mathrm{C}}$ & $2.214 \mathrm{e}-1$ & $2.229 \mathrm{e}-1$ & 0.7 \\
\hline$F_{s-d}$ & $5.063 e-2$ & $4.676 \mathrm{e}-2$ & -7.6 \\
\hline $\mathrm{F}_{\mathrm{S}-\mathrm{e}}$ & $1.889 \mathrm{e}-2$ & $1.938 \mathrm{e}-2$ & 2.6 \\
\hline $\mathrm{F}_{\mathrm{s}-\mathrm{g}}$ & $4.558 \mathrm{e}-2$ & $4.870 e-2$ & 6.8 \\
\hline
\end{tabular}

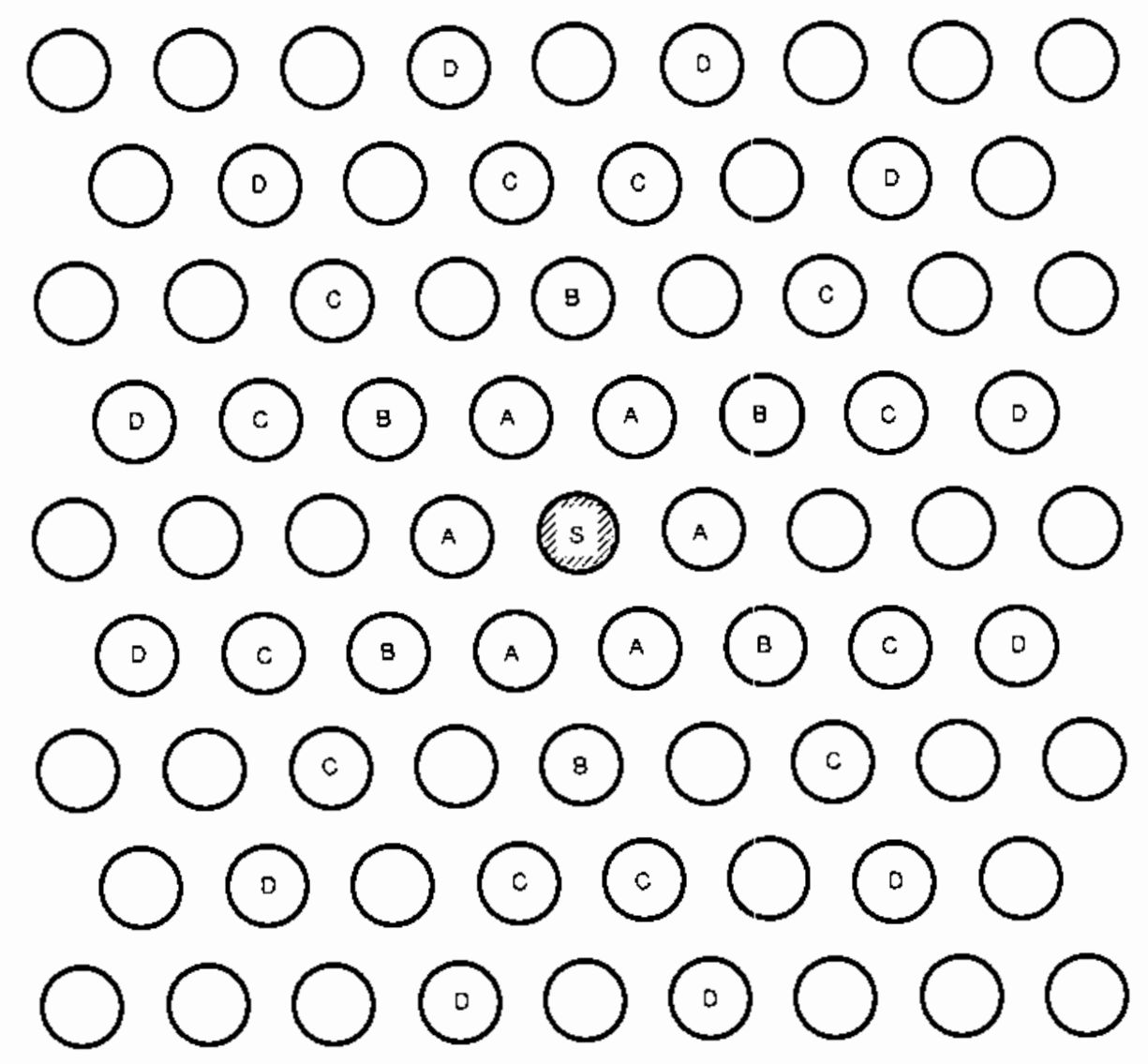

FIGURE 5.3. Whole-Rod Locations for Rods on a Triangular Pitch 
TABLE 5.4. Blackbody Viewfactor Expressions for Whole Rods on a Triangular Pitch

\begin{tabular}{|c|c|c|}
\hline $\begin{array}{l}\text { Blackbody } \\
\text { Viewfactor }\end{array}$ & $\begin{array}{l}\text { PDR (a) } \\
\text { Range }\end{array}$ & Expression \\
\hline \multirow[t]{2}{*}{${ }^{F} S-A$} & $1.0-1.15$ & $1 / \pi\left\{x / 6-\left(\operatorname{PDR}^{2}-1\right)^{0.5}+\operatorname{ATAN}\left(\operatorname{PDR}^{2}-1\right)^{0.5}\right\}$ \\
\hline & $>1.15$ & $1 / \pi\left\{\left(\operatorname{PDR}^{2}-1\right)^{0.5}-\operatorname{ATAN}\left(\mathrm{PDR}^{2}-1\right)^{0.5}-\operatorname{PDR}+\pi / 2\right\}$ \\
\hline \multirow[t]{3}{*}{$\mathrm{F}_{S-B}$} & $1.0-1.15$ & $1 / \pi\left\{\left(\mathrm{PDR}^{2}-1\right)^{0.5}-\operatorname{ATAN}\left(\mathrm{PDR}^{2}-1\right)^{0.5}\right\}$ \\
\hline & $>1.15$ & $1 / \pi\left\{\left(3 \operatorname{PDR}^{2}-1\right)^{0.5}-\operatorname{ATAN}\left(3 \mathrm{PDR}^{2}-1\right)^{0.5}\right.$ \\
\hline & & $\left.=2\left(\mathrm{PDR}^{2}-1\right)^{0.5}+2 \operatorname{ATAN}\left(\mathrm{PDR}^{2}-1\right)^{0.5}-\pi / 6\right\}$ \\
\hline \multirow[t]{5}{*}{$\mathrm{F}_{\mathrm{S}-\mathrm{C}}$} & $1.0-1.15$ & 0 \\
\hline & $>1.15$ & $1 / 2 \times\left\{\left(7 \mathrm{PDR}^{2}-1\right)^{0.5}-\operatorname{ATAN}\left(7 \mathrm{PDR}^{2}-1\right)^{0.5}\right.$ \\
\hline & & $2\left(3 P D R^{2}-1\right)^{0.5}+2 \operatorname{ATAN}\left(3 P D R^{2}-1\right)^{0.5}$ \\
\hline & & $+\left(P D R^{2}-1\right)^{0.5}-\operatorname{ATAN}\left(P^{2} R^{2}-1\right)^{0.5}$ \\
\hline & & $-\operatorname{ATAN}(\sqrt{3} / 5)\}$ \\
\hline \multirow[t]{2}{*}{$F_{S-D}$} & $1.0-1.15$ & 0 \\
\hline & $>1.15$ & $1-6\left(F_{S-A}+F_{S-B}\right)-12 F_{S-C}$ \\
\hline
\end{tabular}

(a) $\mathrm{PDR}=$ pitch-to-diameter ratio 
where $F_{S-B}^{*}=F_{S-B}+F_{S-C}+F_{S-D}$

The whole-rod viewfactors FS-B, FS-C, and FS-D have been combined to form the composite viewfactor $F_{S-B}^{\star}$ because there are no one-sixth rod viewfactors that correspond to FS-C and FS-D.

The whole-rod viewfactors calculated using Equations (5.6) and (5.7) were compared with the viewfactors calculated from the expressions in Table 2.2. The results of this comparison are presented in Table 5.5. In all cases, the viewfactors compare favorably, indicating that the partial rod viewfactors and whole-rod viewfactors are consistent with each other.

Another method verifying the one-sixth rod blackbody viewfactor expressions is to compare results with those obtained from program VIEW, which is described in Section 5.1. This comparison is presented in Table 5.6 for a pitch-todiameter ratio of 1.25 . The accuracy of the viewfactors calculated by program VIEW depends on the accuracy of the scale drawing of the geometry and the level of detail used in digitizing the lengths, especially for curved surfaces. This is especially true for viewfactors with small values that are based on small differences between large lengths. For this reason, $F_{S-e}$ and $F_{S-f}$ are not included in the comparison because of a lack of repeatability in the calculated values.

\subsection{OPEN CHANNEL GEOMETRIES}

The procedure for calculating blackbody viewfactors for an open channel geometry can be verified by comparing the viewfactors calculated by RADGEN with those calculated using documented analytical expressions. Two simple geometries were chosen as comparison cases: a rectangle with a $2: 1$ aspect ratio, shown in Figure 5.4, and a 30-60-90 triangle, shown in Figure 5.5. The analytical expressions used to calculate the individual viewfactors for these geometries are listed in Table 5.7 (Siegel and Howell 1981).

A comparison of the calculated viewfactors for the $2: 1$ rectangle geometry is presented in Table 5.8. A similar comparison for the 30-60-90 triangle is 
presented in Table 5.9. In all cases, the RADGEN values are identical to those calculated using the analytical expression. 
TABLE 5.5. Whole-Rod Viewfactor Comparison for Rods on a Triangular Pitch

\begin{tabular}{lllc}
$\frac{\text { PDR }}{1.0}$ & Method & FS-A & FS ${ }^{\star} 8$ \\
\cline { 3 - 4 } 1.1 & Cox & 0.16667 & 0 \\
& RADGEN & 0.16667 & 0 \\
1.2 & Cox & 0.15758 & 0.00909 \\
& RADGEN & 0.15758 & 0.00909 \\
1.3 & Cox & 0.14274 & 0.02393 \\
& RADGEN & 0.14274 & 0.02393 \\
& Cox & 0.12997 & 0.03670 \\
& RADGEN & 0.12997 & 0.03670
\end{tabular}

IABLE 5.6. Comparison of One-Sixth Rod Viewfactors to Program VIEW Results $(P D R=1.25)$

\begin{tabular}{|c|c|c|c|}
\hline Viewfactor & RADGEN & Program VIEW & $\%$ Error \\
\hline $\mathrm{F}_{\mathrm{s}-\mathrm{a}}$ & $3.096 e-1$ & $3.145 \mathrm{e}-1$ & +1.6 \\
\hline$F_{5-b}$ & $7.595 e-2$ & $7.619 \mathrm{e}-2$ & +0.3 \\
\hline $\mathrm{F}_{\mathrm{S}-\mathrm{C}}$ & $9.103 e-3$ & $8.687 e-3$ & -4.6 \\
\hline$F_{S-d}$ & $1.013 e-2$ & $9.049 e-3$ & -10.7 \\
\hline$F_{S-g}$ & $9.103 e-3$ & $9.350 \mathrm{e}-3$ & +2.7 \\
\hline $\mathrm{F}_{\mathrm{s}-\mathrm{h}}$ & $1.294 \mathrm{e}-1$ & $1.266 \mathrm{e}-1$ & -2.2 \\
\hline$F_{S}=i$ & $1.013 \mathrm{e}-2$ & $9.350 \mathrm{e}-3$ & -7.7 \\
\hline
\end{tabular}




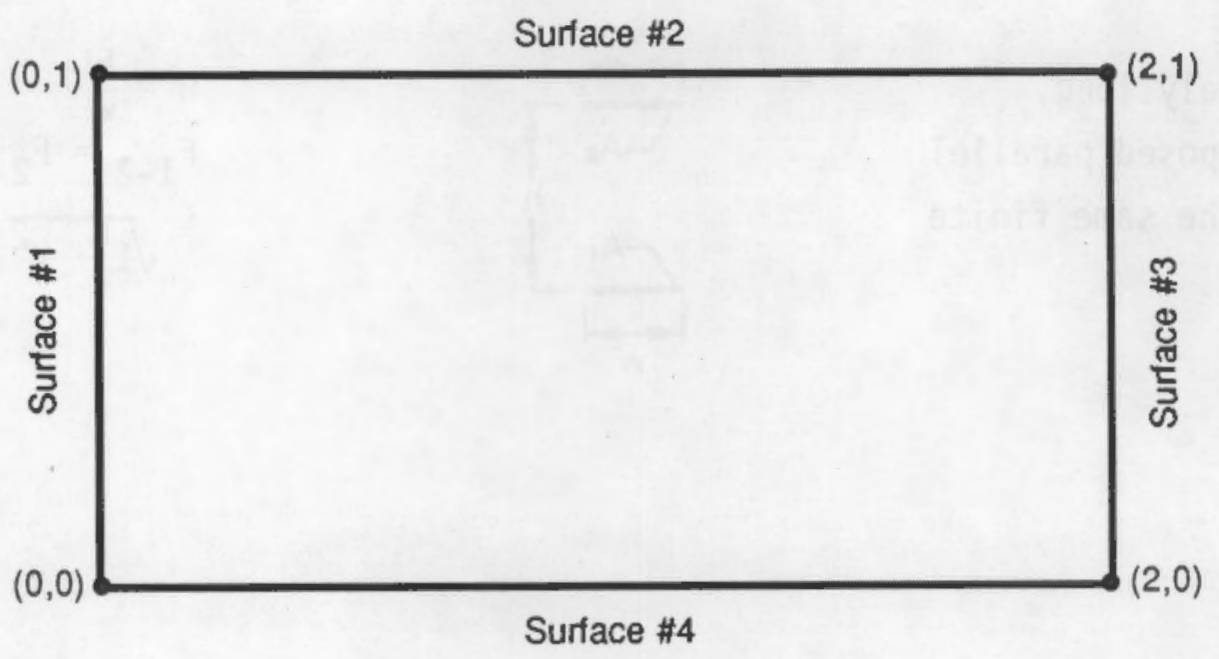

FIGURE 5.4. Radiation Surface Model for a 2:1 Rectangle

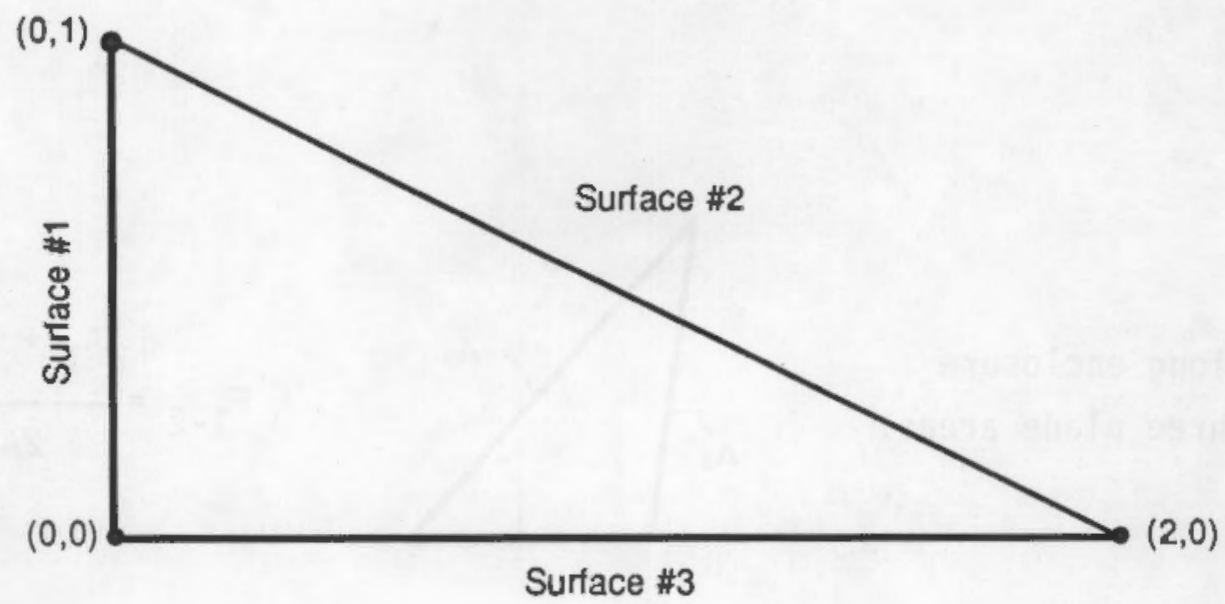

FIGURE 5.5. Radiation Surface Model for a 30-60-90 Triangle 
TABLE 5.7. Blackbody Viewfactor Expressions

\section{Geometry}

Geometry Description

Two infinitely long, directly opposed parallel plates of the same finite width.
Figure
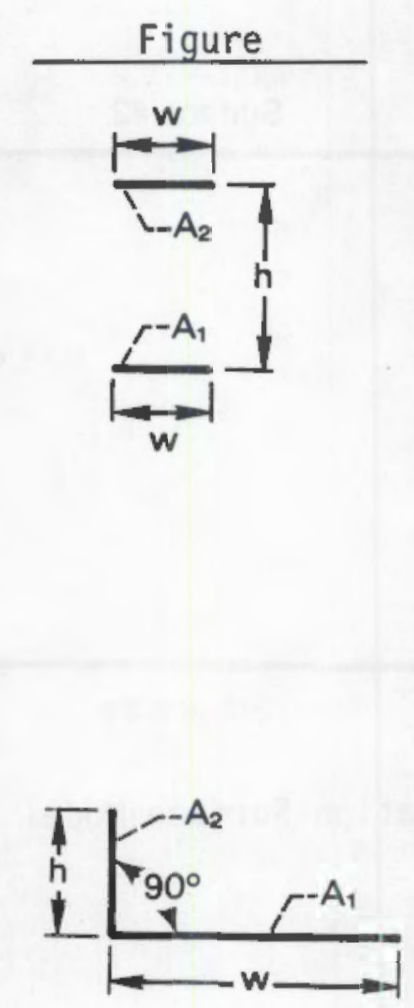

and at an angle of $90^{\circ}$ to each other.

Infinitely long enclosure formed by three plane areas.

Two infinitely long plates of unequal widths $h$ and $w$, having one common edge,

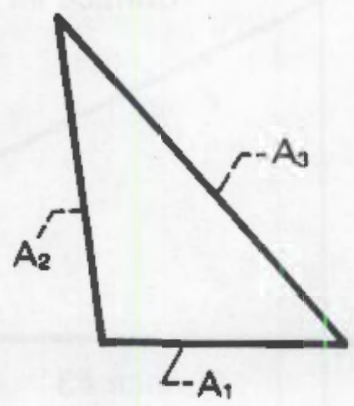

\section{Expression}

$$
\begin{aligned}
& H=\frac{h}{w} \\
& F_{1-2}=F_{2-1}= \\
& \sqrt{1+H^{2}-H}
\end{aligned}
$$

$$
\begin{aligned}
& H=\frac{h}{w} \\
& F_{1-2}=\frac{1}{2} \quad 1+H \\
& -\sqrt{1+H^{2}}
\end{aligned}
$$

$$
F_{1-2}=\frac{A_{1}+A_{2}-A_{3}}{2 A_{1}}
$$


TABLE 5.8. Comparison of Blackbody Viewfactors for a 2:1 Rectangle

\begin{tabular}{|c|c|c|}
\hline Viewfactor & RADGEN Value & Analytical value \\
\hline$F_{1-2}$ & 0.381966 & 0.381966 \\
\hline$F_{1-3}$ & 0.236068 & 0.236068 \\
\hline$F_{2-1}$ & 0.190983 & 0.190983 \\
\hline$F_{2-4}$ & 0.618034 & 0.618034 \\
\hline
\end{tabular}

TABLE 5.9. Comparison of Blackbody Viewfactors for a 30-60-90 Triangle

\begin{tabular}{|c|c|c|}
\hline Viewfactor & RADGEN Value & Analytical Value \\
\hline$F_{1-2}$ & 0.618034 & 0.618034 \\
\hline$F_{1-3}$ & 0.381966 & 0.381966 \\
\hline$F_{2-1}$ & 0.276393 & 0.276393 \\
\hline$F_{2-3}$ & 0.723607 & 0.723607 \\
\hline$F_{3-1}$ & 0.190983 & 0.190983 \\
\hline$F_{3-2}$ & 0.809017 & 0.809017 \\
\hline
\end{tabular}




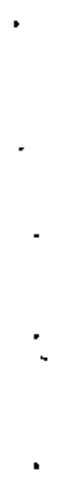




\subsection{REFERENCES}

Cox, R. L. 1977. Radiation Heat Transfer in Arrays of Parallel Cylinders. ORNL-5239, Oak Ridge National Laboratory, Oak Ridge, Tennessee.

McAdams, W. H. 1954. Heat Transmission. McGraw-Hil1, Inc., New York.

Rector, D. R., C. L. Wheeler and N. J. Lombardo. 1986. COBRA-SFS Spent Fuel Storage Thermal-Hydraulic Analys is Computer Program: volume I - Mathematical Models and Numerical Methods. PNL-6049 Vol. I, Pacific Northwest Laboratory, Richland, Washington.

Siege 1, R., and J. R. Howe 11. 1981. Thermal Radation Heat Transfer. McGrawHi11, Inc., New York. 


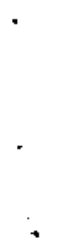

:

. 
APPENDIX A

DERIVATION OF VIEWFACTOR EXPRESSIONS 


\section{DERIVATION OF VIEWFACTOR EXPRESSIONS}

The viewfactor expressions presented in Section 2.0 were derived using the Hottel cross-string method for two-dimensional geometries. For a viewfactor from surface $A_{1}$ to surface $A_{2}$, the Hottel method may be expressed as follows:

$$
F_{12}=\frac{\text { (sum of crossed strings) }- \text { (sum of uncrossed strings) }}{2 \times \text { length of } A_{1}}
$$

where the strings connect the endpoints of surfaces $A_{1}$ and $A_{2}$. For example, the viewfactor for the geometry shown in Figure A.1 may be calculated as

$$
F_{12}=\frac{(a e+d h)-(a b c d+e f g h)}{2 a h}
$$

Note that when there is another surface blocking the path from one point to another, the string is drawn to minimize the path around the obstacle.

In the RADGEN program, expressions are used to calculate viewfactors between each rod segment surface or wall surface and surrounding surfaces. These expressions are derived in terms of nondimensional parameters such as the pitch-to-diameter ratio (PDR), which describes the distance between adjacent rods, or the wall gap-to-radius ratio $(X R)$, which describes the distance between the rod bundle and surrounding walls. An example of adjacent quarter-rod radiation surfaces is shown in Figure A.2. For this geometry, the viewfactor expression using Hottel's method is

$$
F_{12}=\frac{2(b c+c e)-(b f+d e)}{2 b d}
$$




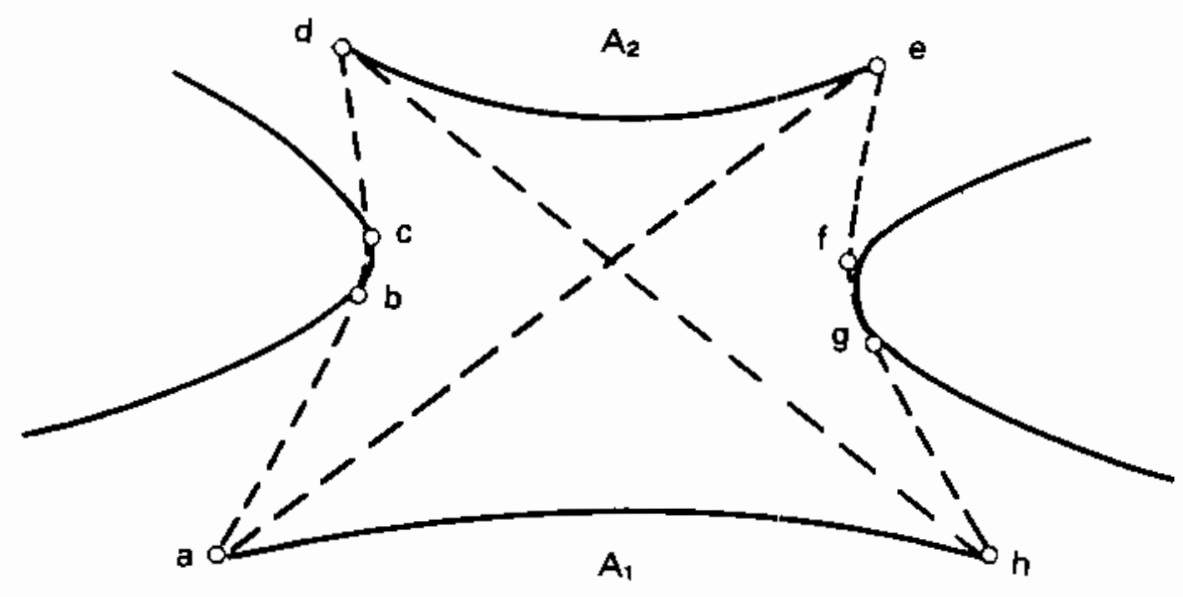

FIGURE A.1. Cross-String Method

The lengths are expressed in terms of nondimensional parameters as follows:

$$
\begin{aligned}
a b & =a c=a d=R ; b f=2(R)(P D R) ; d e=2[(2)(P D R)-R] \\
c e & =\left[(a e)^{2}-(a c)^{2}\right]^{0.5}=\left\{[2 R(P D R)-R]^{2}-R^{2}\right\}^{0.5} \\
& =2 R\left[(P D R)^{2}-P D R\right]^{0.5} \\
\omega & =\pi / 2-A T A N c e / a c=\pi / 2-\text { ATAN 2[(PDR) } 2-P D R] \\
b c & =R \omega=R\left\{\pi / 2-\operatorname{ATAN} 2\left[(P D R)^{2}-P D R\right]^{0.5}\right\}
\end{aligned}
$$

Substituting in these terms, the expression becones

$$
\begin{aligned}
F_{12}= & 2 / \pi\left\{2\left(P D R^{2}-P D R\right)^{0.5}-\operatorname{ATAN}\left[2\left(P D R^{2}-P D R\right)^{0.5}\right.\right. \\
& -2 P D R+1+\pi / 2\}
\end{aligned}
$$

which is the same expression found in Table 2.1. 


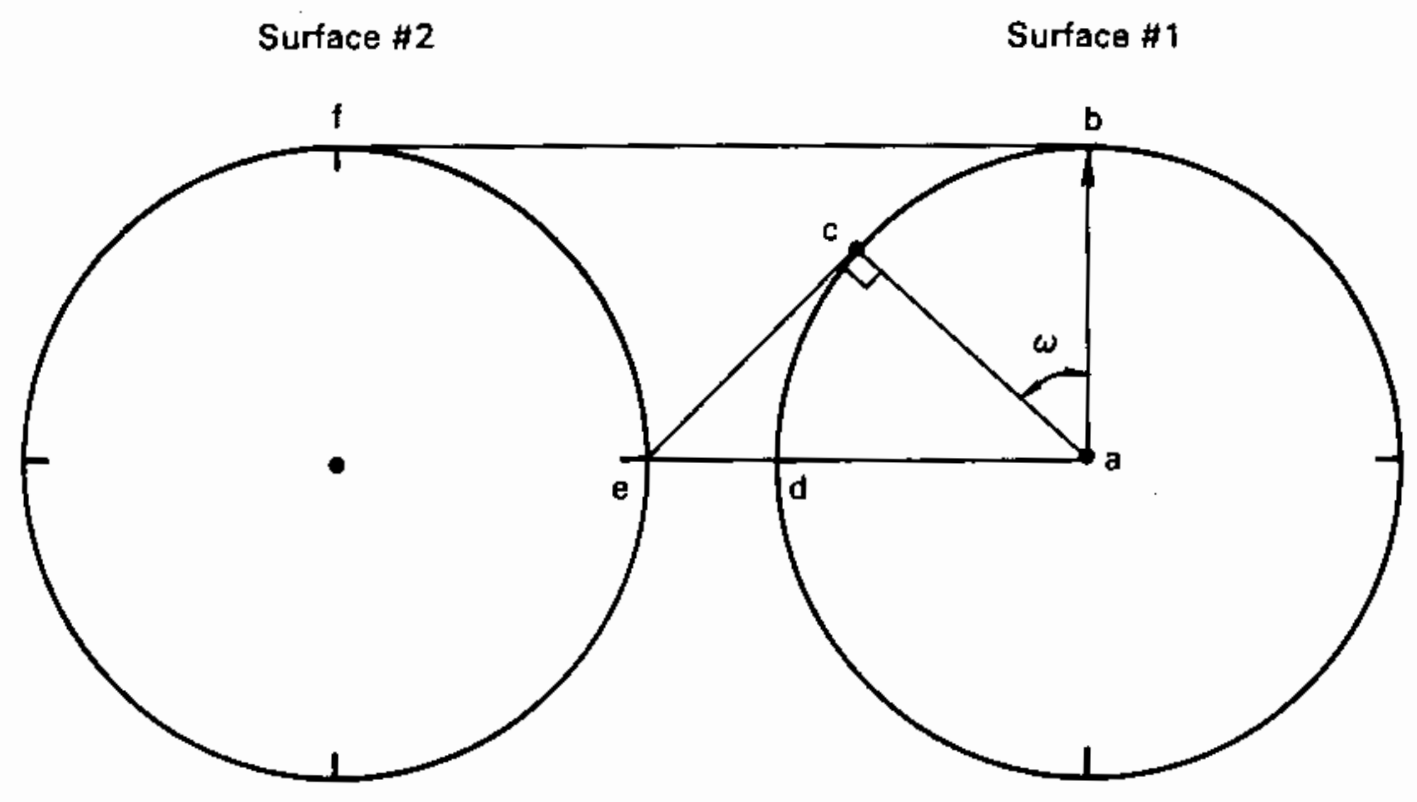

FIGURE A.2. Geometry for Derivation of $F_{12}$ 


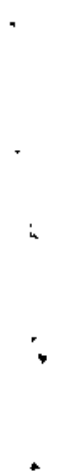


APPENDIX B

VIEW CODE LISTING 


\section{APPENDIX B}

\section{VIEW CODE LISTING}

A listing of the computer program VIEW, written for a Hewlett-Packard Series 85 computer, is presented below. This program was used in the verification of the RADGEN program as described in Section 5.0.

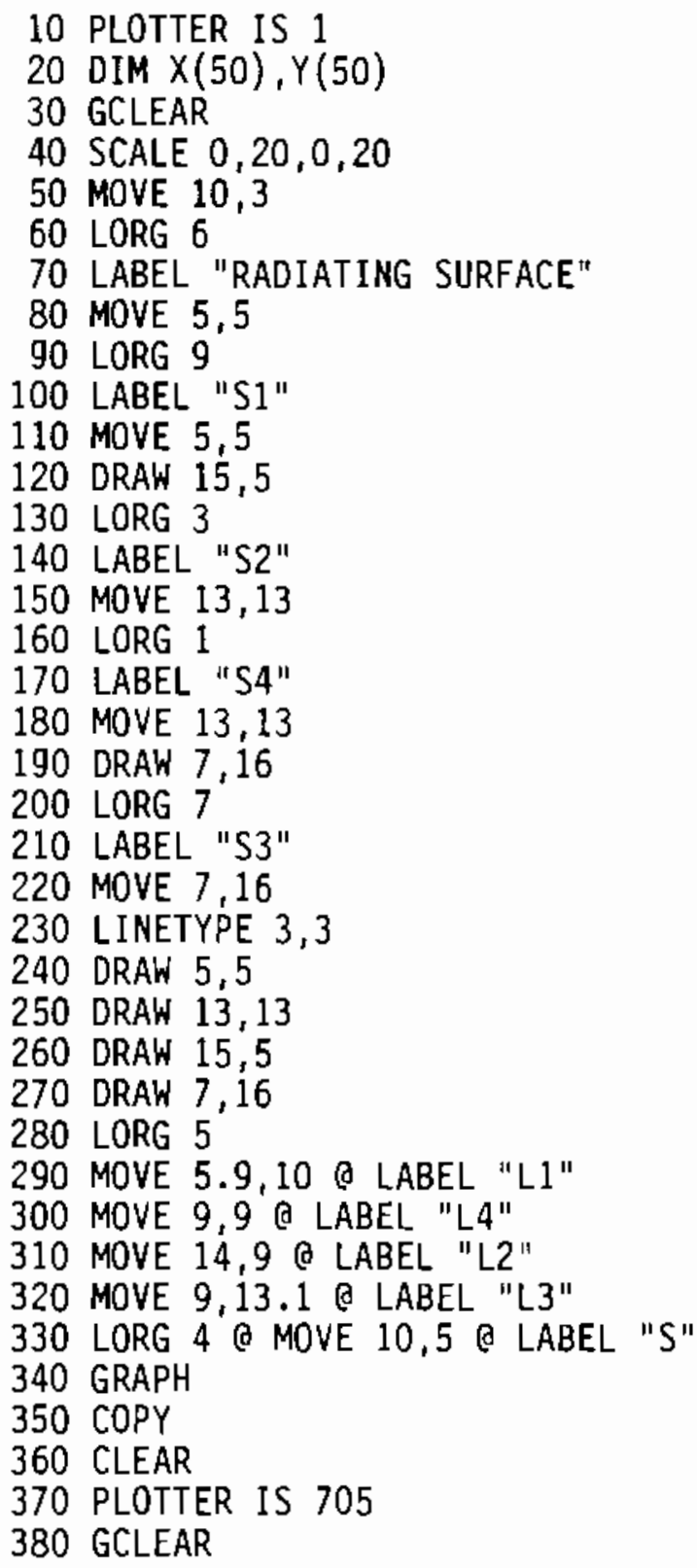




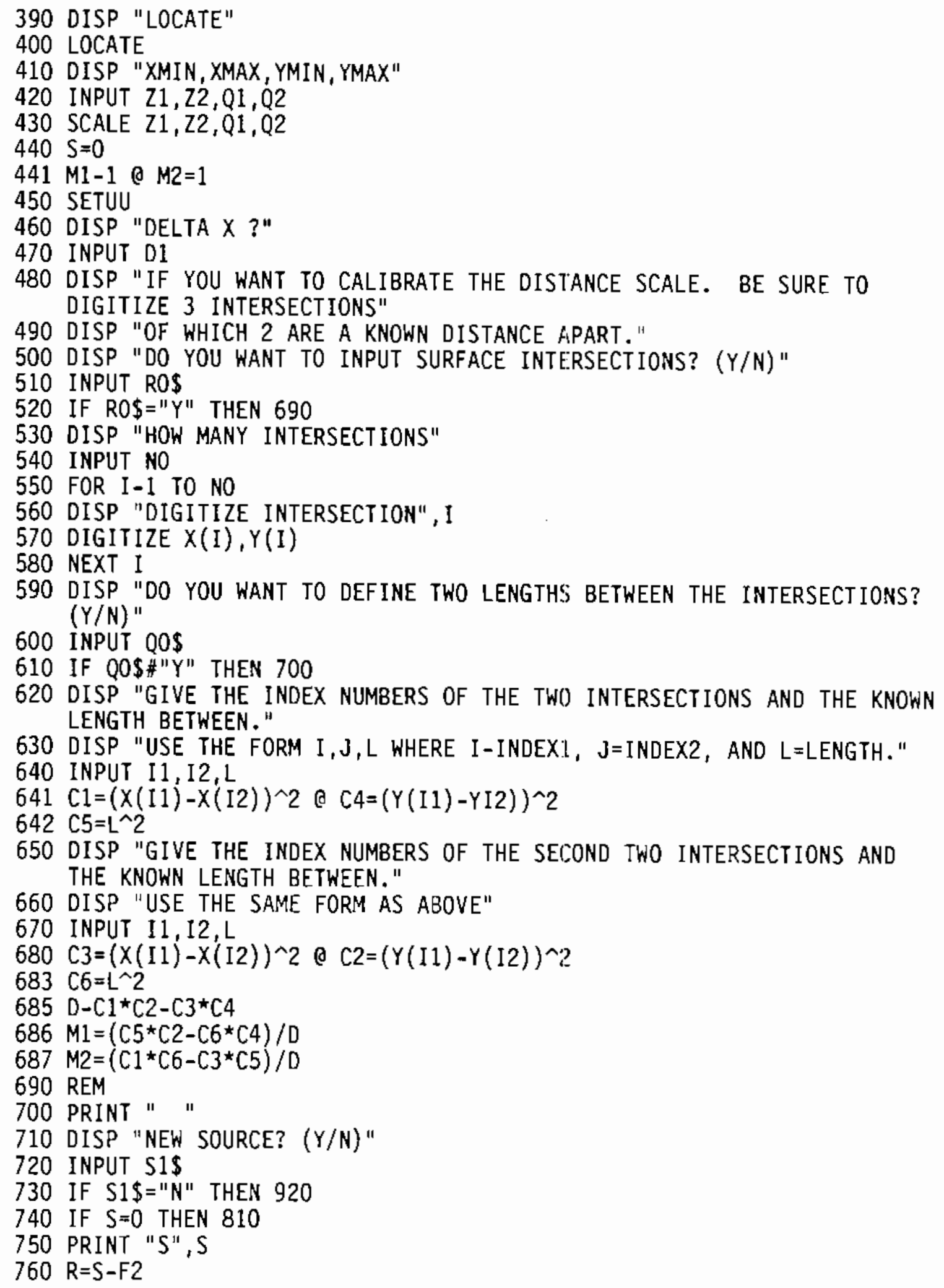




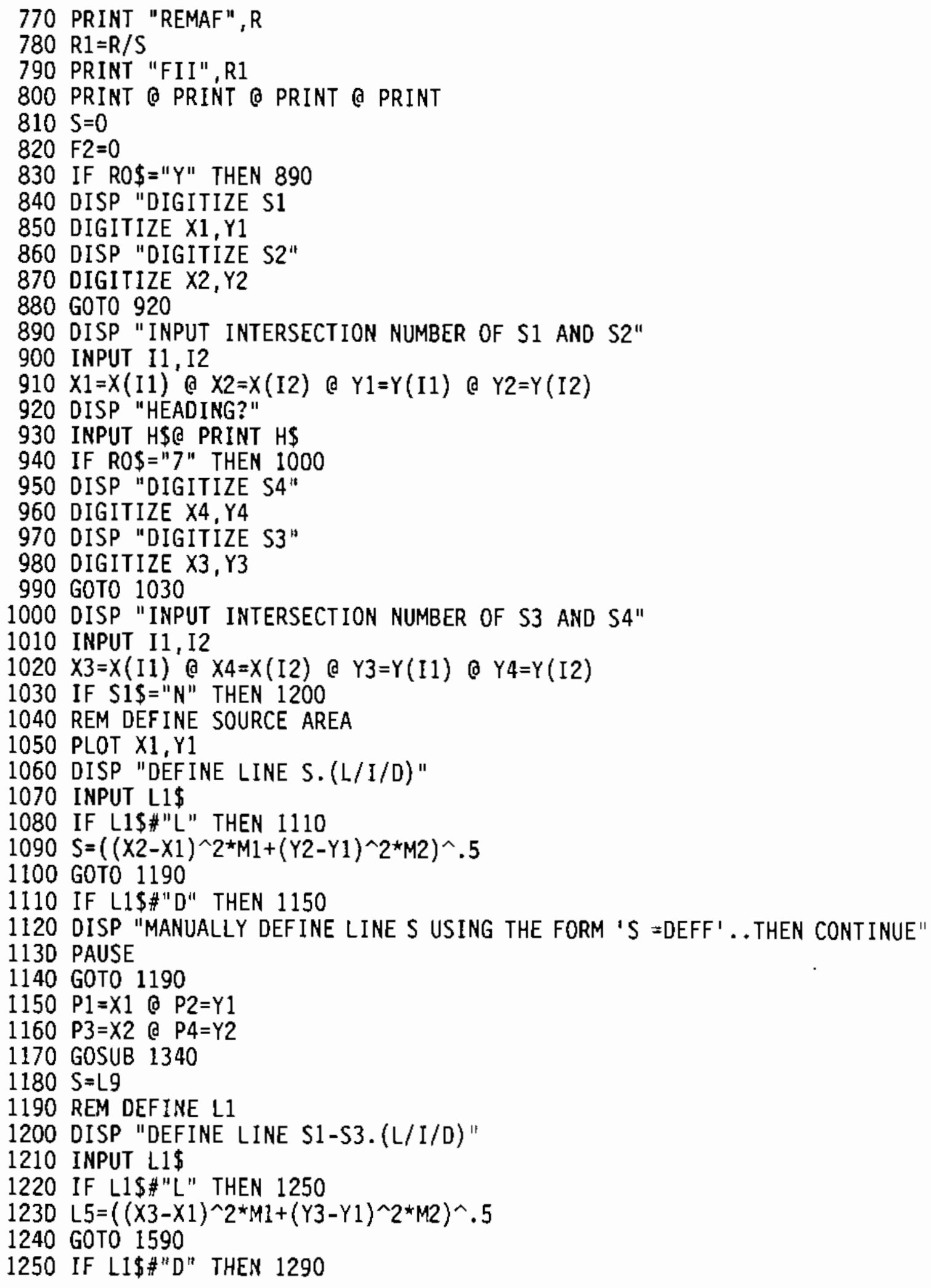


1260 DISP "MANUALLY DEFINE LINE S 1 -S3 USING THE FORM 'L5=DEFF.'. THEN CONTINUE

1270 PAUSE

1280 GOTO 1590

$1290 \mathrm{P} 1=\mathrm{X} 1$ \& $\mathrm{P} 2=\mathrm{Y} 1$

$1300 \quad P 3=X 3$ a $P 4=Y 3$

1310 GOSUB 1340

$1320 \mathrm{~L} 5=\mathrm{L} \mathrm{g}$

1330 GOTO 1590

$1340 \quad L 9=0$

1350 PLOT P1,P2,-2

$1360 X 0=P 1$ \& $Y=P 2$

$1370 \quad X=P 1$ @ $Y=P 2$

1380 FOR I $=1$ TO 1000

1390 IF ABS $(X-X 0)<.1 * D 1$ THEN 1460

$1400 A=(Y-Y O) /(X-X 0)$

1410 IF $A B S(A)>1$ THEN 1460

$1420 S 2=Y+A^{\star} D 1 \star S G N(X-X 0)$

$1430 \mathrm{~S} 1=\mathrm{D} 1 * \mathrm{SGN}(\mathrm{X}-\mathrm{XO})+\mathrm{X}$

1440 PLOT S1, S2

1450 GOTO 1540

1460 IF $A B S(Y-Y 0)<.1 * D 1$ THEN 1520

$1470 A=(X-X 0) /(Y-Y O)$

$1480 S 1=X+A^{*} D 1 * S G N(Y-Y 0)$

$1490 S 2=D 1 * S G N(Y-Y O)+Y$

1500 PLOT S1, S2

1510 GOTO 1540

1520 DISP "SET IT BY HAND"

1530 BEEP a BEEP

$1540 \times O=X$ O $Y O=Y$

1550 DIGITIZE $X, Y$ @ PLOT $X, Y,-2$

$1560 \mathrm{~L}=\mathrm{L}=\mathrm{L} 9+\left((X-X 0)^{\wedge} 2^{\star} \mathrm{M} 1+(Y-Y 0)^{\wedge} 2^{\star} \mathrm{M} 2\right)^{\wedge} .5$

1570 IF $\left((X-P 3)^{\wedge} 2+(Y-P 4)^{\wedge} 2\right)^{\wedge} .5<2^{\wedge} .5^{\star} D 1 / 2$ THEN RETURN

1580 NEXT I

1590 REM DEFINE L2

1600 DISP "DEFINE LINE S2-S4. (L//I/D)"

1610 INPUT L1\$

1620 IF LI\$\#"L" THEN 1650

$1630 L 6=\left((X 4-X 2)^{\wedge} 2 \star M 1+(Y 4-Y 2)^{\wedge} 2 \star M 2\right)^{\wedge} .5$

1640 GOTO 1730

1650 IF L1\$\#"D" THEN 1690

1660 DISP "MANUALLY DEFINE LINE S2-S4 USING THE FORM L6=0EFF.. THEN

1670 PAUSE CONTINUE"

1680 GOTO 1730

$1690 P 1-X 2$ @ P2-Y2

$1700 P 3=X 4$ @ $P 4=Y 4$

1710 GOSUB 1340

1720 L6 $=$ L9 


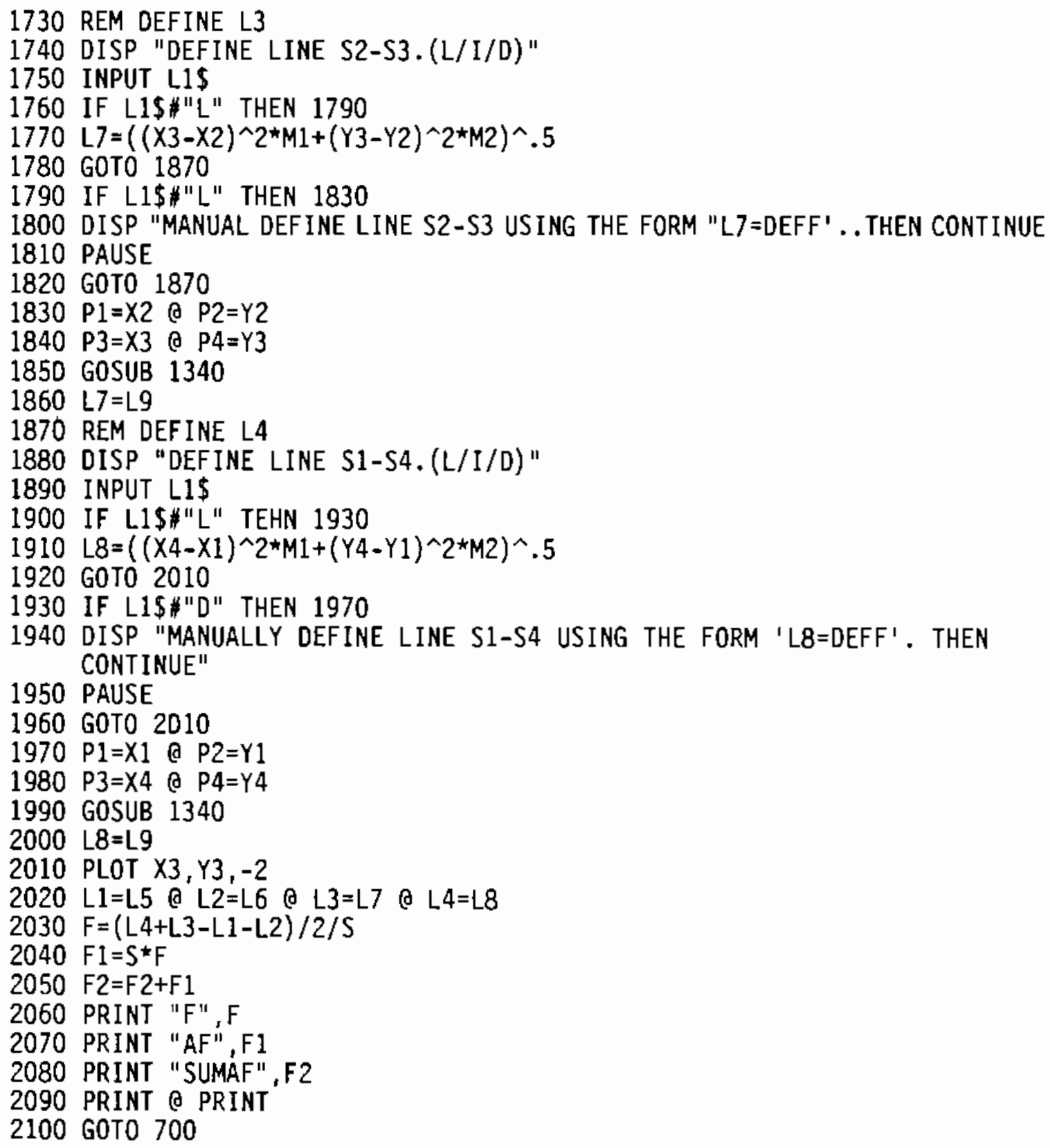




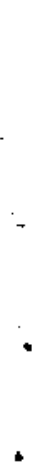

. 


\section{DISTRIBUTION}

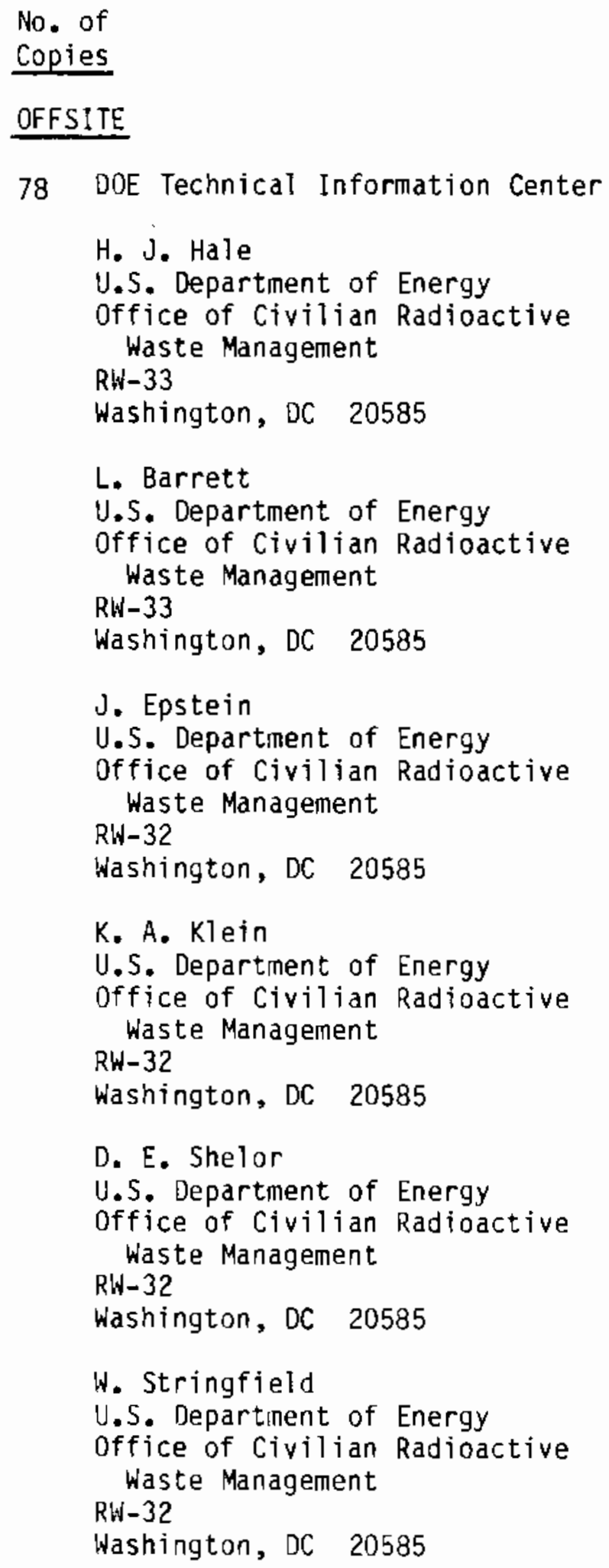

No. of

Copies
J. S. Finucane

U.S. Department of Energy

Energy Information

Administration

EI-53

Washington, DC 20585

M. Fisher

U.S. Department of Energy

Idaho Operations office

550 2nd Street

Idaho Falls, I0 83401

K. G. Golliner

U.S. Department of Energy

Albuquerque Operations office

P.0. Box 5400

Albuquerque, NM 87115

C. J. Daukowski

U.S. Department of Energy

Attention: Defense Programs

San Francisco Operations office

1333 Broadway

Oakland, CA 94612

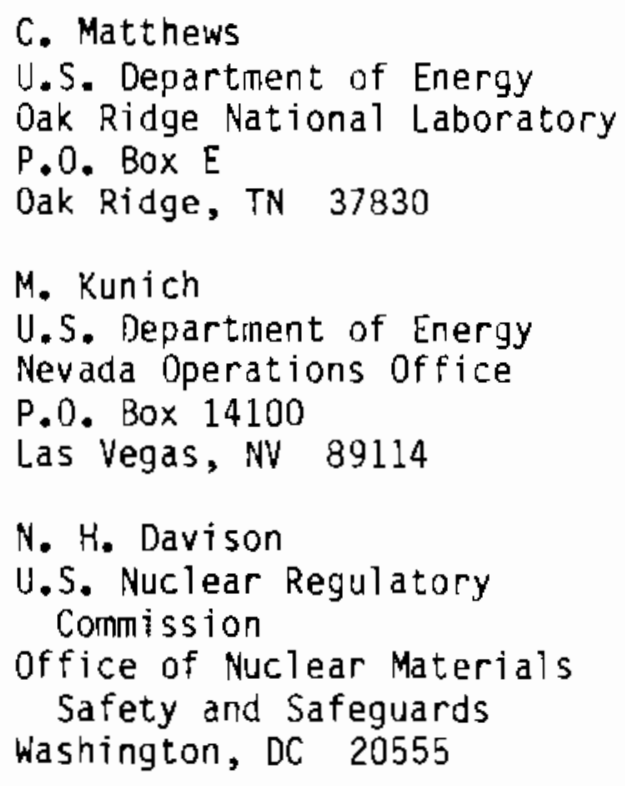


No. of

Copies

C. Feldman

U.S. Nuclear Regulatory

Commis sion

Office of Nuclear Regulatory Research

MS 1130-SS

Washington, DC 20555

W. Lake

U.S. Nuclear Regulatory Commission

Office of Nuclear Materials Safety and Safeguards

MS 396-SS

Washington, DC 20555

C. H. Peterson

U.S. Nuclear Regulatory Commission

Office of Nuclear Material Safety and Safeguards

MS 623-SS

Washington, DC 20555

J. Roberts

U.S. Nuclear Regulatory Commission

Office of Nuclear Material Safety and Safeguards

MS 396-SS

Washington, DC 20555

L. C. Rouse

U.S. Nuclear Regulatory Commission

Office of Spent Fuel Storage Installation

Division of Fuel Cycle and Material Safety

Washington, DC 20555

J. A. Carr

Battelle Memorial Institute

office of Nuclear Waste Isolation

$505 \mathrm{King}$ Avenue

Columbus, $\mathrm{OH} 43201$
No. of

Copies

Technical Library

Battelle Memorial Institute

Office of Nuclear Waste

Isolation

$505 \mathrm{King}$ Avenue

Col umbus, $\mathrm{OH} 43201$

L. J. Jardine

Bechtel Nationa?

P.0. Box 3965

San Francisco, CA 94119

R. Kunita

Carolina Power \& Light Co. P.0. Box 1551

Raleigh, NC 27602

C. K. Anderson

Combustion Engineering, Inc. 1000 Prospect Hill Road

Wiridsor, CT 06095

T. Grant

Ebasco Services Incorporated

Twa World Trade Center

New York, NY 10048

M. F. Jensen

$E G \& G$

P.0. Box 1625

Idaho Falls, ID 83415

P. E. Eggers

Eggers Ridihalgh Partners, Inc. 1445 Summit Street

Co umbus, $\mathrm{OH} 43201$

FLUOR Engineers, Inc. Advanced Technology Division P. D. Box C-11944

Santa Anna, CA 92711-1944

E. E. Voiland

General Electric Company

Nuclear Fuel \& Services Division

$7555 \mathrm{E}$. Collins Road

Morris, IL 60450 
No. of

Copies

R. Anderson

General Nuclear Services, Inc. 135 Darling Drive

Avon, CT 06001

L. B. Ballou

Lawrence Livermore National Laboratory

P.0. Box 808

Livermore, CA 94550

M. W. Schwartz

Lawrence Livermore National Laboratory

P.0. Box 808

Livermore, CA 94550

C. E. Walter

Lawrence Livermore National Laboratory

P.0. Box B08

Livermore, CA 94550

H. Lowenberg

Lowenberg Associates

10901 Rosemont Drive

Rockville, MO 20852

3. Houston

Nuclear Assurance Corporation 5720 Peach Tree Parkway

Norcross, GA 30092

R. T. Haelsig

Nuclear Packaging Inc.

1010 S. 336th Street

Federal Way, WA 98003

L. E. Wiles

Numerical Applications, Inc. 825 Goethals Orive

Richiand, WA 99352

B. Lehnert

NUTECH Engineers

145 Martinvale Lane

San Jose, CA 95116
No. of

Copies

C. V. Parks

Oak Ridge National Laboratory

P.0. Box $X$

Oak Rjdge, TN 37831

D. Woods

Ralph M. Parsons Co.

100 West Walnut Street

Pasadena, CA 91124

J. V. Massey

Reedy and Associates

103 Albright Way

Los Gatos, CA 95030

T. L. Sanders

Sandia National Laboratory

Albuquerque, NM 87115

M. E. Mason

Transnuclear, Inc.

1 N. Broadway

White Plains, NY 10601

TRW Exploration/PRO

P.0. Box 441807

Houston, TX 77244-1807

M. L. Smith

Virginia Electric Power Co.

P.0. Box 26666

Richmond, VA 23261

K. L. Basehore

Virginia Electric and Power Co. Power Station Engineering

The Electric Building

P.0. Box 564

7 th and Frank1 in

Richmond, VA 23204

0. L. Larkin

Washington Public Power Supply System

P.0. Box 968

Richland, WA 99352 
No. of

Copies

R. 0. Anderson

Northern States Power Company

15 S. 15th Street

Minneapolis, MN 55401

G. Swindlehurst

Duke Power Company

P.O. Box 33189

422 S. Church Street

Charlotte, NC 28242

D. Hamilton

Middle South Services, Inc.

Box 61000

New Orleans, LA 70161

G. R. Bond

Manager, Nuclear Fuels

General Public Utilities, NUC

100 Interpace Parkway

Parsippany, NJ 07054

J. R. Ratliff

Tennessee Valley Authority

409 Krystal Building

Chattanooga, TN 37401

B. Rice

Texas Utilities Generating Co.

Skyway Tower

400 North 01 ive Street

LD81

Dallas, TX 75201

H. E. Bliss

Nuclear Fuel Services

Comrnonwealth Edison

72 West Adams Street

P.0. Box 767

Chicago, IL 60690

R. T. Harris

Northeast Utilities

P.0. Box 270

Hartford, CN 06101
No. of

Copies

\author{
A. Ladieu \\ Yankee Atomic Electric Company \\ 1671 Worcester Road \\ Framingham, MA 01701 \\ D. S. Rowe \\ Rowe and Associates \\ Suite 200 \\ 2050 112th Avenue NE \\ Bellevue, WA 98007 \\ Y. Hsi i \\ Division of Systems Integration \\ Office of Nuclear Regulation \\ U.S. Nuclear Regulatory \\ Commission \\ Washington, DC 20555 \\ L. Phillips \\ Division of Systems Integration \\ Office of Nuclear Regulation \\ U.S. Nuclear Regulatory \\ Commission \\ Washington, DC 20555 \\ L. Agee \\ Electric Power Research \\ "nstitute \\ P.0. Box 10412 \\ Palo Alto, CA 94303 \\ R. Lambert \\ Electric Power Research \\ Institute \\ P.0. Box 10412 \\ Paio Alto, CA 94303 \\ G. S. Srikantiah \\ Electric Power Research \\ Institute \\ P.0. Box 10412 \\ Pa:o Alto, CA 94303 \\ R. Rice \\ EG $G$ Idaho, Inc. \\ P.0. Box 1625 \\ Idaho Falls, ID 83415
}


No. of

Copies

C. R. Bolmgren

Westinghouse Electric Corp.

Nuclear Waste Department

P.0. Box 3912

Pittsburgh, PA 15230

D. Klein

Mechanical Engineering

Oepartment

University of Texas

Austin, TX 78712

\section{ONSITE}

4 DOE Richland Operations Office

J. P. Collins

M. S. Karol

D. L. Oleson

J. J. Sutey

3 Westinghouse Hanford Company

C. L. Brown

G. T. Harper

R. E. Stover
No. of

Copies

46 Pacific Northwest Laboratory

G. H. Beeman

O. J. Bradley

J. L. Braitman

J. M. Cuta

J. M. Creer (5)

L. R. Oodd

R. E. Einziger

M. D. Freshley

C. M. Heeb

A. B. Johnson, Jr.

B. M. Johnson

L. T. Lakey

D. L. Lessor

N. J. Lombardo

P. S. Lowery

R. A. McCann

T. E. Michener

D. R. Rector (10)

C. W. Stewart

R. A. Stokes

D. S. Trent

C. L. Wheeler (5)

Technica? Report Files (5)

Publishing Coordination (2) 
* 